\title{
Intraoperative frozen section analysis for the diagnosis of early stage ovarian cancer in suspicious pelvic masses (Review)
}

Ratnavelu NDG, Brown AP, Mallett S, Scholten RJPM, Patel A, Founta C, Galaal K, Cross P, Naik R

Ratnavelu NDG, Brown AP, Mallett S, Scholten RJPM, Patel A, Founta C, Galaal K, Cross P, Naik R.

Intraoperative frozen section analysis for the diagnosis of early stage ovarian cancer in suspicious pelvic masses.

Cochrane Database of Systematic Reviews 2016, Issue 3. Art. No.: CD010360.

DOI: 10.1002/14651858.CD010360.pub2.

www.cochranelibrary.com 
TABLE OF CONTENTS

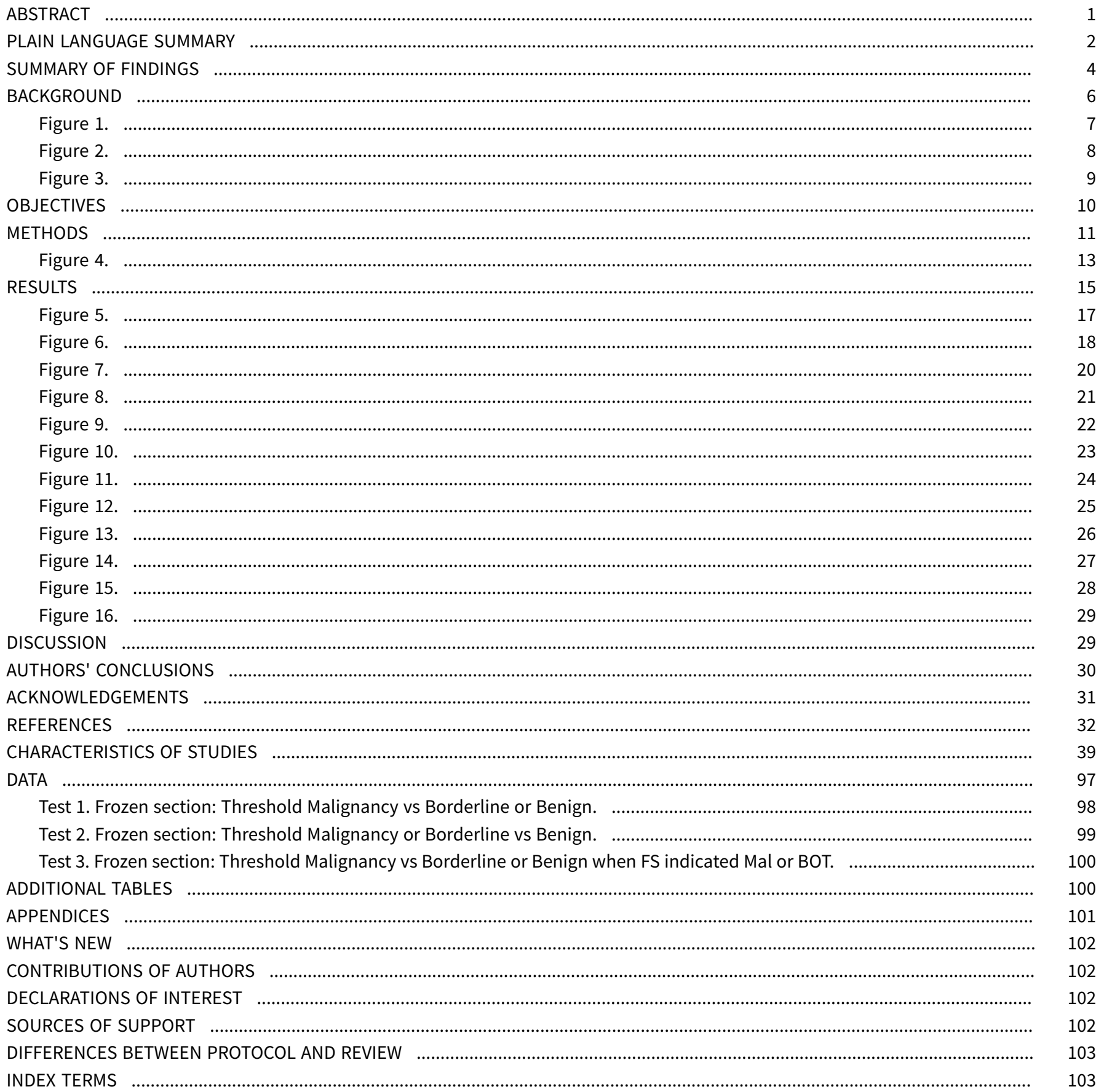




\section{Intraoperative frozen section analysis for the diagnosis of early stage ovarian cancer in suspicious pelvic masses}

Nithya DG Ratnavelu¹, Andrew P Brown², Susan Mallett ${ }^{3}$, Rob JPM Scholten ${ }^{4}$, Amit Patel ${ }^{5}$, Christina Founta 6 , Khadra Galaal ${ }^{7}$, Paul Cross $^{8}$, Raj Naik ${ }^{9}$

1Gynaecological Oncology, Northern Gynaecological Oncology Centre, Gateshead, UK. 2Obstetrics \& Gynaecology, Northumbria Healthcare NHS Foundation Trust, Ashington, UK. 3Public Health, Epidemiology and Biostatistics, University of Birmingham, Birmingham, UK. ${ }^{4}$ Dutch Cochrane Centre, Julius Center for Health Sciences and Primary Care / University Medical Center Utrecht, Utrecht, Netherlands. ${ }^{5}$ Gynaecological Oncology, University Hospitals Bristol NHS Foundation Trust, Bristol, UK. ${ }^{6}$ Gynaecological Oncology, GRACE Centre, Musgrove Park Hospital, Taunton, UK. ${ }^{7}$ Gynaecological Oncology, Princess Alexandra Wing, Royal Cornwall Hospital, Truro, UK. ${ }^{8}$ Department of Pathology, Queen Elizabeth Hospital, Gateshead, UK. ${ }^{9}$ Northern Gynaecological Oncology Centre, Gateshead, UK

Contact: Nithya DG Ratnavelu, Gynaecological Oncology, Northern Gynaecological Oncology Centre, Queen Elizabeth Hospital, Sheriff Hill, Gateshead, Tyne and Wear, NE9 6SX, UK. nithya_dgr@hotmail.com.

Editorial group: Cochrane Gynaecological, Neuro-oncology and Orphan Cancer Group.

Publication status and date: Edited (no change to conclusions), published in Issue 9, 2016.

Citation: Ratnavelu NDG, Brown AP, Mallett S, Scholten RJPM, Patel A, Founta C, Galaal K, Cross P, Naik R. Intraoperative frozen section analysis for the diagnosis of early stage ovarian cancer in suspicious pelvic masses. Cochrane Database of Systematic Reviews 2016, Issue 3. Art. No.: CD010360. DOI: 10.1002/14651858.CD010360.pub2.

Copyright ( 2016 The Cochrane Collaboration. Published by John Wiley \& Sons, Ltd.

\section{A B S T R A C T}

\section{Background}

Women with suspected early-stage ovarian cancer need surgical staging which involves taking samples from areas within the abdominal cavity and retroperitoneal lymph nodes in order to inform further treatment. One potential strategy is to surgically stage all women with suspicious ovarian masses, without any histological information during surgery. This avoids incomplete staging, but puts more women at risk of potential surgical over-treatment.

A second strategy is to perform a two-stage procedure to remove the pelvic mass and subject it to paraffin sectioning, which involves formal tissue fixing with formalin and paraffin embedding, prior to ultrathin sectioning and multiple site sampling of the tumour. Surgeons may then base further surgical staging on this histology, reducing the rate of over-treatment, but conferring additional surgical and anaesthetic morbidity.

A third strategy is to perform a rapid histological analysis on the ovarian mass during surgery, known as 'frozen section'. Tissues are snap frozen to allow fine tissue sections to be cut and basic histochemical staining to be performed. Surgeons can perform or avoid the full surgical staging procedure depending on the results. However, this is a relatively crude test compared to paraffin sections, which take many hours to perform. With frozen section there is therefore a risk of misdiagnosing malignancy and understaging women subsequently found to have a presumed early-stage malignancy (false negative), or overstaging women without a malignancy (false positive). Therefore it is important to evaluate the accuracy and usefulness of adding frozen section to the clinical decision-making process.

\section{Objectives}

To assess the diagnostic test accuracy of frozen section (index test) to diagnose histopathological ovarian cancer in women with suspicious pelvic masses as verified by paraffin section (reference standard).

\section{Search methods}

We searched MEDLINE (January 1946 to January 2015), EMBASE (January 1980 to January 2015) and relevant Cochrane registers. 


\section{Selection criteria}

Studies that used frozen section for intraoperative diagnosis of ovarian masses suspicious of malignancy, provided there was sufficient data to construct $2 \times 2$ tables. We excluded articles without an available English translation.

\section{Data collection and analysis}

Authors independently assessed the methodological quality of included studies using the Quality Assessment of Diagnostic Accuracy Studies tool (QUADAS-2) domains: patient selection, index test, reference standard, flow and timing. Data extraction converted $3 \times 3$ tables of per patient results presented in articles into $2 \times 2$ tables, for two index test thresholds.

\section{Main results}

All studies were retrospective, and the majority reported consecutive sampling of cases. Sensitivity and specificity results were available from 38 studies involving 11,181 participants (3200 with invasive cancer, 1055 with borderline tumours and 6926 with benign tumours, determined by paraffin section as the reference standard). The median prevalence of malignancy was $29 \%$ (interquartile range (IQR) $23 \%$ to $36 \%$, range $11 \%$ to $63 \%$ ). We assessed test performance using two thresholds for the frozen section test. Firstly, we used a test threshold for frozen sections, defining positive test results as invasive cancer and negative test results as borderline and benign tumours. The average sensitivity was $90.0 \%$ (95\% confidence interval (CI) $87.6 \%$ to $92.0 \%$; with most studies typically reporting range of $71 \%$ to $100 \%$ ), and average specificity was $99.5 \%$ ( $95 \% \mathrm{Cl} 99.2 \%$ to $99.7 \%$; range $96 \%$ to $100 \%)$.

Similarly, we analysed sensitivity and specificity using a second threshold for frozen section, where both invasive cancer and borderline tumours were considered test positive and benign cases were classified as negative. Average sensitivity was $96.5 \%$ (95\% Cl 95.5\% to 97.3\%; typical range $83 \%$ to $100 \%$ ), and average specificity was $89.5 \%$ ( $95 \% \mathrm{Cl} 86.6 \%$ to $91.9 \%$; typical range $58 \%$ to $99 \%$ ).

Results were available from the same 38 studies, including the subset of 3953 participants with a frozen section result of either borderline or invasive cancer, based on final diagnosis of malignancy. Studies with small numbers of disease-negative cases (borderline cases) had more variation in estimates of specificity. Average sensitivity was $94.0 \%$ (95\% Cl 92.0\% to 95.5\%; range $73 \%$ to $100 \%$ ), and average specificity was $95.8 \%$ (95\% Cl 92.4\% to $97.8 \%$; typical range $81 \%$ to $100 \%)$.

Our additional analyses showed that, if the frozen section showed a benign or invasive cancer, the final diagnosis would remain the same in, on average, $94 \%$ and $99 \%$ of cases, respectively.

In cases where the frozen section diagnosis was a borderline tumour, on average $21 \%$ of the final diagnoses would turn out to be invasive cancer.

In three studies, the same pathologist interpreted the index and reference standard tests, potentially causing bias. No studies reported blinding pathologists to index test results when reporting paraffin sections.

In heterogeneity analyses, there were no statistically significant differences between studies with pathologists of different levels of expertise.

\section{Authors' conclusions}

In a hypothetical population of 1000 patients ( 290 with cancer and 80 with a borderline tumour), if a frozen section positive test result for invasive cancer alone was used to diagnose cancer, on average 261 women would have a correct diagnosis of a cancer, and 706 women would be correctly diagnosed without a cancer. However, 4 women would be incorrectly diagnosed with a cancer (false positive), and 29 with a cancer would be missed (false negative).

If a frozen section result of either an invasive cancer or a borderline tumour was used as a positive test to diagnose cancer, on average 280 women would be correctly diagnosed with a cancer and 635 would be correctly diagnosed without. However, 75 women would be incorrectly diagnosed with a cancer and 10 women with a cancer would be missed.

The largest discordance is within the reporting of frozen section borderline tumours. Investigation into factors leading to discordance within centres and standardisation of criteria for reporting borderline tumours may help improve accuracy. Some centres may choose to perform surgical staging in women with frozen section diagnosis of a borderline ovarian tumour to reduce the number of false positives. In their interpretation of this review, readers should evaluate results from studies most typical of their population of patients.

\section{PLAIN LANGUAGE SUMMARY}

\section{Is a 'quick diagnosis' test on an ovarian mass during surgery accurate?}

\section{The issue}

When women go to their doctor with a mass that could be ovarian cancer, they are normally referred for surgery, since the mass may need to be removed and examined microscopically in a laboratory in a procedure known as paraffin section histopathology. A third of women with ovarian cancer present with a cyst or mass without any visible evidence of spread elsewhere. However, in these apparently early-stage 
cancers (confined to the ovary) surgical staging is required to decide if chemotherapy is required. This staging consists of sampling tissues within the abdomen, including lymph nodes.

Different staging strategies exist. One is to perform surgical staging for all women who might have a cancer, to get information about spread. This may result in complications due to additional surgical procedures that may turn out to be unnecessary in approximately two thirds of women.

A second strategy is to perform an operation to remove just the suspicious mass and await the paraffin section diagnosis. This may result in needing a further operation in one third of women if cancer is confirmed, putting them at increased risks from another operation.

A third strategy is to send the mass to the laboratory during the operation for a quick diagnosis, known as 'frozen section'. This helps the surgeon decide if further surgical treatment is required during a single operation.

\section{Why is this review important?}

Frozen section is not as accurate as the traditional slower paraffin section examination, and it entails a risk of incorrect diagnosis, meaning that some women may not have all the samples taken at the initial surgery and may need to undergo a second operation; and others may undergo unnecessary surgical sampling.

\section{How was this review conducted?}

We searched all available studies reporting use of frozen section in women with suspicious ovarian masses. We excluded studies without an English translation and studies without enough information to allow us to analyse the data.

\section{What are the findings?}

We included 38 studies (11,181 women), reporting three types of diagnoses from the frozen section test.

1. Cancer, which occurred in an average of $29 \%$ of women.

2. Borderline tumour, which occurred in $8 \%$ of women.

\section{Benign mass.}

In a hypothetical group of 1000 patients where 290 have cancer and 80 have a borderline tumour, 261 women would receive a correct diagnosis of a cancer and 706 women would be correctly diagnosed without a cancer based on a frozen section result. However, 4 women would be incorrectly diagnosed as having a cancer where none existed (false positive), and 29 women with cancer would be missed and potentially need further treatment (false negative).

If surgeons used a frozen section result of either a cancer or a borderline tumour to diagnose cancer, 280 women would be correctly diagnosed with a cancer and 635 women would be correctly diagnosed without a cancer. However, 75 women would be incorrectly diagnosed as having a cancer, and 10 women with cancer would be missed on the initial test and found to have a cancer after surgery.

If the frozen section result reported the mass as benign or malignant, the final diagnosis would remain the same in, on average, $94 \%$ and $99 \%$ of the cases, respectively.

In cases where the frozen section diagnosis was a borderline tumour, there is a chance that the final diagnosis would turn out to be a cancer in, on average, $21 \%$ of women.

\section{What does this mean?}

Where the frozen section diagnosis is a borderline tumour, the diagnosis is less accurate than for benign or malignant tumours. Surgeons may choose to perform additional surgery in this group of women at the time of their initial surgery in order to reduce the need for a second operation if the final diagnosis turns out to be a cancer, as it would on average in one out of five of these women. 


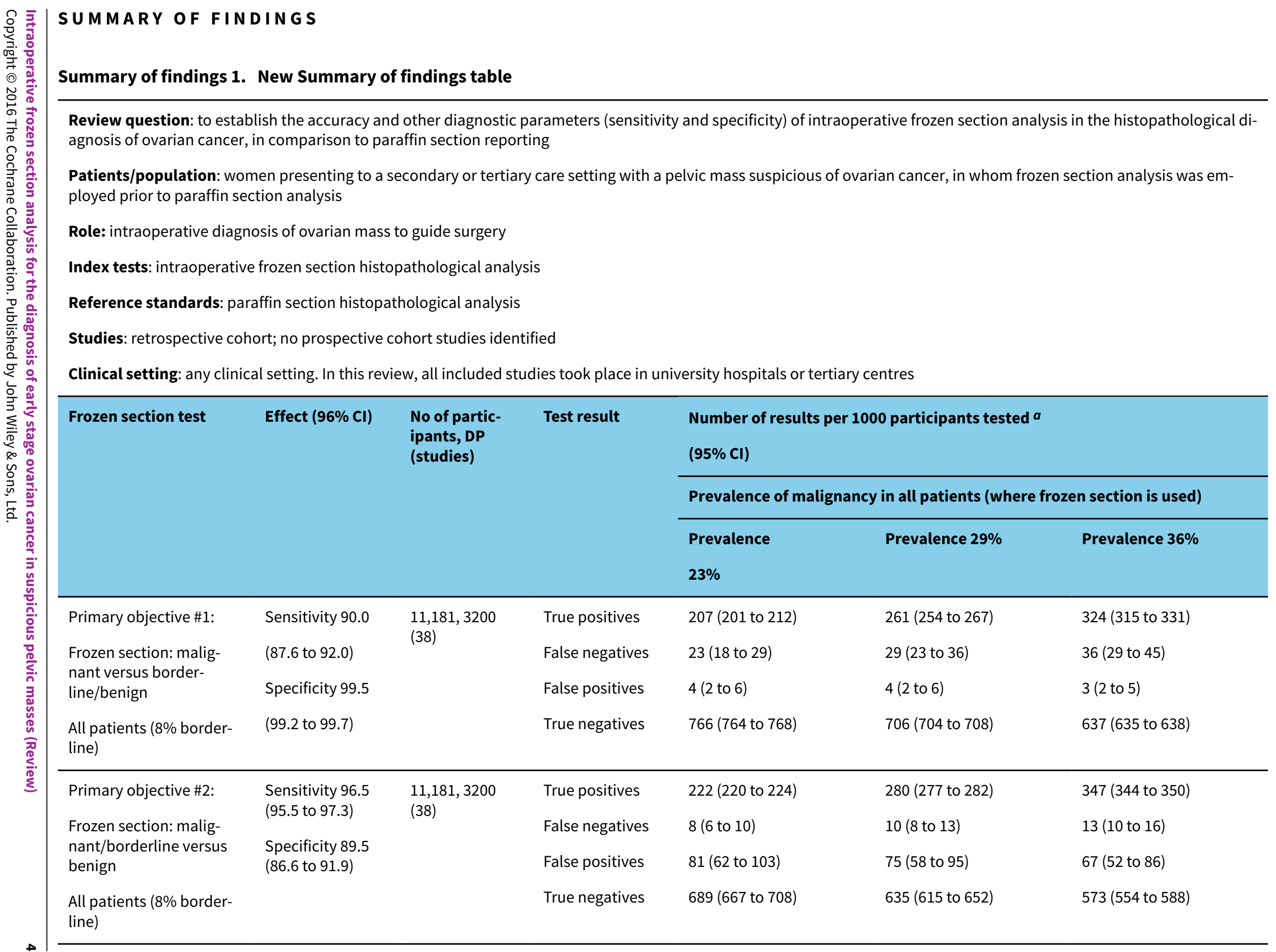




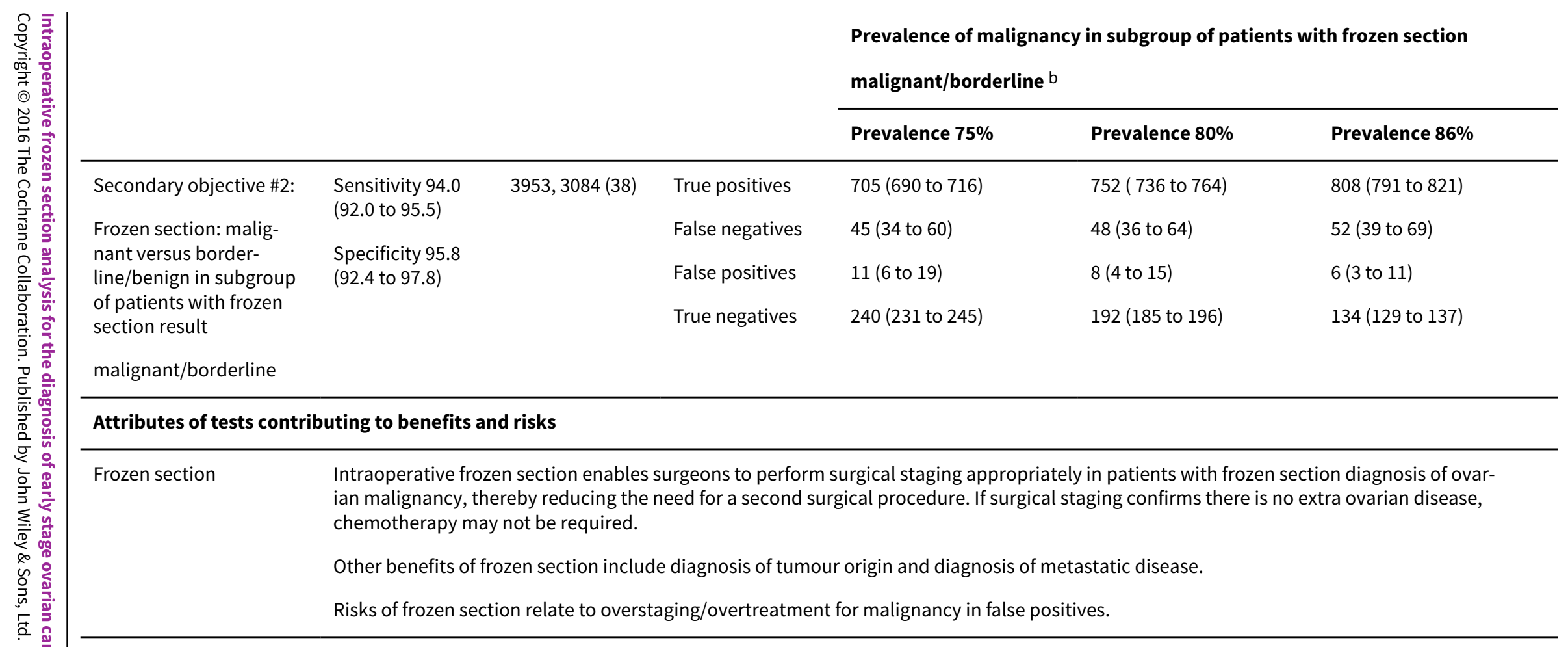

\section{Overall quality of evidence/risk of bias:}

Patient selection: included studies are retrospective. The majority report consecutive cases, but in several the sampling is unclear

Index test: deferred and unclear frozen section results reported and excluded from $3 \times 3$ tables

Reference standard: Pathologists must have been aware of frozen section results at time of performing paraffin section. Four studies reported the same pathologist interpreting both tests.

Flow and timing: paraffin section takes place after frozen section so no bias in timing.

Precision: Average estimates of both sensitivity and specificity have good precision.

Cl: confidence interval; DP: disease positive.

aPrevalence of malignancy from included studies. median, lower and upper interquartile range values of $23 \%, 29 \%$ and $36 \%$ respectively.

bPrevalence of malignancy from included studies from subgroup of cases where frozen section of malignant or borderline may be used to refer to cancer surgery: median, lower and upper interquartile range values of $75 \%, 80 \%$ and $86 \%$ respectively. 


\section{B A C K G R O U N D}

\section{Target condition being diagnosed}

In 2012, 238,719 women worldwide were diagnosed with epithelial ovarian cancer (EOC), and 151,905 died from the disease, corresponding to an annual incidence of 6.1 cases per 100,000 women, an annual mortality rate of 4.3 deaths per 100,000 and a cumulative lifetime risk of $0.5 \%$ (GLOBOCAN 2012). Ovarian cancer is the sixth most common cancer and the seventh most common cause of cancer death in women. A woman's risk of developing cancer of the ovary by age 75 years varies between countries, ranging from $0.5 \%$ to $1.6 \%$. This corresponds to an agestandardised rate of ovarian cancer from 5 to 14 cases per year in 100,000 women under 75 . In Europe, $30 \%$ to $44 \%$ of women with ovarian cancer are alive five years after diagnosis (EUROCARE 2003). The poor survival associated with ovarian cancer is largely because most women are diagnosed when the cancer is already at an advanced stage (Jemal 2008), with only $30 \%$ being early-stage, that is, confined to the ovary (NCIN 2015).

Early-stage ovarian cancer, or stage I and II according to the International Federation of Gynecology and Obstetrics (FIGO 2015), has a combined incidence of less than $35 \%$, with five-year survival rates of $92 \%$ and $55 \%$ for stage I and stage II, respectively (Cancer Research UK 2012) (Appendix 1).

Currently, women presenting with a pelvic mass suspected of being ovarian cancer are triaged according to the risk of malignancy index (RMI) (Bailey 2006; Jacobs 1990). RMI is a product (RMI = $\mathrm{U} \times \mathrm{M} \times \mathrm{CA125)}$ of suspicious ultrasound features of the mass (multilocular cysts, solid areas, metastases, ascites and bilateral lesions), menopausal status (postmenopausal $=3$ ) and serum CA125 levels (IU/ml). There is some uncertainty as to the optimal threshold for the RMI; however, women with high RMIs (e.g. > 200) are usually scheduled for staging laparotomy at cancer centres.

Unlike advanced disease, early disease may not be obvious at surgery. It is up to gynaecological cancer centres to decide how they manage these masses. Some may choose to await final histology before planning surgical staging; others may opt to surgically stage those with high RMI; and others may employ frozen section analysis to provide an intraoperative diagnosis.

The value of surgical staging is to detect micrometastases, present in approximately $25 \%$ cases of invasive epithelial ovarian cancer, which are not macroscopically evident and would warrant adjuvant chemotherapy (Helewa 1986).

\section{Index test(s)}

Intraoperative frozen section histopathological analysis of a suspicious pelvic mass may facilitate the appropriate selection of women requiring surgical staging. Frozen sections are not routinely performed in all gynaecological cancer units in the United Kingdom; as a result, optimal surgical staging may be omitted at primary laparotomy, particularly in early-stage disease. In the ICON 1 trial, adjuvant platinum-based chemotherapy offered improved overall survival in clinically stage I disease (ICON 1 ). This study included $93 \%$ of cases with clinically early-stage disease who underwent hysterectomy, bilateral salpingo-oophorectomy and omentectomy as a minimum surgical procedure. Optimal staging was therefore not performed.

The importance of optimal surgical staging was further highlighted in the ACTION study (Trimbos 2003), which showed that in a subgroup analysis on the effect of surgical staging, the benefit of adjuvant chemotherapy appeared to be limited to patients who underwent suboptimal staging and so had a higher risk of undetected residual disease. In a subgroup analysis of patients with optimal surgical staging, adjuvant chemotherapy was not associated with overall or recurrence-free survival. Optimal staging was shown to be an independent prognostic factor for progressionfree and overall survival. Optimal staging included omentectomy, washings, peritoneal biopsies, and pelvic and paraaortic lymph node sampling. Women with early stage epithelial ovarian cancer who undergo optimal surgical staging survive longer than those suboptimally staged (Trimbos 2010). However, this benefit of surgical staging did not reach significance in a recent Cochrane review update of these studies with 10-year outcome data (Lawrie 2015).

If the frozen section shows a suspicious pelvic mass to be benign, a full staging procedure is not necessary, and fertility-sparing surgery could be offered if appropriate. Unnecessary surgical staging can lead to lymphoedema, lymphocyst formation, and visceral and neurovascular injury. Lymphoedema and lymphocyst formation are often chronic conditions that can negatively affect quality of life.

If the frozen section shows a borderline or malignant ovarian tumour, surgeons often perform optimal staging. Therefore, the potential benefits of performing intraoperative frozen section include: reducing surgical morbidity associated with unnecessary optimal surgical staging; reducing the need for a second surgical procedure to complete surgical staging where it has been suboptimal; and reducing operating costs.

Several studies and reviews have reported high sensitivity, specificity and overall accuracy when comparing intraoperative frozen section with paraffin section examination (Cross 2012; Gol 2003; Medeiros 2005; Naik 2006).

\section{Clinical pathway}

Most women with suspected early ovarian cancer undergo surgical staging to identify metastases. This optimally includes inspection and palpation of peritoneal cavity and organs, biopsy of peritoneum and suspicious nodules, peritoneal washings, total abdominal hysterectomy (TAH), bilateral salpingo-oophorectomy (BSO), omentectomy, and retroperitoneal lymph node assessment and sampling. An appendicectomy can be performed if the tumour is mucinous. Failure to complete the above staging in cases of malignancy is called suboptimal staging. Diagnosis is confirmed by paraffin section examination of surgical specimens, which is usually reported a few days after the surgery. This is the 'gold standard' of histopathological reporting (Figure 1). 
Figure 1. Flow diagram showing clinical pathway if no frozen section available and staging offered based on paraffin section

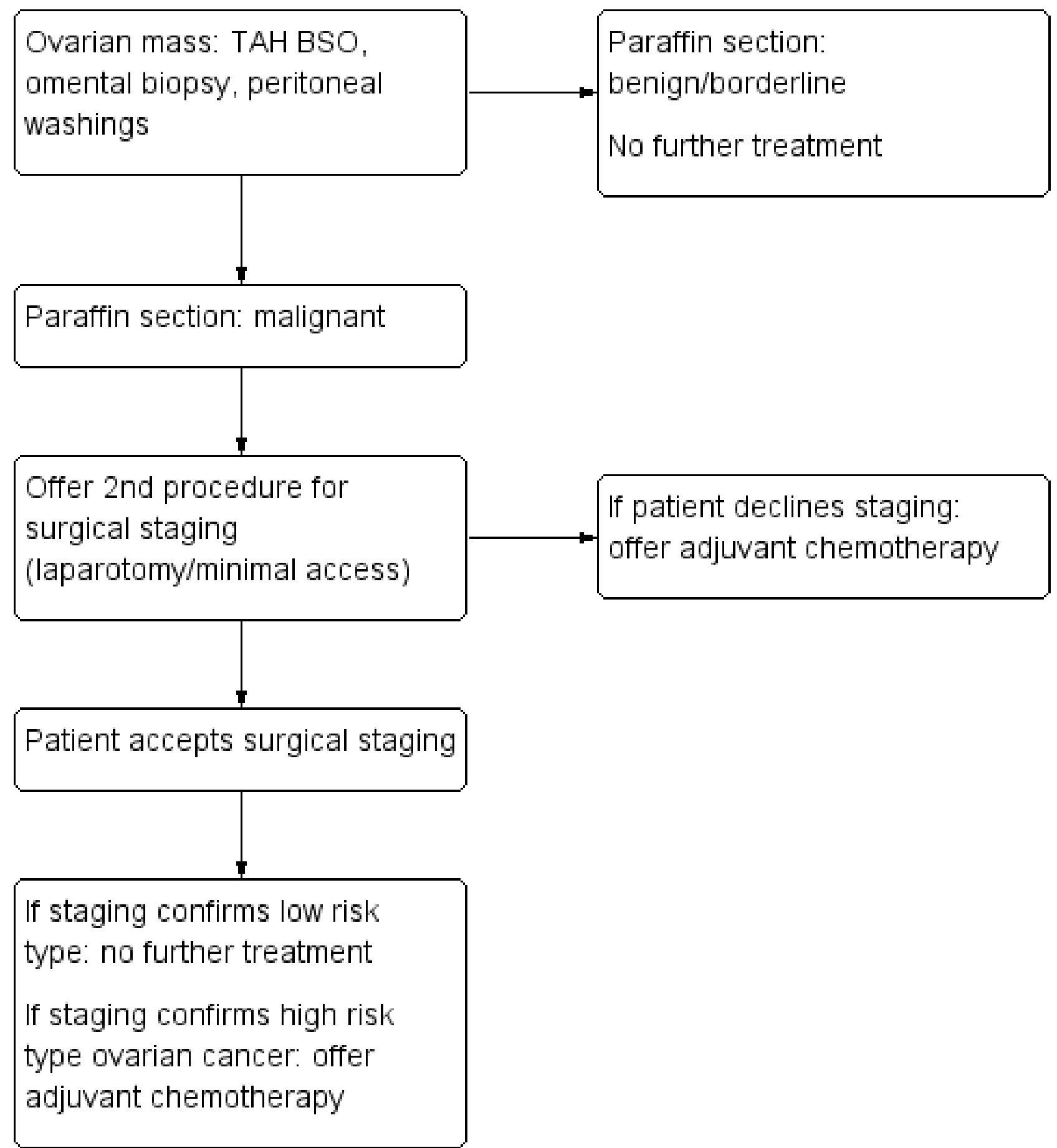

When centres use paraffin sections to guide management rather than frozen sections, a second surgical procedure may be required in order to complete staging in women with confirmed ovarian cancer. This may increase anxiety in addition to increasing the risk of surgical and anaesthetic morbidity.

Where frozen section is used in the clinical pathway, it is used on the same tissue samples as will be used for paraffin section, but allows decisions about the need for further surgical staging to be made within the same operation. Where the frozen section result is benign, patients need only be offered further surgical staging if the subsequent paraffin section result is malignant (Figure 2). Where the frozen section result is malignant, patients can be offered immediate surgical staging without the need for a second surgery (Figure 2). Where the frozen section result is borderline, there are two options (Figure 3). In option 1, the clinical team and patient agree in advance to await the paraffin section result, with further surgical staging or adjuvant chemotherapy offered if subsequent 
paraffin result is malignant. In option 2, they agree in advance to proceed to immediate surgical staging. Adjuvant chemotherapy decisions are made on the basis of paraffin section test results (Figure 1, Figure 2, Figure 3).

Figure 2. Flow diagram showing clinical pathway for frozen section benign or malignant and surgical staging offered. Example average numbers are shown for a hypothetical population of $\mathbf{1 0 0 0}$ women, with prevalences of malignancy $29 \%$, borderline $8 \%$, benign $63 \%$. Prevalences are based on averages across all included studies.

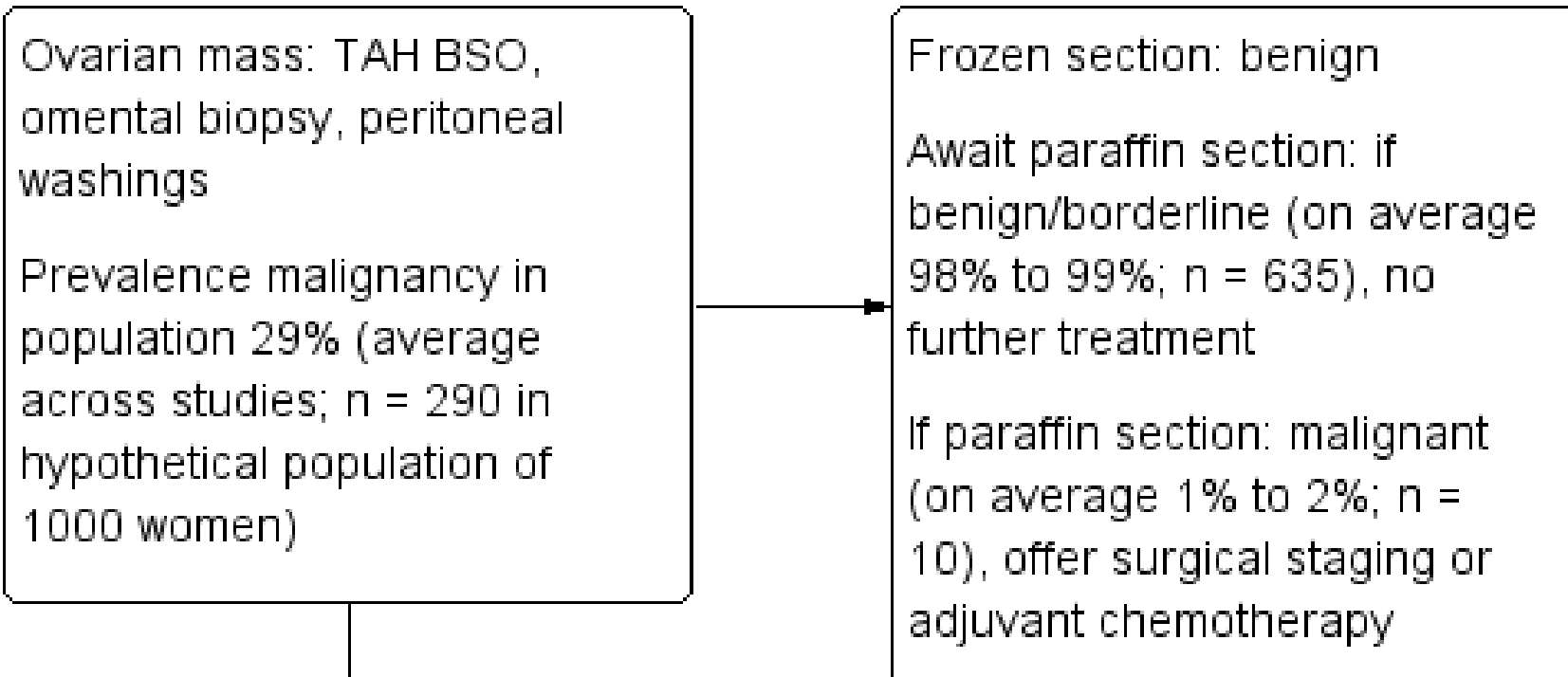

Frozen section: malignant (on average $29 \%$; $n=261$ )

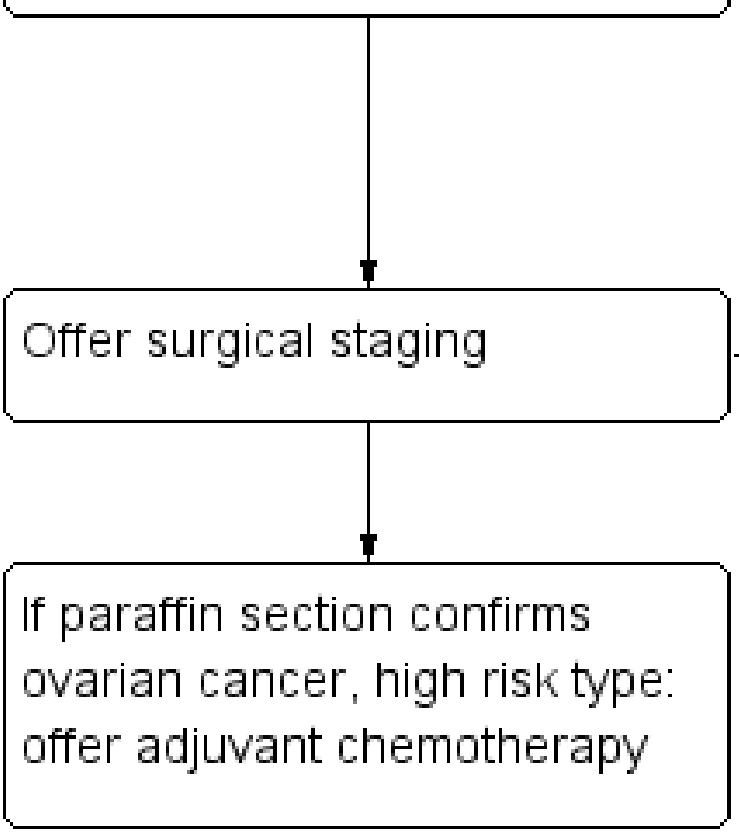

\section{If paraffin section confirms} ovarian cancer, low risk type: no further treatment 
Figure 3. Flow diagram showing clinical pathway options (stage or not to stage) for borderline frozen section diagnosis. Example average numbers are shown for a hypothetical population of 1000 women, with prevalences of malignancy $29 \%$, borderline $8 \%$, benign $63 \%$. Prevalences are based on averages across all included studies.

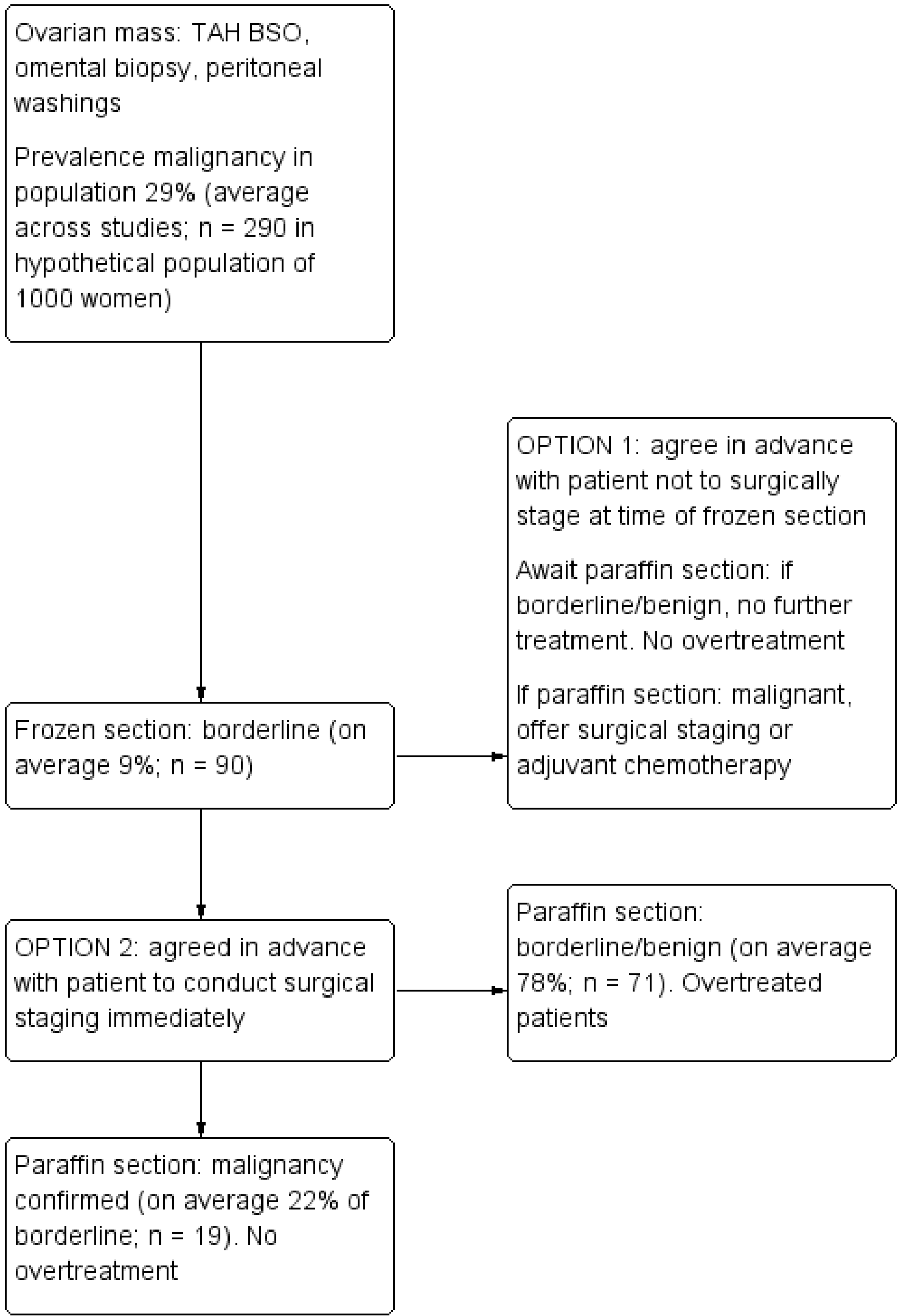


In women with macroscopically evident stage III disease, there is no need to use frozen section to confirm malignancy. However, as discussed earlier, there is a proportion of women with apparently stage I disease who have microscopic involvement of paraaortic lymph nodes or omentum and are upstaged after surgical staging. These women are offered dual-agent chemotherapy with a taxane.

In women with low risk disease, that is, stage IA grade 1 disease; or in those with comprehensively staged stage IB grade 1-2 disease, experts thought until recently that there was no survival advantage associated with adjuvant chemotherapy (Winter-Roach 2012). However, an update of these data suggest that there may be a longer term advantage of chemotherapy, even in these women (Lawrie 2015). For women who have had suboptimal staging, clinicians should discuss a second surgical staging procedure or adjuvant chemotherapy (NICE 2011). Therefore, the clinical consequence of suboptimal surgical staging is that women who appear to have low-risk stage I ovarian cancer may require adjuvant chemotherapy.

In the cases of high risk disease, that, is stage IB grade 3; stage IC and higher; and clear cell cancers, six cycles of adjuvant platinumbased chemotherapy are recommended (NICE 2011). Due to the good response rate to chemotherapy, early-stage serous ovarian cancers are often treated with six cycles of adjuvant dual-agent chemotherapy, including a taxane. With regard to clear cell cancers, as the response to chemotherapy is often poor, there may be a therapeutic benefit to performing lymphadenectomy in case of micrometastases. It should be noted, however, that NICE guidance recommends assessment of retroperitoneal lymph nodes but not systematic or block dissection of retroperitoneal lymph nodes in women with clinically apparent stage I disease. Maggioni 2006 demonstrated that patients undergoing systematic pelvic and paraaortic lymphadenectomy compared to sampling were found to have more micrometastases ( $22 \%$ versus $9 \%$ ), leading to upstaging of apparent stage I disease to stage IIIC. However, there was greater morbidity, operating time and hospital cost with no demonstrable overall survival advantage.

\section{Prior test(s)}

Serum CA125 and abdominal ultrasound are performed as part of the RMI assessment. Women presenting with a pelvic mass and a high RMI score will usually undergo a computed tomography (CT) scan, magnetic resonance imaging (MRI) of the pelvis and abdomen, or both to establish the extent of disease. Interpretation of the histology slides at frozen section is made independently of these prior tests, and so these bear no relevance to the diagnostic accuracy of the frozen section test.

\section{Role of index test(s)}

Intraoperative frozen section analysis may allow appropriate selection of women with suspicious pelvic masses who would benefit from optimal surgical staging.

\section{Alternative test(s)}

The 'gold standard' for the diagnosis of ovarian cancer is histopathological examination of surgical specimens by paraffin section after laparotomy. In women not undergoing frozen section, surgeons may choose to await paraffin section histology prior to performing staging; to stage all women deemed to have a high risk of malignancy; or to stage according to clinical suspicion, for example by performing biopsy on peritoneal adhesions or sampling enlarged lymph nodes.

\section{Rationale}

The importance of optimal surgical staging in ovarian cancer is now well established. Frozen section analysis at diagnostic laparotomy may allow the surgeon to accurately identify those women with early stage ovarian cancer (who may otherwise not have been identified during the initial procedure) who will benefit from optimal surgical staging. This may avoid the need for a subsequent restaging procedure or adjuvant chemotherapy (Trimbos 2003).The role of intraoperative frozen section analysis in the diagnosis and management of early stage disease is particularly topical at present, with many recent studies reporting high sensitivities and specificities for this diagnostic test. We decided to review the evidence for and against frozen section as an accurate test to diagnose early ovarian cancer.

\section{O B J E C T IVES}

\section{Primary objectives}

To assess the diagnostic test accuracy of frozen section (index test) in the histopathological diagnosis of ovarian cancer in women with suspicious pelvic masses as verified by paraffin section (reference standard).

Within our review we aimed to establish the diagnostic accuracy of frozen section in comparison to a reference standard diagnosis of cancer from paraffin section, using measures of sensitivity and specificity. There were two primary objectives.

1. To determine the accuracy of frozen section to identify cancer cases, using a test threshold for frozen section that defines cancer as a positive test result and considers both borderline and benign results as test negative (Table 1 ). The rationale is that clinical and surgical management is different where a case of malignancy is identified.

2. To assess the accuracy of frozen section to identify cancer, using a test threshold for frozen section that defines both cancer and borderline cases as positive test results and considers benign results as test negative (Table 2). The rationale is that the literature reports a high rate of cases where the frozen section result was borderline, but the final result from paraffin section was malignant. There are potentially serious repercussions from managing patients with a cancer outside a cancer pathway when 'under staging' occurs, that is, if patients with malignancy do not receive surgical staging, including lymphadenectomy. This is particularly relevant in women found to have borderline ovarian masses at frozen section, as many will receive a final paraffin section diagnosis of malignancy.

Which threshold is considered most useful in practice depends on the clinicians' judgement.

\section{Secondary objectives}

1. To establish if intraoperative frozen section analysis allows the surgeon to accurately identify the cases of early stage ovarian cancer that may benefit from optimal surgical staging. 
2. To assess the accuracy of final diagnosis of malignancy, in a subgroup of women with a frozen section result of either borderline or cancer. This corresponds to one strategy for referral for cancer treatment.

\section{METHODS}

\section{Criteria for considering studies for this review Types of studies}

We included studies published in any language and, where possible, had non-English articles translated. We excluded studies that involved ten or fewer patients.

Studies were eligible if:

1. Both frozen section analysis and paraffin section analysis were performed in the same patient;

2. The absolute numbers of observations of true positives, false positives, false negatives and true negatives were available or derivable from the data reported in the primary studies.

We included both prospective and retrospective studies. However, we excluded retrospective studies that collected data for a specific histological type only, such as borderline tumours, due to the risk of reporting bias.

We excluded studies in which frozen section analysis was performed for conditions other than ovarian malignancy as well as studies for which no English translation was available.

\section{Participants}

Women presenting to a secondary or tertiary care setting with a pelvic mass suspicious of ovarian cancer, in whom physicians employed frozen section analysis prior to paraffin section analysis.

\section{Index tests}

Intraoperative frozen section histopathological analysis. Test results were classified as malignant, borderline or benign. We present results using two different thresholds for the index test; malignant vs borderline/benign, and malignant/borderline vs benign. The reference standard remains diagnosis of malignancy in all analyses in the review.

The diagnostically important distinction to make is between malignant/borderline and benign frozen section, because although only women with malignant disease require surgical staging, studies have found the risks of borderline frozen section returning as malignant to be high, and inadequately staging these women at primary laparotomy may be deemed unacceptable (Cross 2012; Puls 1997). However, many would argue that performing unnecessary staging on women with borderline disease confers unnecessary morbidity.

\section{Target conditions}

Ovarian malignancy, not obvious at a surgically or radiologically advanced stage.

\section{Reference standards}

Paraffin section histopathological analysis. Test results are classified as malignant, borderline or benign. We present results using the threshold for women classified as having ovarian cancer as 'malignant' versus women not having cancer as 'borderline or benign'.

\section{Search methods for identification of studies}

\section{Electronic searches}

We identified eligible studies by searching the following electronic databases.

- The Cochrane Gynaecological Cancer Group Specialised Register January 2015.

- Cochrane Central Register of Controlled Trials (CENTRAL),(2015, Issue 1).

- MEDLINE - Ovid (January 1946 to January 2015).

- EMBASE - Ovid (January 1980 to January 2015).

- Database of Abstracts of Reviews of Effects (DARE) (Issue 4, 2014).

- Health Technology Assessments (HTA) Database (Issue 4, 2014).

The MEDLINE search strategy included both subject headings (MeSH terms) and text words for the target condition (ovarian malignancy) and the histological technique under investigation ('Frozen Section analysis'). We did not apply language restrictions. We adapted the MEDLINE search to search CENTRAL, EMBASE, DARE and HTA databases. In particular, we adapted the MEDLINE $\mathrm{MeSH}$ terms into the corresponding terms available in the EMTREE vocabulary. We present full details of the MEDLINE and EMBASE search strategies, together with a brief summary of the MEDLINE search strategy, in Appendix 2. We imported all citations identified by the MEDLINE and EMBASE search strategies into an electronic database. We identified all potentially eligible articles on PubMed and used the 'related articles' feature to carry out a further search for newly published papers.

\section{Searching other resources}

\section{Unpublished and grey literature}

We searched for ongoing trials in the following trial registers and contacted experts in the field to identify any further ongoing trials.

- metaRegister of Controlled Trials (mRCT) (http:// www.controlled-trials.com/mrct/).

- Physicians Data Query (PDQ) (http://www.cancer.gov/ cancertopics/pdq).

- ClinicalTrials.gov (http://clinicaltrials.gov/).

- National Cancer Institute (http://www.cancer.gov/clinicaltrials/ search).

\section{Handsearching}

We handsearched the citation lists of included studies, key textbooks and existing systematic reviews and checked their references. When we retrieved relevant studies (even if we finally excluded them), we also searched their references in order to minimise the potential for missing relevant studies. We handsearched conference reports in the following sources.

- Gynecologic Oncology (Annual Meeting of the American Society of Gynecologic Oncologists).

- International Journal of Gynecologic Cancer (Annual Meeting of the International Gynecologic Cancer Society). 
- British Gynaecological Cancer Society.

- European Society of Gynaecological Oncology.

- Society of Gynaecological Oncologists.

\section{Data collection and analysis}

\section{Selection of studies}

We downloaded all titles and abstracts retrieved by electronic searching to Endnote and removed duplicates. Two authors (NR and $A P$ ) independently examined the remaining reference titles and abstracts to retrieve the full text of all potentially relevant reports. Three authors (NR, $A B$ and $C F$ ) independently reviewed all relevant reports according to the pre-defined inclusion criteria to determine eligibility. We resolved any disagreements through arbitration by another author (RS), and we documented reasons for exclusions.

\section{Data extraction and management}

One author (TL) designed and trialled a data extraction form specifically to collect details from selected studies. Two authors (NR and $A B$ ) recorded the relevant information for each individual study, without concealing the study authorship or publication details. This information included: lead author, year of publication, accrual dates, country and setting, study design, method of recruitment, setting, number and characteristics of participants, any additional preoperative investigations performed, the reference standard used, any comparator tests used, follow-up, and information related to the pathologists interpreting the specimens (background specialty, level of expertise). Two authors (NR and AB) extracted data from the selected reports, and two authors (RS and SM) checked the data extractions.

\section{Assessment of methodological quality}

Two review authors ( $N R$ and $A B$ ) independently assessed the methodological quality of each included study using the revised Quality Assessment of Diagnostic Accuracy Studies tool (QUADAS-2) (Whiting 2011). We consulted a third author (RS) in case of discrepancy between authors. The QUADAS-2 tool is structured into a series of questions in four domains that should be answered 'yes', 'no' or 'unclear', and it aims to evaluate the spectrum of bias. We resolved any disagreements by discussion. Figure 4 is a graphic summary of the methodological quality of included studies. 
Figure 4. Study flow diagram.

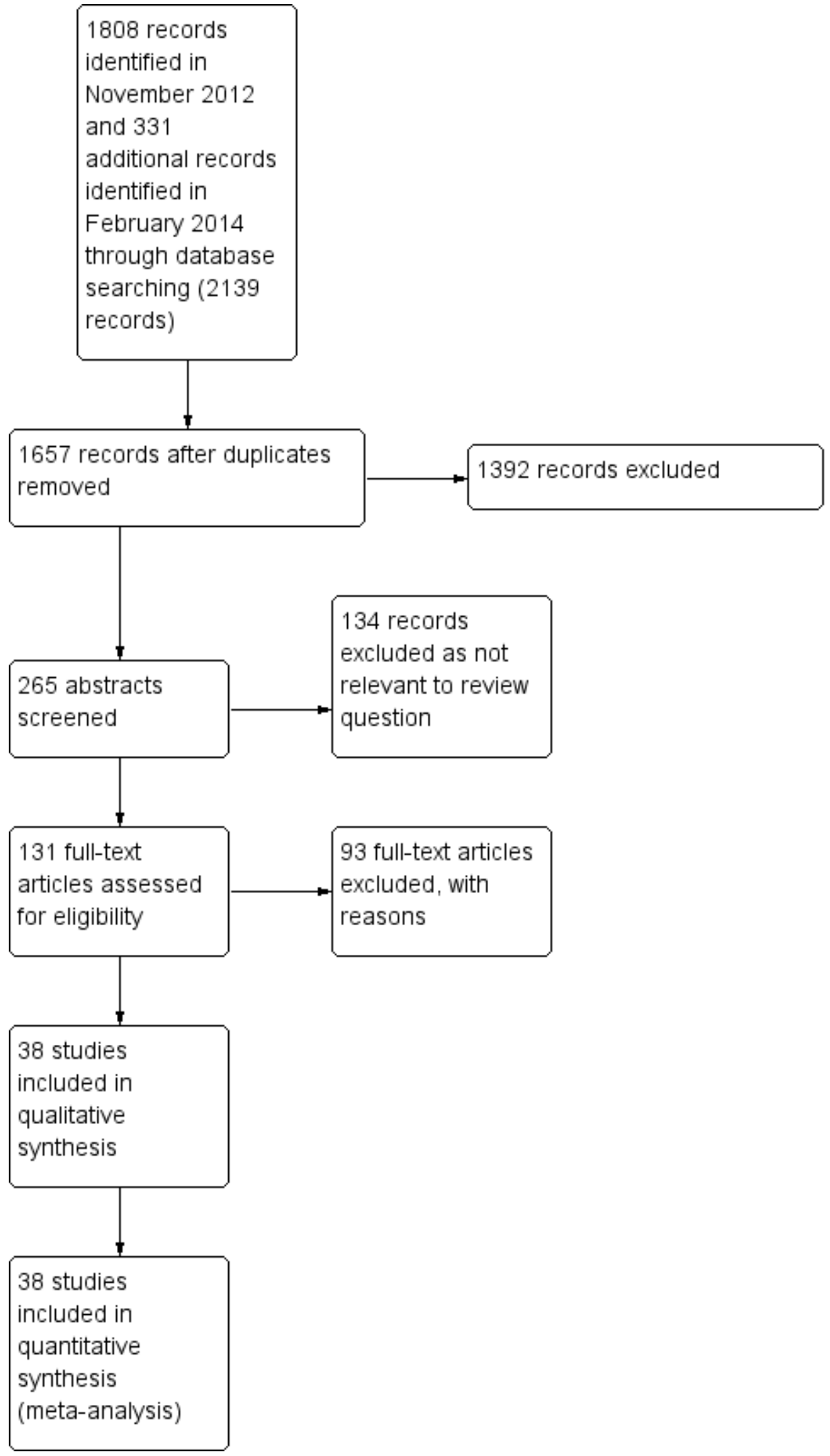


We assessed the core QUADAS items in the following domains: patient selection, index test, reference standard, flow and timing.

\section{Patient selection}

Could the selection of patients have introduced bias?

1. Was a consecutive or random sample of patients enrolled?

a. Yes; a study ideally should enrol a consecutive or random sample of eligible patients with suspected disease to prevent the potential for bias.

b. No, a non-consecutive sample of patients was used.

c. Unclear.

2. Was a case-control design avoided?

a. Yes; studies enrolling participants with known disease and a control group without the condition may exaggerate diagnostic accuracy.

b. No.

c. Unclear.

3. Did the study avoid inappropriate exclusions?

a. Yes; studies that make inappropriate exclusions (for example, not including 'difficult-to-diagnose' patients) may result in overestimation of diagnostic accuracy.

b. No.

c. Unclear.

4. Were the patients selected representative of the patient population the index test would apply to?

a. Yes; patients with a high risk of malignancy index $(\mathrm{RMI}>200)$ are usually the subjects who would benefit from this index test.

b. No; use of the index test in patients at low risk of malignancy or in those with incidental finding at laparotomy for other condition may bias the results.

c. Unclear.

\section{Index test}

Could the conduct or interpretation of the index test have introduced bias?

1. Were the index test results interpreted without knowledge of the results of the reference standard?

a. Yes; knowledge of the reference standard may influence interpretation of index test results. The potential for bias is related to the subjectivity of interpreting index test and the order of testing. If the index test is always conducted and interpreted before the reference standard, this item can be rated 'yes'.

b. No; if there was a previous histological diagnosis of malignancy made during investigation of the same cyst, this item can be rated 'no'.

c. Unclear.

2. Were the index test results interpreted by a pathologist specialising in gynaecological oncology?

a. Yes; specialist centres employing dedicated gynaecological oncology pathologists may perform better in interpreting frozen section slides and thereby improve the sensitivity and specificity of the test.

b. No.

c. Unclear.

\section{Reference standard}

Could the reference standard, its conduct or its interpretation have introduced bias?

1. Is the reference standard likely to correctly classify the target condition?

a. Yes; estimates of test accuracy are based on the assumptions that the reference standard is $100 \%$ sensitive and that specific disagreements between the reference standard and index test result from incorrect classification by the index test.

b. No.

c. Unclear.

2. Were the reference standard results interpreted without knowledge of the results of the index test?

a. Yes; knowledge of the index test results may influence interpretation of the reference standard results. Potential for bias is related to the potential influence of previous knowledge on the interpretation of the reference standard.

b. No.

c. Unclear.

\section{Flow and timing}

Could the patient flow have introduced bias?

1. Did all patients receive a reference standard, and if so did they receive the same reference standard?

a. Yes; verification bias occurs when only a proportion of the study group receives confirmation of the diagnosis by the reference standard, or if some patients receive a different reference standard. If the results of the index test influence the decision on whether to perform the reference standard or which reference standard is used, estimated diagnostic accuracy may be biased. Accepted best practice is to verify all frozen section diagnoses with paraffin section histology.

b. No.

c. Unclear.

2. Were all patients included in the analysis?

a. Yes; all participants recruited into the study should be included in the analysis. A potential for bias exists if the number of patients enrolled differs from the number of patients included in the $2 \times 2$ table of results, because patients lost to follow-up differ systematically from those who remain.

b. No.

c. Unclear.

\section{Statistical analysis and data synthesis}

We entered data into Cochrane's statistical software, Review Manager 2014, to calculate sensitivity and specificity for each study (we also present 95\% confidence intervals of these point estimates in a forest plot). We present individual study results graphically by plotting estimates of sensitivities and specificities in receiver operating characteristic (ROC) space. All studies reported $3 \times 3$ tables per patient enabling extraction of $2 \times 2$ tables from all studies for three analyses of accuracy:

1. Reference test (paraffin test): positive result malignancy, negative result borderline or benign. Index test (frozen section): 
positive result malignancy, negative result borderline or benign (Table 1).

2. Reference test: positive result malignancy, negative result borderline or benign. Index test: positive result malignancy or borderline, negative result benign (Table 2).

3. Subgroup analysis of malignant and borderline by index test. Reference test: positive result malignancy, negative result borderline or benign. Index test: positive result malignancy, negative result borderline or benign.

We used xtmelogit commands in the Stata 13.1 statistical package (Stata 2013) to meta-analyse pairs of sensitivity and specificity using a bivariate random-effects approach (Reitsma 2005). The bivariate approach was suitable for test results from $2 \times 2$ tables based on categorical test thresholds. This approach enabled us to calculate summary estimates of sensitivity and specificity, while correctly dealing with any correlation that might exist between sensitivity and specificity as well as the following sources of variation.

1. Imprecision in measurement of sensitivity and specificity within each study.

2. Variation beyond chance in sensitivity and specificity between studies.

We incorporated covariates in the bivariate model in order to examine the effect of potential sources of heterogeneity on sensitivity and specificity. We used the results of the bivariate model to calculate likelihood ratio tests in order to assess the statistical significance of covariates.

\section{Investigations of heterogeneity}

We constructed a ROC plot of sensitivity versus 1 - specificity and explored the heterogeneity of the sensitivity and specificity estimates by examining both the ROC plot and forest plot.

In the protocol, we proposed to run a separate heterogeneity analysis for the following situations if there were sufficient studies reporting differences in these study characteristics.

- Preoperative investigation including a combination of imaging and tumour markers (CA $125+/-$ HE4).

- Preoperative imaging including CT or MRI scans.

- RMI score $>200$.

- High risk study population, for example in a tertiary referral centre.

- Size of ovarian cyst.

- Ovarian cyst histological type, for example mucinous or serous.

- Expertise of pathologist reporting.

However, studies reported only two of these characteristics: expertise of reporting pathologist and whether there was a high risk study population, for example, in a tertiary referral centre. All studies took place in university hospitals or tertiary referral centres, so we could not examine for heterogeneity of study setting. We were able to conduct a heterogeneity analysis for expertise of pathologist reporting, for primary objective \#1 and secondary objective $\# 2$, although the model did not converge in a heterogeneity analysis of primary objective \#2. For primary outcome \#2, the model did not converge, as there were only four studies in the less experienced group, one of which was Toneva 2012, where specificity was low (mostly likely due to small study size bias). Data extraction grouped pathologist expertise into four categories as described in the studies (specialist gynaecological pathologist, consultant pathologist, general pathologist or reader expertise not recorded). For heterogeneity analyses, we divided readers into more experienced (specialist gynaecological pathologist or consultant pathologist) and less experienced/unknown expertise (general pathologist or reader expertise not recorded). We conducted covariate analysis specifying reader expertise as a covariate in STATA as recommended in the Methods of the Cochrane Handbook for Diagnostic Test Accuracy Reviews (Macaskill 2010).

\section{Sensitivity analyses}

We had planned sensitivity analyses for studies without verification bias and those without missing data.

\section{Assessment of reporting bias}

We documented data regarding loss to follow-up and any loss of data from pre-specified outcomes. As recommended in , we did not conduct analyses to test for reporting bias (Macaskill 2010).

\section{RES U LTS}

\section{Results of the search}

Results of the combined CENTRAL, MEDLINE, EMBASE, DARE and HTA searches until January 2015 yielded 1657 records. Four review authors (NR, $A B, A P$ and $C F$ ) independently screened and reviewed the titles and abstracts. Of these, 131 were selected for classification. Two authors (NR and AB) read the full-text articles and assessed eligibility for the review. We discussed any dispute with a third author (RS) (Figure 4). We excluded 93 studies for the reasons summarised below. Some were excluded for more than one reason.

- They were reviews, editorials, commentaries, case reports, surveys, letters to the editor or conference abstracts (26).

- They were meta-analyses (2).

- An English translation was not available (6).

- We were unable to construct $2 \times 2$ tables from the results (13).

- They were not studies using frozen section intraoperative diagnosis (33).

- They reported only certain histologies (epithelial, serous or mucinous) (11).

- They reported only borderline diagnoses (8); these studies were not representative of the preselected population and did not meet the inclusion criteria.

- They did not represent the population studied by this review (20); these studies included predominantly benign populations and populations in which evidence of extra-ovarian spread was present at time of frozen section.

For further details see Characteristics of excluded studies.

We included 38 studies in 11,181 women. All studies evaluated the index test of frozen section in comparison to the reference standard of paraffin section.

\section{Methodological quality of included studies}

Of the 38 included studies, we considered 1 study to be at high risk of bias (Wang 1998), and we had concerns regarding 
the applicability in 2 studies (Ilvan 2005; Wang 1998;). Wang 1998 reported outcomes of 792 consecutive gynaecological frozen sections, which included 299 samples from ovarian tissue, 360 samples from lymph nodes, 56 from uterine tissue and 77 samples from other sites. The same pathologist reported the paraffin and frozen sections. Ilvan 2005 reported making $7.5 \%$ of their frozen section diagnoses on gross/macroscopic inspection alone. In fact, grossly benign specimens were submitted in 46 cases. In some cases, two experienced pathologists in gynaecological pathology employed touch imprint methodology for diagnosis as well.
Overall, we found that the quality of the included studies was acceptable with a low or unclear risk of bias (Figure 5; Figure 6). However, we note that in many studies our assessment of risk of bias was unclear; for example, it is not clear if pathologists interpreted the reference test (paraffin) without knowledge of the index test (frozen section), but this is unlikely to have introduced bias in the diagnosis of ovarian cancer. 
Figure 5. Risk of bias and applicability concerns summary: review authors' judgements about each domain for each included study

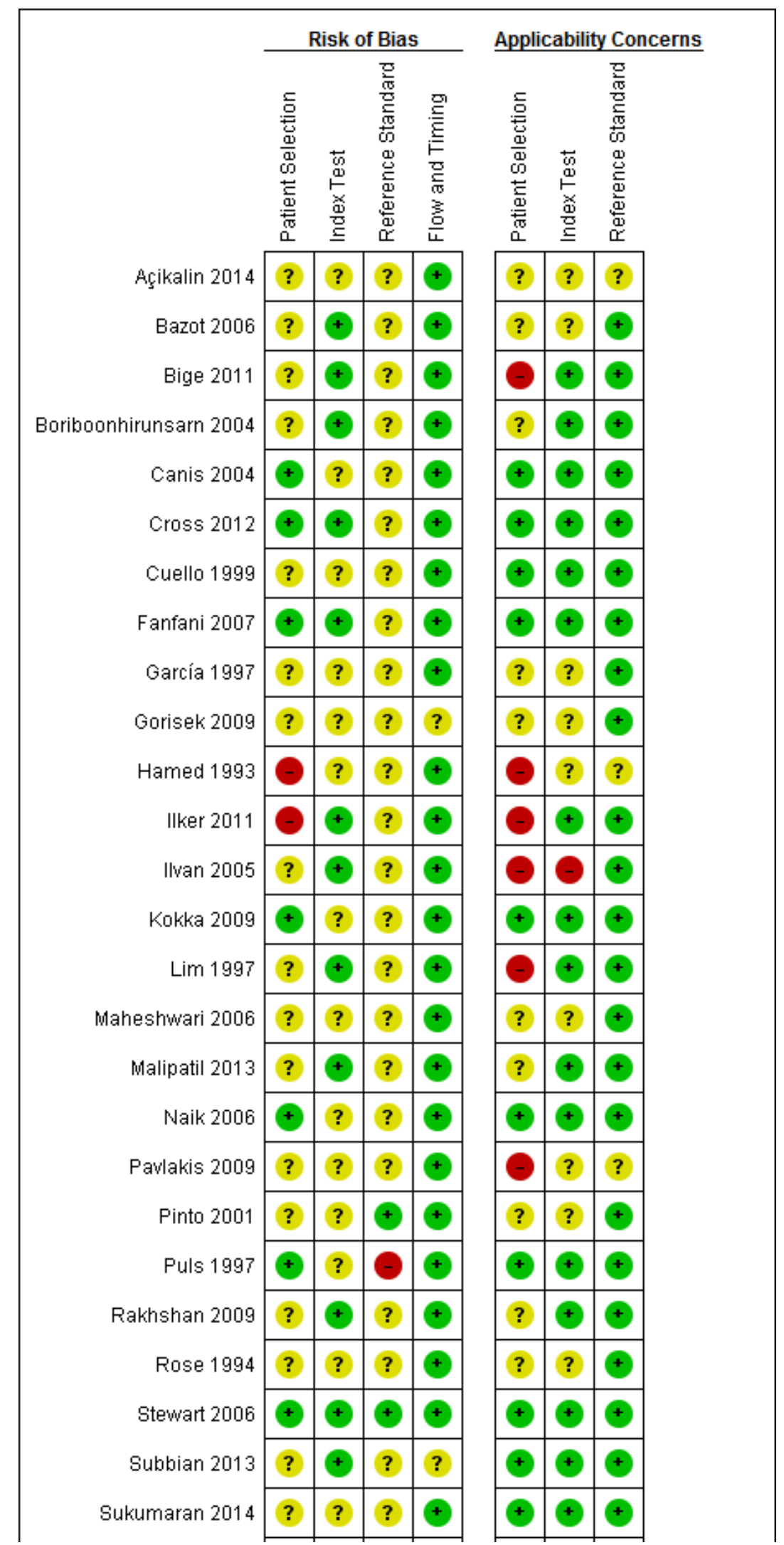

Intraoperative frozen section analysis for the diagnosis of early stage ovarian cancer in suspicious pelvic masses (Review) 
Figure 5. (Continued)

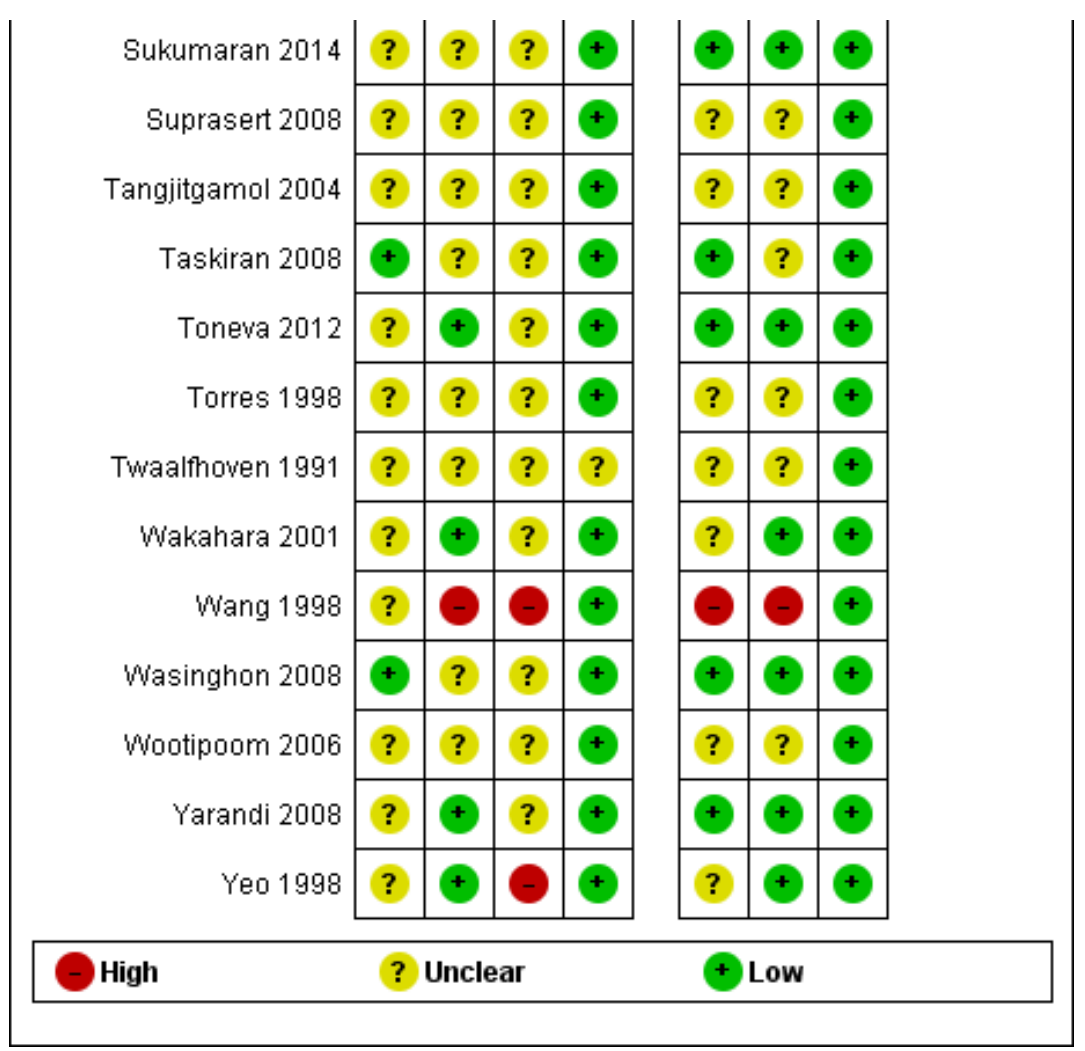

Figure 6. Risk of bias and applicability concerns graph: review authors' judgements about each domain presented as percentages across included studies

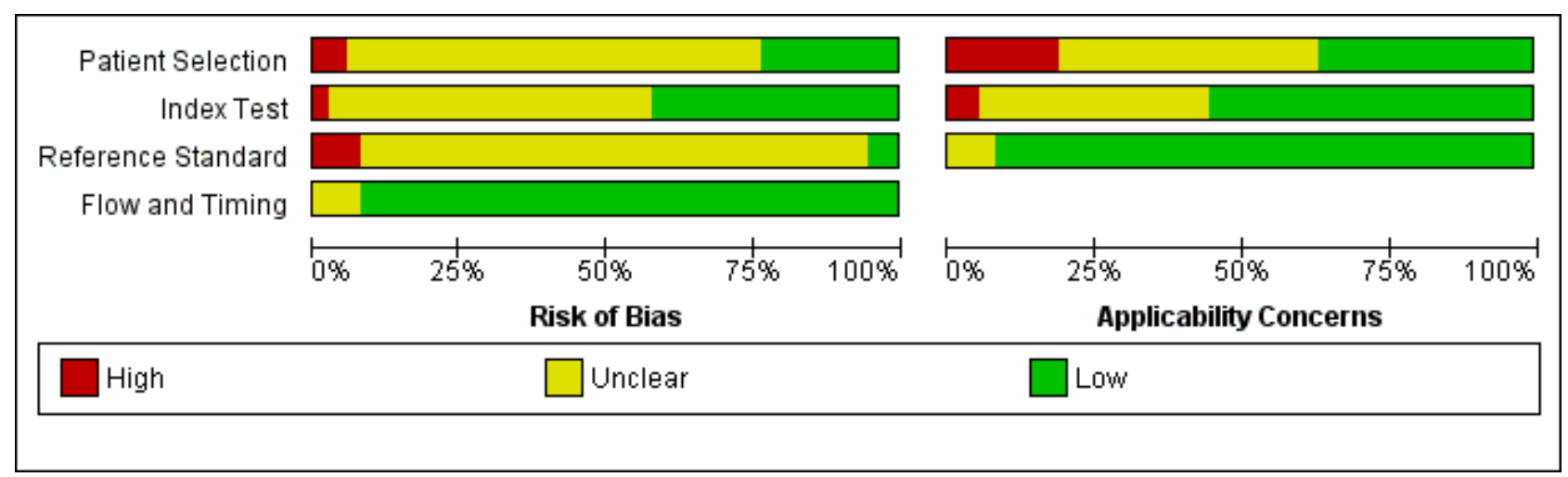

\section{Types of studies}

We included 38 retrospective studies. There were no case-control studies. The sampling methods were consecutive in most studies and unreported in the rest. All took place in university hospitals or tertiary care settings (see Characteristics of included studies).

We excluded eight studies because we could not extract $2 \times 2$ tables; these studies only included cases with borderline results by frozen section.

The interest in borderline ovarian tumours at frozen section diagnosis arises from the fact that this diagnostic group is most likely to see a change in diagnosis at paraffin section. This fact has been attributed to various factors, namely ovarian histology, size of mass and expertise of pathologist. In this review, two studies discussed the ability of frozen section to predict malignancy depending on histology (Cross 2012; Puls 1997). Puls 1997 included only serous or mucinous ovarian masses, analysing the effect of weight on interpretation of frozen section and reporting the greatest discordance between frozen and paraffin section in frozen section-reported borderline mucinous masses weighing over $1360 \mathrm{~g}$, with $50 \%$ (four out of eight) being upgraded to malignant at paraffin section. Cross 2012 reported the majority of sampling errors in serous and mucinous tumours, which accounted 
for $52.3 \%$ of their 1439 ovarian masses submitted for frozen section. The false negative rate for serous tumours was $0.7 \%$ and for mucinous tumours $3.8 \%$. Furthermore, $47.2 \%$ of all borderline tumours were reclassified as malignant on paraffin section, and these were evenly distributed amongst the serous and mucinous categories.

\section{Patient selection}

We considered participants in the included studies to be representative of patients receiving the index test in clinical practice. The majority of studies reported women with pelvic masses, although none provided information regarding tumour markers, such as CA125, or preoperative imaging.

\section{Index test methods}

All patients in the included studies received the index test, namely frozen section, and a number of studies provided details of frozen sectioning. Typically, this involved taking between 1 and 7 sections from the ovarian mass, cut into $5 \mu \mathrm{m}$ thick frozen sections.

Pathologists of varying expertise performed analyses of the frozen section: specialist gynaecological pathologist (6), consultant pathologist (8) or general pathologist (4); studies did not record expertise in 20 cases.

Several studies reported 'deferred' or unclear diagnoses at frozen section, where the pathologist was unable to make a diagnosis on the submitted material. We excluded these results from $3 \times 3$ tables. Pathologists may defer diagnosis to paraffin section for 3 reasons: not enough tissue is submitted for analysis; the pathologist is unable to make a diagnosis; or there are technical issues.

\section{Reference standard methods}

All patients received the reference standard, namely paraffin section. In three studies (Puls 1997; Wang 1998; Yeo 1998), the same pathologist interpreted the paraffin section and the frozen section. The other included studies did not mention whether they employed the same pathologist to interpret both index and reference standard tests. No studies reported blinding of pathologists to index test results when reporting paraffin sections. There were no biases with flow or timing, as paraffin section was always performed after frozen section, with both tests conducted on samples taken at the same time.

\section{Flow and timing}

All patients who received frozen section then received paraffin section. There was no bias in flow or timing amongst included studies. The only potential source of bias was interpretation of both reference and index tests by the same reporting pathologist, as indicated in the studies of Puls 1997, Wang 1998 and Yeo 1998. In clinical practice, it is likely that most surgeons, at the time of submitting the surgical specimen for paraffin section, will indicate to the pathologist that a frozen section has already been performed and detail the results of the frozen section. As blinding from this has not been reported in any of the included studies, it is entirely reasonable to believe that pathologists were aware of the frozen section results when interpreting the paraffin section.

Paraffin section analysis was performed on the same submitted mass as the frozen section, and therefore time interval to paraffin section was not an issue, as there was no risk of disease progression between tests.

\section{Investigations of heterogeneity}

Unfortunately, only one study gave adequate information about histology of all frozen sections performed (Cross 2012). Puls 1997 gave enough information for $2 \times 2$ tables to be constructed for serous, mucinous and endometrioid tumours only. We were therefore unable to perform a heterogeneity analysis according to histopathological type.

None of the included studies provided sufficient information regarding preoperative investigations or imaging, RMI value, or size of mass to conduct heterogeneity analyses.

We investigated variability between studies to establish whether levels of expertise of pathologists reading the frozen section results could explain heterogeneity between studies. We found that there was no statistically significant difference between studies with different levels of expertise of pathologists in primary outcome $\# 1$ and secondary outcome \#2. For primary outcome \#2, the model did not converge, as there were only four studies in the less experienced group, one of which was Toneva 2012, where specificity was low (mostly likely due to small study size bias). The lack of heterogeneity due to expertise of pathologists may be due to the fact that the included studies originated from university hospitals or tertiary centres.

\section{Sensitivity analyses}

We did not conduct sensitivity analyses, as all studies excluded verification bias. A sensitivity analysis based on missing data will be included in a review update, but we note there was only a small amount of missing data.

\section{Findings}

Thirty-eight studies were suitable for addressing the review objectives, as we were able to extract $3 \times 3$ tables from all studies based on thresholds of cancer, borderline and benign for both frozen and paraffin section results. There were a total of 169 deferred diagnoses excluded from 11,350 cases (1.5\% of all cases), leaving 11,181 cases for analysis. Unfortunately, only one study commented on surgical staging with regard to frozen section, and therefore we could not perform an analysis to address secondary objective \#1 (Naik 2006). The results addressing the two primary objectives and secondary objective \#2 are detailed below. We summarise these results in the Summary of findings 1, giving different examples of pre-test prevalences of malignancy to allow clinicians to infer the relevance of the data according to their population.

\section{Primary objective \#1: accuracy of frozen section cancer results to identify women with cancer}

Sensitivity and specificity results were available from 38 studies involving 11,181 participants (3200 identified with cancer, 1055 as borderline and 6926 as benign by paraffin section reference standard). We used a test threshold for frozen sections to define cancer as a positive test result and borderline and benign results as negative test results. The prevalence of cancer ranged from $11 \%$ to $63 \%$. The average sensitivity was $90.0 \%$ (95\% confidence interval (CI) $87.6 \%$ to $92.0 \%$; typical range $71 \%$ to $100 \%$, with one small 
study, García 1997, reporting it as 64\%), and the average specificity was $99.5 \%$ ( $95 \% \mathrm{Cl} 99.2 \%$ to $99.7 \%$ : range $96 \%$ to $100 \%$ ).

Figure 7 is a forest plot of sensitivity and specificity with $95 \%$ confidence intervals for all studies, ordered by the percentage of cancer cases, that is, disease positive (DP) in each study to give insight into the representativeness of the study. Figure 8 shows the results from all studies in a ROC plot. Both figures show that the data are homogeneous enough to combine by meta-analysis and give summary estimates. The average sensitivity was $90.0 \%$ (95\% Cl $87.6 \%$ to $92.0 \%$; range $64 \%$ to $100 \%$ ), and the average specificity was $99.5 \%$ (95\% Cl $99.2 \%$ to $99.7 \%$ : range $96 \%$ to $100 \%)$. Results for specificity were more homogenous than for sensitivity, where we have ordered studies in the forest plot by the number of cancer cases. Studies with small numbers of cancer cases have wider confidence intervals for sensitivity, and study estimates are likely to be less reliable. This is particularly pertinent for García 1997, with 11 cancer cases.

Figure 7. Forest plot: frozen section threshold malignant vs borderline or benign

\begin{tabular}{|c|c|c|c|c|c|c|c|c|c|c|c|c|}
\hline Sludy & TP & $\boldsymbol{\varphi P}$ & $\mathrm{FN}$ & IN & SBen study & F OP & seor study & N Mal stady & Sensainity $(95 \mathrm{~s} \mathrm{CD}$ & Specficity (95N Cl) & Seersitinaty $(95 \mathrm{~N} \mathrm{Cl})$ & Specificity ig5 CD \\
\hline Cross 2012 & 415 & 5 & 101 & 918 & 54.0 & 5160 & 10.0 & 36.0 & $0.60[0.77,0.84]$ & $0.9910 .90,100$ & - & \\
\hline Stewart 2006 & 251 & 4 & 15 & 644 & 60.0 & 266.0 & 110 & 29.0 & $0.94[0.91,0.97]$ & $0.92 \mathrm{p.98}, 1.00]$ & $=$ & \\
\hline Protaks 2009 & 135 & 0 & 19 & 691 & 70.0 & 154.0 & 11.0 & 18.0 & $0.88[0.81,0.82]$ & $1.000 .99,1.00]$ & $=$ & \\
\hline Ackain 2014 & 132 & 0 & 6 & 144 & 43.0 & 1300 & 90 & 49.0 & $0.96[0.91,0.90]$ & $1,00010.97,1.000$ & & \\
\hline Factant 2007 & 106 & 2 & 21 & 182 & 41.0 & 127.0 & 18.0 & 41.0 & $0.83[0.76,0.89 \mid$ & 0.200 .95 .1 .00 & & \\
\hline Eipe 2011 & 115 & 5 & 6 & 393 & 71.0 & 121.0 & 5.0 & 23.0 & $0.95[0.90,0.99]$ & $0.99 \mathrm{p} 0.97,1.00]$ & & te \\
\hline Man 2005 & 104 & 0 & 16 & 394 & 69.0 & 120.0 & 800 & 24.0 & $0.87[0.79,0.82]$ & $1.000 .98,1.00]$ & & \\
\hline Rose $1 \mathrm{~ms}$ & 111 & 1 & 9 & 262 & 61.0 & 120.0 & 80 & 31.0 & $0.93[086,0.97]$ & $1.00 \mathrm{p} .98,100]$ & & \\
\hline Wasinghen 2008 & 82 & 8 & 21 & 265 & 58.0 & 103.0 & 15.0 & 27.0 & $0.80[0.71,0.87]$ & $0.97[0.94,0.99]$ & & \\
\hline Taskeran 2008 & so & 0 & 2 & 112 & 48.0 & 92.0 & 70 & 45.0 & $0.98[0.92,1,00]$ & $1.000 .97,1.00]$ & & \\
\hline Mahisstrwati 2006 & 66 & 2 & 6 & 116 & 51.0 & 92.0 & 50 & 440 & $0.93[0.86,0.90 \mid$ & $0.990 .94,1.00]$ & $\rightarrow$ & \\
\hline Bubumaran 2014 & 73 & 1 & 15 & 144 & 51.0 & 88.0 & 110 & 38.0 & $0.83[0.73,0.80]$ & $0.920 .95,1.00]$ & $\rightarrow$ & \\
\hline Gorisek 2009 & 73 & 0 & 9 & 49 & 2.0 & 82.0 & 35.0 & 63.0 & $0.89[0.80,0.98]$ & $1.000 .93,1.00]$ & - & \\
\hline Wootopom 2006 & 60 & 2 & 11 & 132 & 53.0 & 79.0 & 100 & 37.0 & $0.06[076,0.80]$ & 0.89 p..85, 1.00$]$ & $\rightarrow$ & \\
\hline Wang 1968 & 69 & 0 & 4 & 223 & 68.0 & 73.0 & 80 & 25.0 & $0.95[0.87,0.89 \mid$ & $1.00 \mathrm{p} 0.98,1.00]$ & & \\
\hline Tangitgamol 2004 & 62 & 0 & 10 & 127 & 67.0 & $\pi 2.0$ & 7.0 & 36.0 & $0.85[0.75,0.93]$ & $1.00 \mathrm{p.97}, 1.00]$ & $\rightarrow$ & \\
\hline Cuel10 1993 & 67 & 3 & 4 & 415 & 81.0 & $n .0$ & 5.0 & 15.0 & $0.94[0.86,0.80]$ & 0.89 p.80 1.00$]$ & & \\
\hline Pimb 2001 & e4 & 1 & 5 & 173 & 64.0 & 69.0 & 70 & 28.0 & $0.93[084,0.96 \mid$ & $0.2010 .97,100$ & $-\infty$ & \\
\hline Rakhshan 2009 & 60 & 1 & 5 & 216 & 72.0 & 65.0 & 5.0 & 23.0 & $0.92[0.83,0.97]$ & $1.00 \mathrm{p.97}, 1.00]$ & $\rightarrow$ & \\
\hline Twssihoven 1991 & 54 & 0 & 6 & 108 & 65.0 & 60.0 & 8.0 & 36.0 & $0.90[0.79,0.80]$ & $1.000 .97,1.00]$ & - & \\
\hline Subbian 2013 & 55 & 1 & 5 & 56 & 35.0 & 60.0 & 140 & 51.0 & $0.92[0.82,0.97]$ & $0.900 .91,100$ & $\rightarrow$ & - \\
\hline Hamed 1903 & 55 & 1 & 0 & 268 & 80.0 & 55.0 & 30 & 17.0 & $1.00[0.94,1,00]$ & $1.00 \mathrm{p} .9 \mathrm{~B}, 1.00]$ & & \\
\hline Wakahara 2001 & 54 & 0 & 0 & 133 & 63.0 & 54.0 & 8.0 & 29.0 & $1.00[0.93,1.00]$ & $1.000 .97,1.00]$ & & \\
\hline Maipsail 2013 & 45 & 0 & 8 & 165 & 69.0 & 5.0 & 70 & 24.0 & $0.05[072,0.80]$ & 1.00 p. .90 .100$]$ & - & \\
\hline Eoriboonhizursam 2004 & 47 & 0 & 5 & 95 & 61.0 & 52.0 & 4.0 & 35.0 & $0.90[0.79,0.97]$ & $1.00 p .96 .100]$ & $\rightarrow$ & \\
\hline Suprasert 2008 & 46 & 0 & 4 & 62 & 38.0 & 50.0 & 17.0 & 45.0 & 0.92 [0.81, 0.89] & $1.00 \mathrm{p} 0.94,1.00 \mathrm{]}$ & $\rightarrow$ & \\
\hline Yeo 1958 & 40 & 0 & 6 & 270 & 79.0 & 48.0 & 6.0 & 16.0 & $0.87[074,0.96]$ & $1.000 .89,1.00]$ & $\rightarrow$ & \\
\hline Nak 2006 & 40 & 1 & 5 & 83 & 57.0 & 45.0 & 90 & 350 & $0.80[076,0.96 \mid$ & $0 \% 90.94,100$ & $\rightarrow$ & \\
\hline Puls 1997 & 27 & 1 & 11 & 255 & 73.0 & 38.0 & 140 & 13.0 & $0.71[0.54,0.85]$ & 1.00 p.98, 1.00$]$ & $\because-$ & \\
\hline Bazot 2006 & 29 & 1 & 7 & 114 & 62.0 & 3.0 & 15.0 & 24.0 & $0.81[0.64,0.82]$ & 0.99 p.95, 1.00$]$ & -- & \\
\hline Torres 1906 & 20 & 2 & 7 & 96 & 63.0 & 35.0 & 80 & 20.0 & $0.60[0.63,0.92]$ & $0.900 .92,1.00]$ & -- & \\
\hline Lim 1927 & 34 & 0 & 1 & 136 & 75.0 & 35.0 & 5.0 & 20.0 & $0.97[0.85,1,00]$ & $1.000 .97,1.000$ & & \\
\hline ther 2011 & 20 & 0 & 8 & 238 & 86.0 & 28.0 & 3.0 & 11.0 & $0.71[0.51,0.87]$ & 1.00 p.98, 1.00 & $=-$ & \\
\hline Tonera 2012 & 25 & 0 & 3 & 38 & 27.0 & 20.0 & 30.0 & 42.0 & $0.69[072,0.80]$ & $1.000 .81,1.00]$ & $\because-$ & \\
\hline Yeradi 2008 & $n$ & 3 & 2 & 79 & 74.0 & 24.0 & 40 & 23.0 & $0.92[0.73,0.98 \mid$ & $0.96 p .90 .0 .99]$ & $\rightarrow$ & \\
\hline Caris 2004 & 18 & 3 & 4 & 111 & 64.0 & 22.0 & 20.0 & 16.0 & $0.82[0.60,0.95]$ & $0.97 p .93,0.99]$ & $=-$ & \\
\hline Kolks 2009 & 19 & 0 & 1 & 30 & 40.0 & 20.0 & 20.0 & 40.0 & $0.95[0.75,1.00]$ & $1.000 .88,1.00]$ & - & - \\
\hline Bertia 1997 & 7 & 0 & 4 & 19 & 530 & 11.0 & 100 & 37.0 & $0.64[0.31,0.89]$ & $1,000.82,100$ & -1 & \\
\hline
\end{tabular}


Figure 8. Summary ROC plot of 1 frozen section: threshold malignancy vs borderline or benign

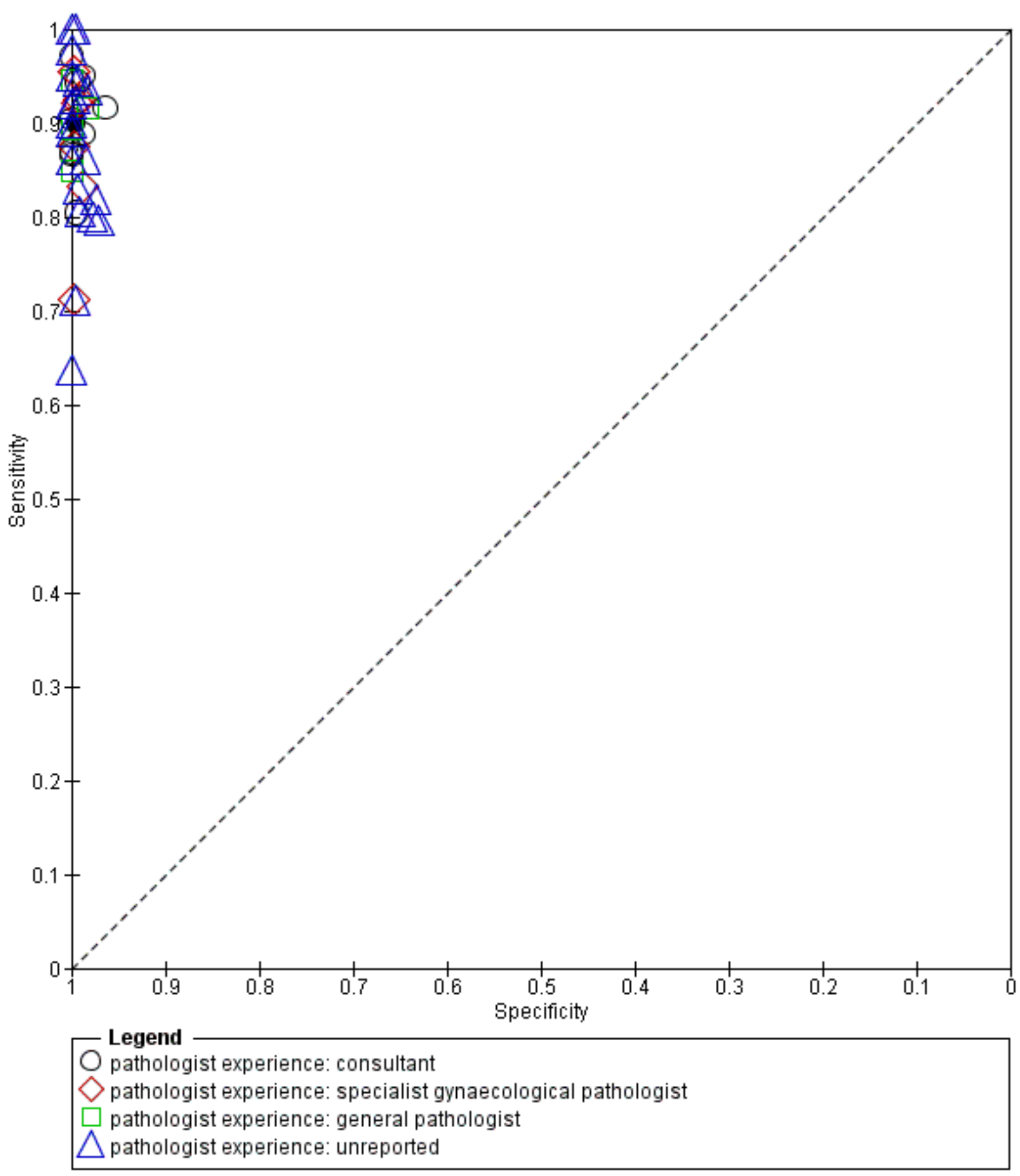

We completed a pre-specified analysis of heterogeneity based on pathologist reader expertise, defining four reader groups that we then grouped into two categories to enable analysis to have a sufficient number of studies in each group: more specialised (consultant, and specialist gynaecological pathologist) and other (general pathologist or expertise not reported). Figure 8 shows the expertise of pathologists for each study using different symbols.
Statistical analysis did not show a statistically significant difference in sensitivity and specificity based on reader expertise.

\section{Primary objective \#2: accuracy of frozen section cancer or borderline results to identify women with cancer}

Sensitivity and specificity results were available from the same 38 studies using the test threshold for frozen section where we 
considered both cancer and borderline cases to be positive and benign cases to be negative. The average sensitivity was $96.5 \%$ (95\% Cl $95.5 \%$ to $97.3 \%$; typical range $83 \%$ to $100 \%$, with one very small study, García 1997, reporting a sensitivity of 0\%) and the average specificity was $89.5 \%(95 \% \mathrm{Cl} 86.6 \%$ to $91.9 \%$ : typical range $58 \%$ to $99 \%$, with one study, Gorisek 2009, reporting a specificity of $29 \%$ ). Results were reasonably homogeneous except for differences likely to be due to small sample sizes.

Figure 9 is a forest plot of sensitivity and specificity with 95\% confidence intervals for all studies, ordered by the number of disease negative cases ( $D N=$ benign) with the studies reporting the largest numbers of benign cases at the top. In addition, we show the percentage of cancer, borderline and benign in each study to give insight into the representativeness of the study. The percentage of borderline cases is likely to influence the specificity results, as many of these cases are not found to be malignant by the reference test of paraffin section. This is well demonstrated by Gorisek 2009, with only $2 \%$ of benign cases, where specificity is reduced due to the high proportion of borderline cases in the study population.

Figure 9. Forest plot: frozen section threshold malignant or borderline vs benign

\begin{tabular}{|c|}
\hline Study \\
\hline Cross 2012 \\
\hline Pavalas 2009 \\
\hline Stewart 2006 \\
\hline Cuetio 1969 \\
\hline Bige 2011 \\
\hline $\operatorname{man} 2005$ \\
\hline Wasinghen 2000 \\
\hline Yoo 1909 \\
\hline Hamed 1993 \\
\hline Rose 1994 \\
\hline Puls 1997 \\
\hline Iher 2011 \\
\hline Wang 1958 \\
\hline Raktishian 2009 \\
\hline Fanfani 2007 \\
\hline Pinto 2001 \\
\hline Maipstil 2013 \\
\hline Subimaran 2014 \\
\hline Acikalin 2014 \\
\hline Lm 1997 \\
\hline Woctipoom 2006 \\
\hline Wakahara 2001 \\
\hline Tangitgamol 2004 \\
\hline Mates hrmai 2006 \\
\hline Bazot 2006 \\
\hline Caris 2004 \\
\hline Taskeran 2008 \\
\hline Twashoven 1900 \\
\hline Eoriboonhizunaam 2004 \\
\hline Toeres 1998 \\
\hline Nak 2006 \\
\hline Yorandi 2008 \\
\hline Suprasent 2008 \\
\hline Subtian 2013 \\
\hline Borkak 2009 \\
\hline Toneva 2012 \\
\hline Kokks 2009 \\
\hline Gartia 1997 \\
\hline
\end{tabular}

\begin{tabular}{|c|c|c|c|}
\hline & IP & 1 & \\
\hline$\theta 7$ & 115 & 19 & \\
\hline & 7 & 5 & 58 \\
\hline & 87 & 7 & \\
\hline & 20 & 1 & \\
\hline & 27 & 1 & \\
\hline & 33 & 3 & \\
\hline & 44 & 3 & \\
\hline 43 & 13 & 3 & \\
\hline 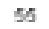 & 9 & 0 & \\
\hline 16 & 17 & 6 & \\
\hline 37 & 35 & 1 & \\
\hline 24 & 7 & 4 & \\
\hline 72 & 18 & 1 & \\
\hline 6) & 11 & 2 & \\
\hline 14 & 29 & 13 & \\
\hline 87 & 12 & 2 & \\
\hline 50 & 14 & 3 & \\
\hline 87 & 24 & 1 & \\
\hline 35 & 26 & 3 & \\
\hline 34 & 8 & 1 & \\
\hline 74 & 15 & 5 & \\
\hline 54 & 11 & 0 & \\
\hline 71 & 8 & 1 & \\
\hline 9 & 7 & 3 & \\
\hline 34 & 15 & 2 & \\
\hline 21 & 25 & 1 & \\
\hline 90 & 12 & 2 & 1 \\
\hline 58 & 9 & 2 & \\
\hline 42 & 8 & 3 & \\
\hline 29 & 2 & 6 & \\
\hline 43 & 12 & 2 & \\
\hline$n$ & 5 & 2 & \\
\hline 48 & 16 & 2 & \\
\hline 58 & & 3 & \\
\hline 81 & 35 & 1 & \\
\hline 26 & 16 & 2 & \\
\hline 19 & 11 & 1 & \\
\hline & & & \\
\hline
\end{tabular}

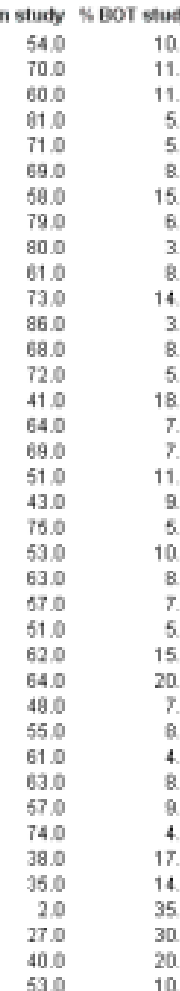

\begin{tabular}{|c|c|c|}
\hline tudy & 5. Mal study & $\approx 0 \mathrm{~N}$ \\
\hline 100 & 360 & $9 m 0$ \\
\hline 11.0 & 18.0 & 631.0 \\
\hline 11.0 & 29.0 & 648.0 \\
\hline 50 & 15.0 & 418.0 \\
\hline 50 & 23.0 & 386.0 \\
\hline 80 & 24.0 & 384.0 \\
\hline 150 & 27.0 & 273.0 \\
\hline 60 & 150 & 270.0 \\
\hline 30 & 17.0 & 269.0 \\
\hline 80 & 31.0 & 263.0 \\
\hline 140 & 13.0 & 256.0 \\
\hline 30 & 11.0 & 238.0 \\
\hline 80 & 25.0 & 223.0 \\
\hline 50 & 23.0 & 217.0 \\
\hline 180 & 41.0 & 184.0 \\
\hline 7.0 & 28.0 & 174.0 \\
\hline 7.0 & 24.0 & 165.0 \\
\hline 11.0 & 38.0 & 145.0 \\
\hline 90 & 49.0 & 144.0 \\
\hline 50 & 20.0 & 130.0 \\
\hline 100 & 370 & 1340 \\
\hline 80 & 29.0 & 133.0 \\
\hline 7.0 & 36.0 & 127.0 \\
\hline 50 & 44.0 & 118.0 \\
\hline 150 & 24.0 & 115.0 \\
\hline 200 & 16.0 & 114.0 \\
\hline 70 & 45.0 & 112.0 \\
\hline 80 & 36.0 & 105.0 \\
\hline 4.0 & 35.0 & 95.0 \\
\hline 80 & 28.0 & 88.0 \\
\hline 90 & 35.0 & 840 \\
\hline 4.0 & 23.0 & 82.0 \\
\hline 17.0 & 45.0 & 62.0 \\
\hline 140 & 51.0 & 57.0 \\
\hline 350 & 63.0 & 49.0 \\
\hline 300 & 42.0 & 39.0 \\
\hline 200 & 40.0 & 30.0 \\
\hline 100 & 370 & 19.0 \\
\hline
\end{tabular}

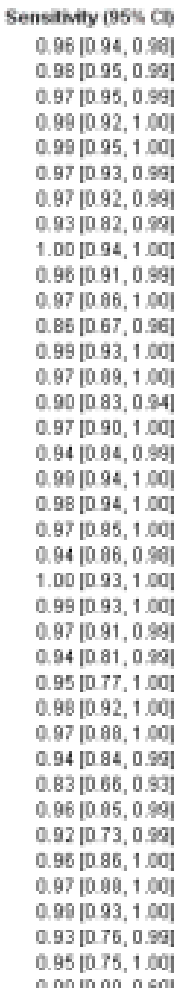

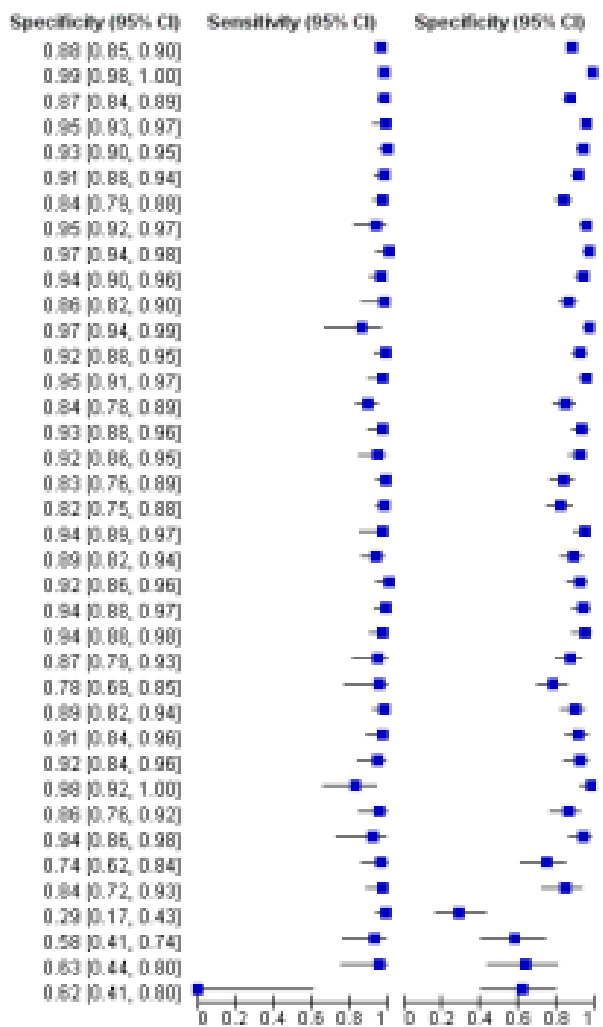

Figure 10 shows the results from all studies in a ROC plot. 
Figure 10. Summary ROC plot of 2 frozen section: threshold malignancy or borderline vs benign

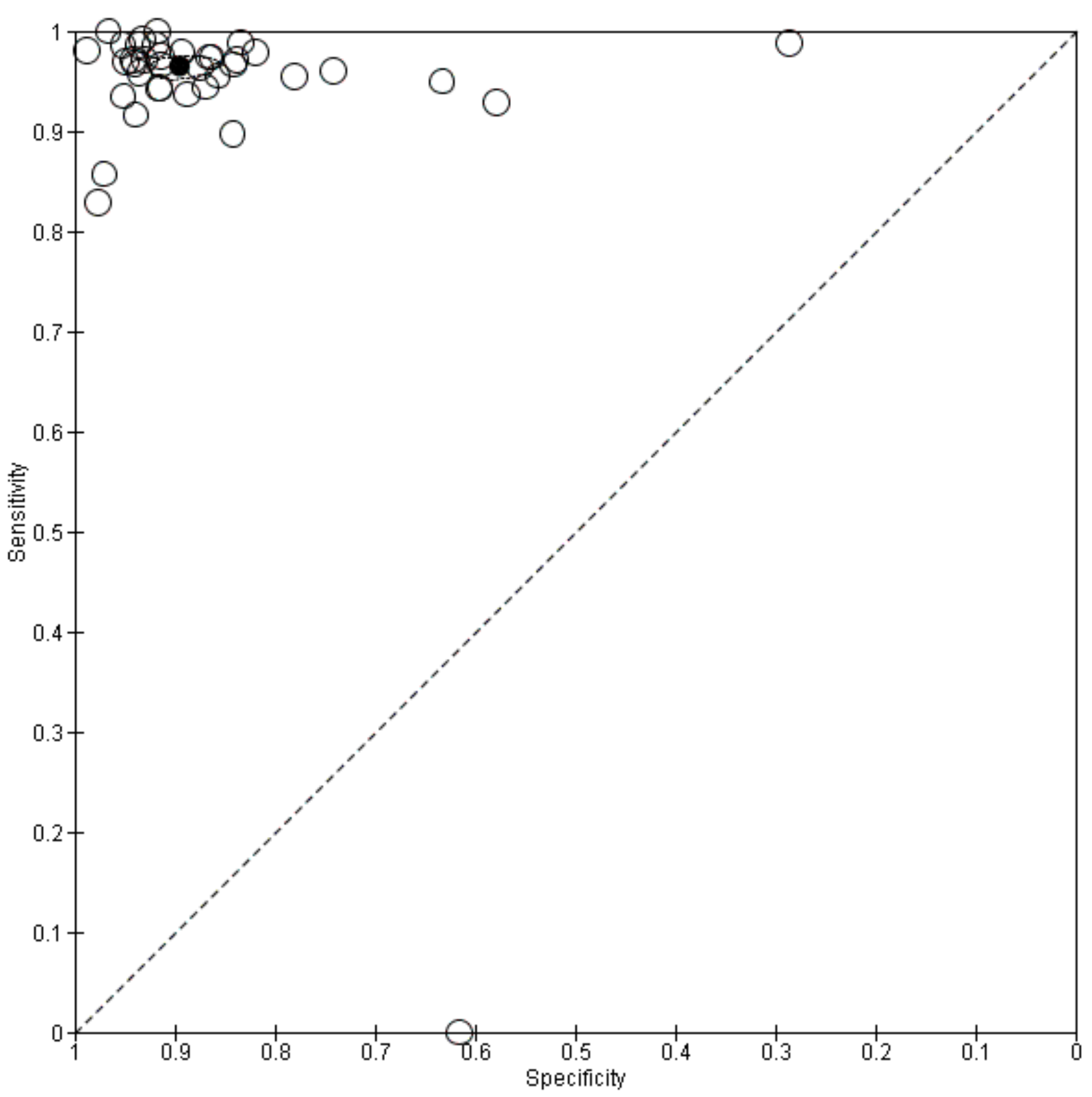

Both figures show that sensitivity is reasonably homogeneous, but as expected, specificity is more variable in studies with a relatively high percentage of borderline cases and a low number of disease negative (i.e. benign) cases (García 1997; Gorisek 2009; Kokka 2009; Toneva 2012). We have used bivariate meta-analysis to obtain estimates for both average sensitivity and average specificity, as there are a reasonable number of studies. The average sensitivity was $96.5 \%$ (95\% Cl $95.5 \%$ to $97.3 \%$; typical range $83 \%$ to $100 \%$, with one very small study, García 1997, reporting a sensitivity of 0\%), and the average specificity was $89.5 \%(95 \% \mathrm{Cl} 86.6 \%$ to $91.9 \%$ : typical range 58 to 99 , with one study, Gorisek 2009, reporting a specificity of $29 \%$ ).
We attempted a pre-specified analysis of heterogeneity based on reader expertise, but models did not converge.

\section{Secondary objective \#2: accuracy of final diagnosis of malignancy in women with a frozen section result of either borderline or cancer}

Sensitivity and specificity results were available from the same 38 studies, including the subset of 3953 participants with a frozen section result of either borderline or invasive cancer, based on the accuracy of referral for cancer management, that is, surgical staging in invasive cancer.

Figure 11 is a forest plot of sensitivity and specificity with $95 \%$ confidence intervals for all studies, ordered by the number of 
borderline cases in each study, with the studies reporting the highest number of borderline cases shown at the top.

Figure 11. Forest plot: frozen section malignant or borderline only. Threshold malignant

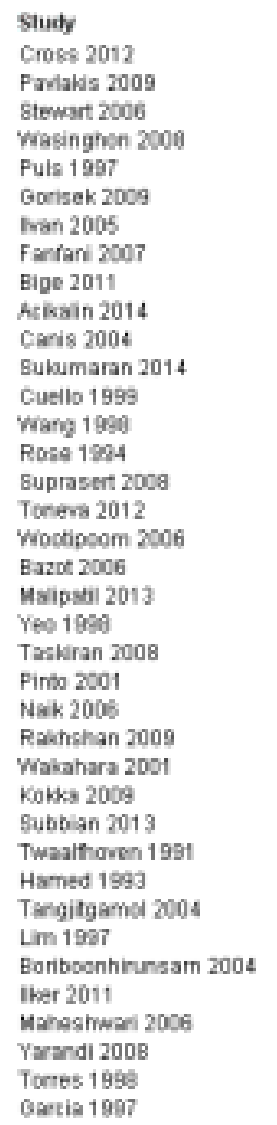

\begin{tabular}{|c|c|c|c|c|c|c|}
\hline IP & FP & FN & IN & 5 mat afs Mal + Bot & * DW & Sensit: \\
\hline 415 & 5 & 82 & 110 & 81.0 & 1150 & $0.84[0.80,0.67]$ \\
\hline 135 & 0 & 15 & 103 & 52.0 & 103.0 & $0.90[0.84,0.94]$ \\
\hline 251 & 4 & 8 & 83 & 78.0 & 87.0 & $0.97[0.94,0.99]$ \\
\hline 92 & 8 & 18 & 36 & 69.0 & 440 & $0.82[0.73,0.08$ \\
\hline 27 & 1 & 10 & 34 & 51.0 & 350 & $0.73[0.56,0.86]$ \\
\hline 73 & 0 & 8 & 35 & 70.0 & 350 & $0.90[0.81,0.98]$ \\
\hline 104 & 0 & 13 & 33 & $n .0$ & 330 & $0.89[0.82,0.94]$ \\
\hline 106 & 2 & 8 & 27 & 80.0 & 2900 & $0.93[0.87,0.97]$ \\
\hline 115 & 5 & 5 & 22 & 82.0 & 27.0 & $0.95[0.91,0.98]$ \\
\hline 132 & 0 & 3 & 26 & 84.0 & 260 & $0.98[0.94,1.00$ \\
\hline 18 & 3 & 3 & 22 & 46.0 & 250 & $0.86[0,64,0.97]$ \\
\hline 73 & 1 & 14 & 23 & 78.0 & 24.0 & $0.84[0.74,0.91]$ \\
\hline 67 & 3 & 3 & 17 & 78.0 & 200 & $0.96[0.89,0.951$ \\
\hline 69 & 0 & 3 & 18 & $\infty 0.0$ & 160 & $0.96[0.80,0.99$ \\
\hline 111 & 1 & 4 & 16 & 87.0 & 17.0 & $0.97[0.91,0.981$ \\
\hline 46 & 0 & 2 & 16 & 75.0 & 160 & $0.95[0.86,0.99$ \\
\hline 26 & 0 & 1 & 16 & 62.0 & 160 & $0.96[0.80,1.00$ \\
\hline 68 & 2 & 6 & 13 & 83.0 & 150 & $0.92[0.89,0.97]$ \\
\hline 29 & 1 & 5 & 14 & 62.0 & 15.0 & $0.85[0.89,0.99$ \\
\hline 46 & 0 & 8 & 14 & 78.0 & 14.0 & $0.90[0.78,0.97]$ \\
\hline 40 & 0 & 3 & 13 & 77.0 & 130 & $0.93[0.81,0.99$ \\
\hline 20 & 0 & 0 & 12 & 88.0 & 120 & $1.00[0.96,1.00]$ \\
\hline 64 & 1 & 3 & 11 & 85.0 & 120 & $0.96[0.87,0.99$ \\
\hline 40 & 1 & 3 & 11 & 78.0 & 120 & $0.93[0.81,0.95$ \\
\hline 60 & 1 & 3 & 10 & 85.0 & 11.0 & $0.95[0.87,0.97$ \\
\hline 54 & 0 & 0 & 11 & 83.0 & 11.0 & $1.00[0.93,1.00]$ \\
\hline 19 & 0 & 0 & 11 & 63.0 & 11.0 & $1.00[0.82,1.00$ \\
\hline 55 & 1 & 3 & 8 & 87.0 & 90 & $0.95[0.86,0.9 \mathrm{~m}$ \\
\hline 54 & 0 & 4 & 9 & 87.0 & 90 & $0.93[0.83,0.98]$ \\
\hline 66 & 1 & 0 & 8 & 86.0 & 90 & $1.00[0.94,1.00$ \\
\hline 62 & 0 & 9 & 8 & 90.0 & 60 & $0.97[0.77,0.94]$ \\
\hline 34 & 0 & 0 & 8 & 81.0 & 80 & $1.00[0.90,1.00$ \\
\hline 47 & 0 & 2 & 8 & 86.0 & 8.0 & $0.96[0.86,1.00]$ \\
\hline 20 & 0 & 4 & 7 & $n .0$ & 7.0 & $0.83[0.63,0.95]$ \\
\hline 86 & 2 & 3 & 5 & 93.0 & 70 & $0.97[0.90,0.97$ \\
\hline 22 & 3 & 0 & 2 & 81.0 & 5.0 & $1.00[0.85,1.00$ \\
\hline 28 & 2 & 1 & 0 & 94.0 & 20 & $0.97[0.82,1.00$ \\
\hline 7 & 0 & 2 & 1 & $\$ 0.0$ & 1.0 & $0.78[0.40,0.97]$ \\
\hline
\end{tabular}

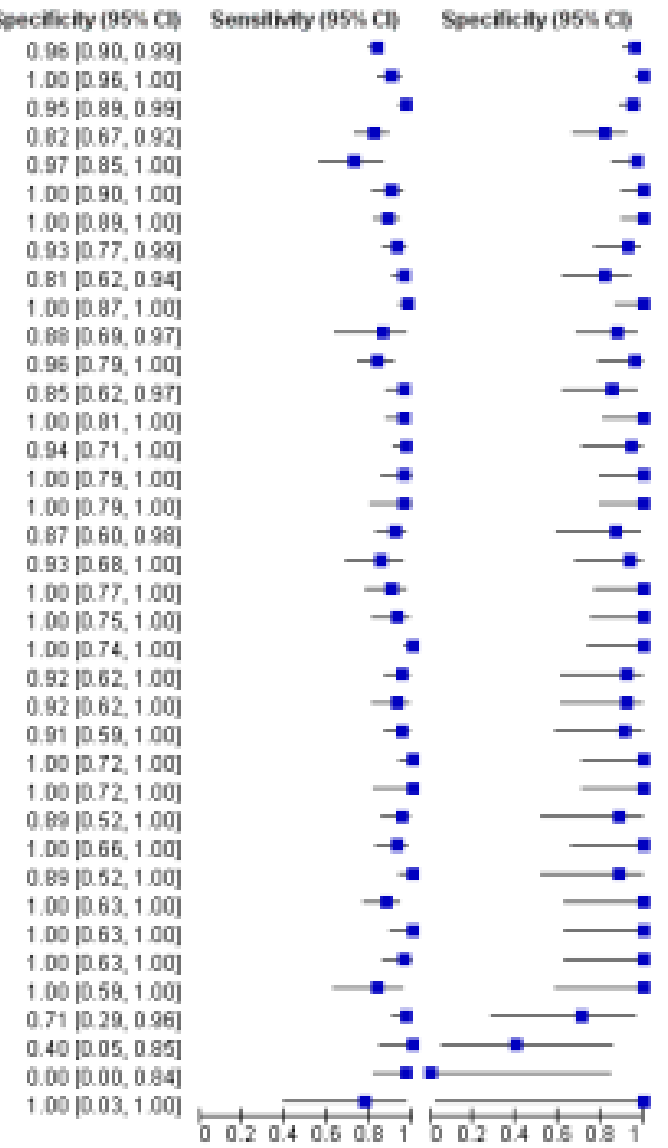

Studies with small numbers of disease negative cases (borderline cases) at the bottom of the plot have more variation in estimates of specificity, most likely due to small numbers in a study, likely overriding any other potential sources of bias in these studies. We include the percentage of malignant cancer in these patients with frozen section results of either cancer or borderline to aid

understanding of how studies may compare to other centres. The percentage of borderline cases is likely to influence the specificity results, as many of these cases are not malignant according to the reference test of paraffin section. Figure 12 shows the results from all studies in a ROC plot. 
Figure 12. Figure 8 (Analysis 3)

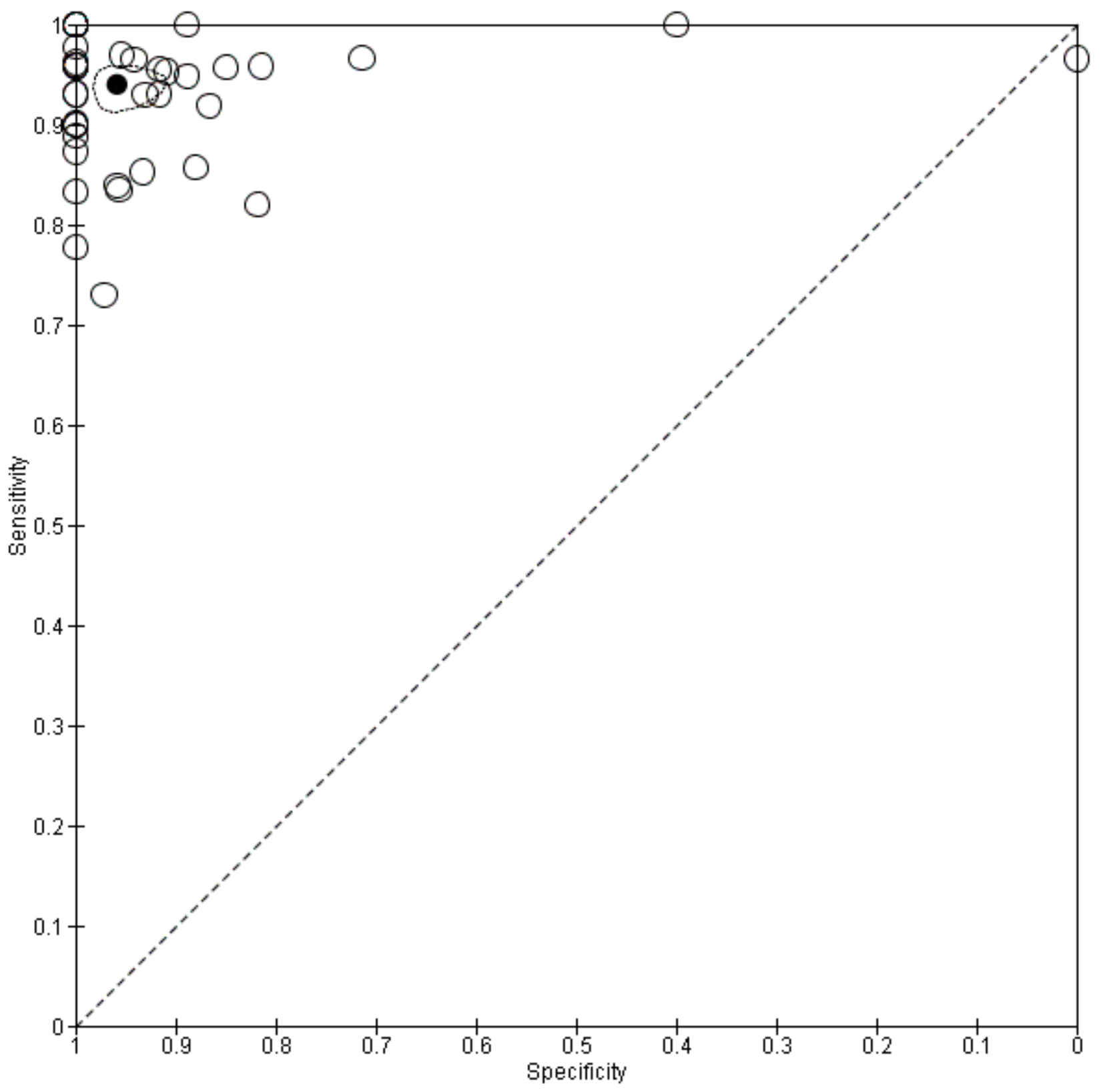

Both figures show that sensitivity and specificity are more heterogeneous than other analyses. Results from studies with low numbers of borderline cases are particularly heterogeneous due to small sample sizes of two, five and seven borderline cases (in Torres 1998, Maheshwari 2006 and Yarandi 2008, respectively). We used bivariate meta-analysis to obtain estimates both for average sensitivity and average specificity, as there were a reasonable number of studies. The average sensitivity was $94.0 \%$ (95\% CI 92.0\% to $95.5 \%$; range $73 \%$ to $100 \%$ ), and the average specificity was $95.8 \%(95 \% \mathrm{Cl} 92.4 \%$ to $97.8 \%$ : typical range $81 \%$ to $100 \%$, with three outlier studies, Torres 1998, Yarandi 2008 and Maheshwari 2006 , showing specificities of $0 \%, 40 \%$ and $71 \%$, respectively).

Figure 13 presents the reference standard result for all studies for frozen section diagnoses of either cancer or borderline. Across all studies, an average of $81 \%$ of results were malignant by the reference standard (median $81 \%$, interquartile range (IQR) $78 \%$ to $84 \%$ ), $17 \%$ were borderline (IQR $14 \%$ to $21 \%$ ) and $2 \%$ were benign (IQR 2\% to 5\%). 


\section{Figure 13. Frozen section result malignant or borderline: final diagnosis by reference standard}

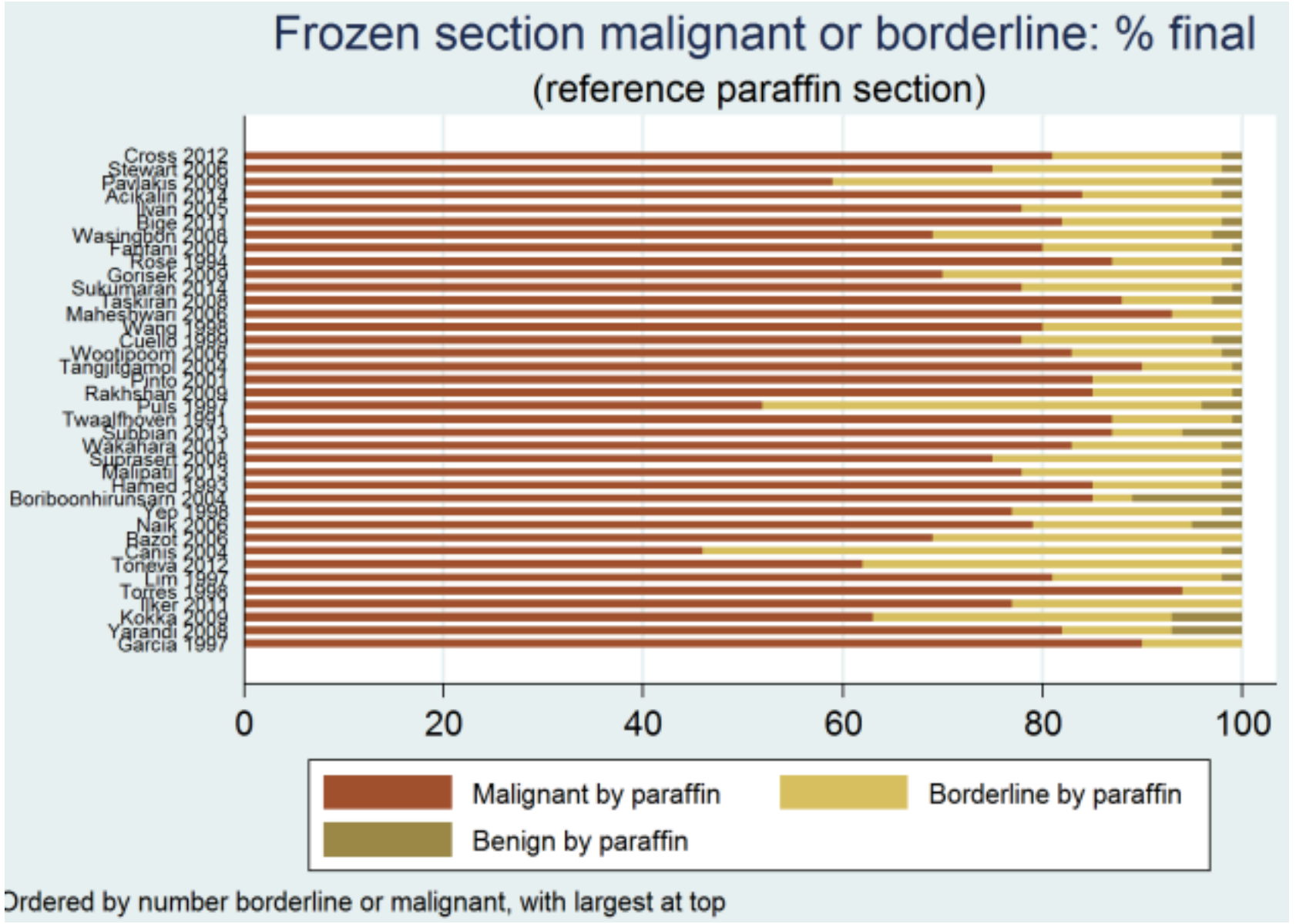

\section{Additional analyses}

Figure 14, Figure 15 and Figure 16 provide a breakdown of frozen section results by postsurgical reference standard for benign, cancer and borderline results, respectively, to provide additional insight on the correspondence between test results. This provides further information to help understand how frozen section results were updated following postsurgical paraffin section confirmation in our included studies. 
Figure 14. Frozen section result benign: final diagnosis by reference standard

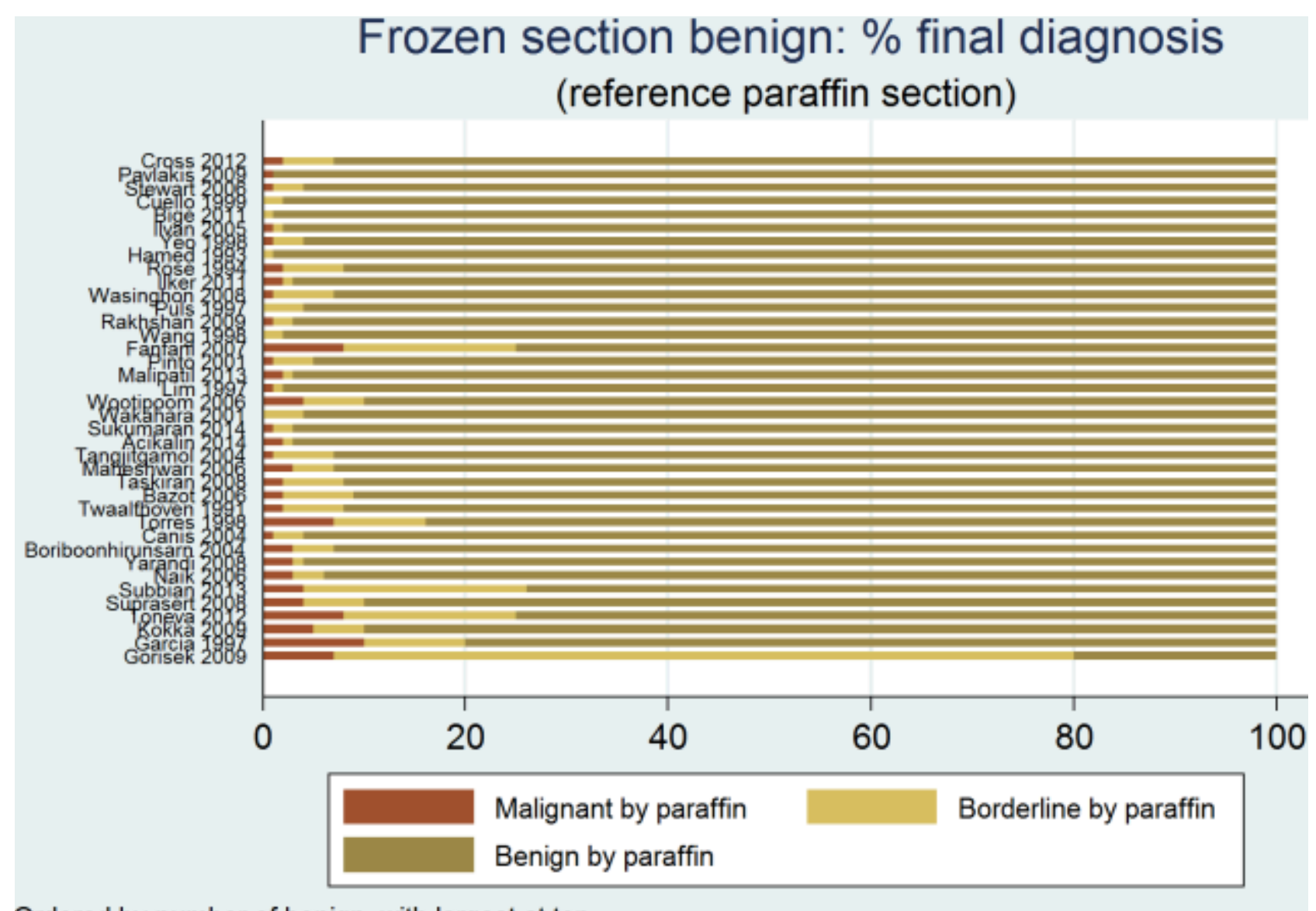

Ordered by number of benign, with largest at top 
Figure 15. Frozen section result malignant: final diagnosis by reference standard

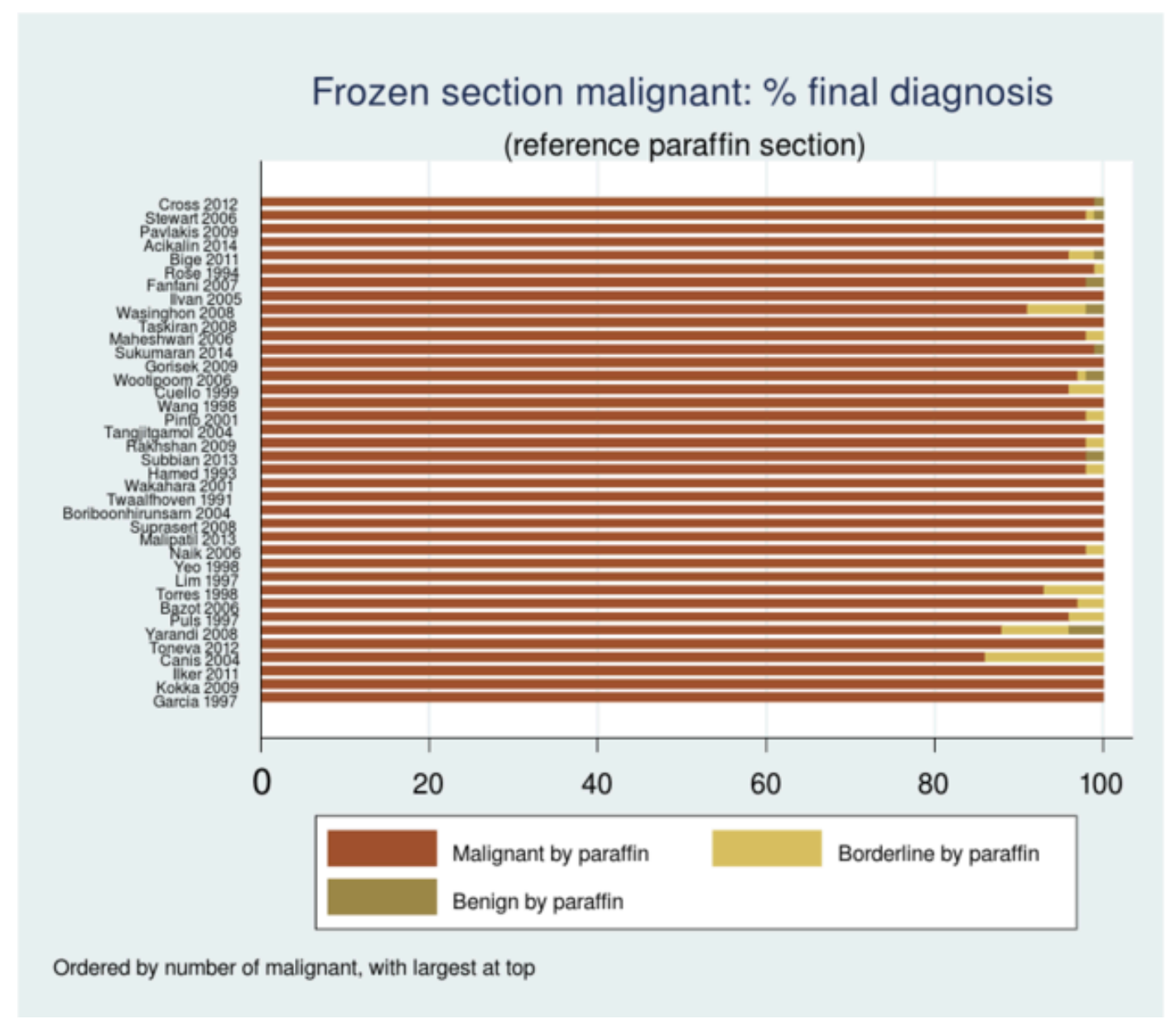


Figure 16. Frozen section result borderline: final diagnosis by reference standard

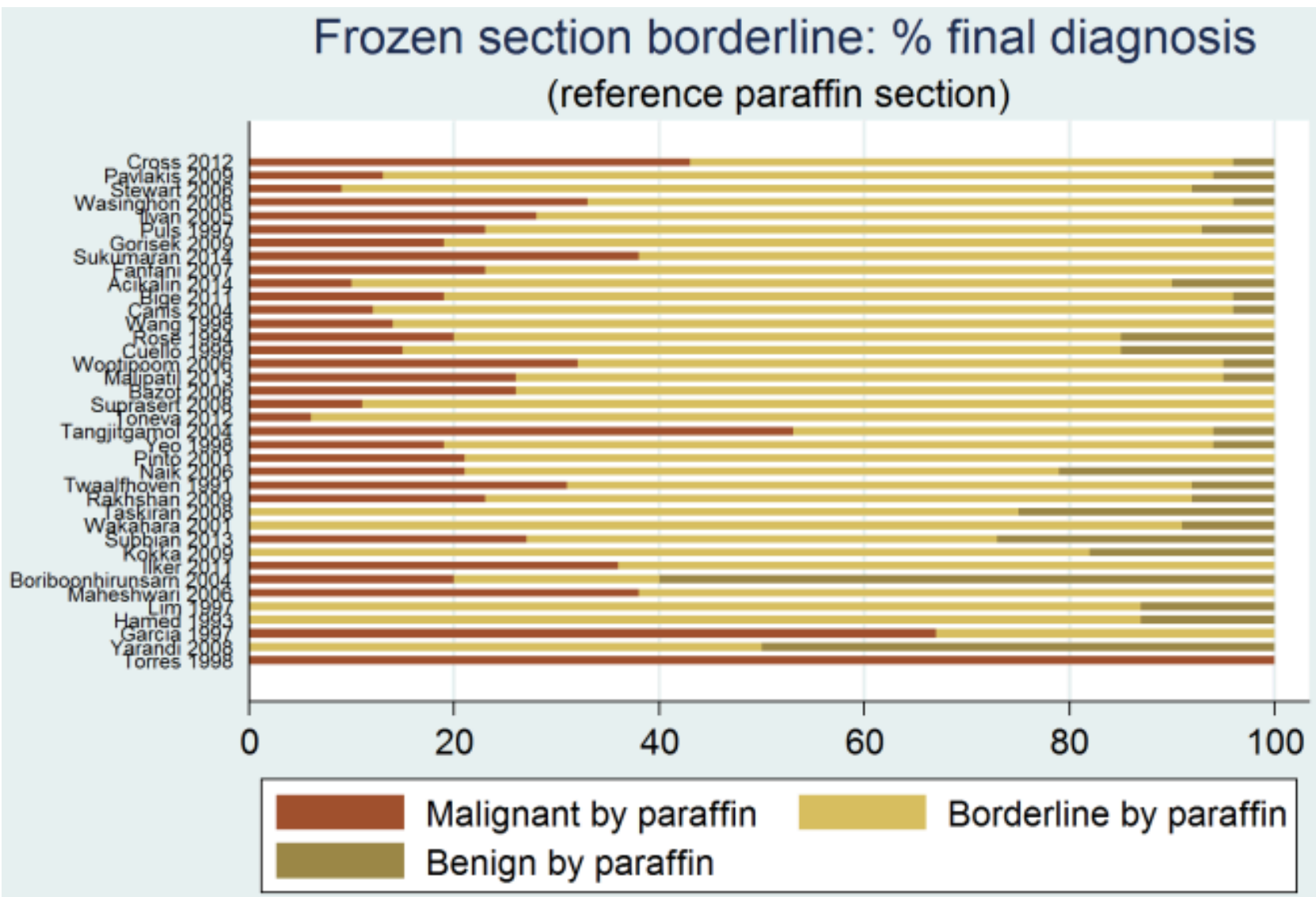

\section{Ordered by number of borderline, with largest at top}

On average, 94\% (IQR 92\% to 96\%) of benign diagnoses from frozen section were found to be benign on paraffin section.

On average, 99\% (IQR 98\% to 100\%) of cancer results from frozen section were found to be cancerous on paraffin section.

However, for borderline results from frozen section, on average only $73 \%$ (IQR $63 \%$ to $78 \%$ ) remained borderline, but $21 \%$ (IQR $14 \%$ to $26 \%$ ) were upgraded to cancer, and $6 \%$ (IQR 2 to $8 \%$ ) were downgraded to benign.

\section{DISCUSSION}

\section{Summary of main results}

We report the largest review of frozen section accuracy in ovarian masses to date, with a median prevalence of $29 \%$ cancers (IQR $23 \%$ to $36 \%$ ) across the included studies. In the Summary of findings 1 we have provided examples of prevalence of malignancy to help clinicians to interpret presented results and inform their practice. Accuracy results were relatively consistent between studies, except for studies with small numbers of cases. All studies were retrospective, with the majority reporting consecutive cases. We excluded deferred and unclear frozen section results from analysis. We expect that reference standard interpretation was not blinded to frozen section results.

In a hypothetical study of 1000 patients, of whom 290 had cancer and 80 were borderline, on average 261 women $(95 \% \mathrm{Cl} 254$ to
267) would receive a correct diagnosis of cancer based on a frozen section result of cancer, and 706 women $(95 \% \mathrm{Cl} 704$ to 708$)$ would be correctly diagnosed without cancer. However, on average 4 women $(95 \% \mathrm{Cl} 2$ to 6$)$ would be incorrectly diagnosed as having a cancer (false positive), and 29 women $(95 \% \mathrm{Cl} 23$ to 36$)$ with cancer would be missed at the time of surgery (false negative).

Likewise, in a hypothetical population of 1000 women, of whom 290 had cancer and 80 were borderline, based on a frozen section result of either cancer or borderline to diagnose cancer, on average 280 women ( $95 \% \mathrm{Cl} 277$ to 282 ) would be correctly diagnosed with a cancer and correctly receive surgical staging. Six hundred and thirty-five women ( $95 \% \mathrm{Cl} 615$ to 652 ) would be correctly diagnosed without cancer. However, on average 75 women $(95 \% \mathrm{Cl} 58$ to 95) would be incorrectly diagnosed as having a cancer on frozen section and would be over treated with surgical staging. Ten women (95\% $\mathrm{Cl} 8$ to 13 ) with cancer would be missed at the time of surgery and might require a second surgical procedure for staging.

Our additional analyses showed that if the frozen section was benign or cancerous, then the final diagnosis would remain the same in, on average, $94 \%$ and $99 \%$ of cases, respectively (Figure 14; Figure 15).

In cases where the frozen section diagnosis was borderline, there is a chance that the final diagnosis would turn out to be cancer in, on average, $21 \%$ of women (Figure 16 ). 
On investigating the factors that could lead to variability between studies, we found that there was no difference in diagnostic accuracy between levels of expertise of pathologists. In cases where there was a discordance between frozen section and paraffin section, most studies tabulated reasons for discordance that fell into one of two categories: tissue sampling error (where the sampled portions of the mass failed to give the paraffin section diagnosis); or interpretation error (where the pathologist incorrectly reported the frozen section samples). Tissue sampling error was more commonly reported in borderline frozen section diagnoses.

\section{Strengths and weaknesses of the review}

\section{Strengths}

This review presents a meticulous analysis of existing literature and interprets the data with presentation of clinical relevance. By applying previously defined, clear criteria for eligibility, we aimed to minimise heterogeneity in included studies. We excluded studies that did not represent the population in which frozen section might be used to assess suspicious ovarian masses. We assessed methodological quality and risk of bias. Although several studies had small sample sizes, the number of studies included in the review $(N=38)$ and the number of patients $(N=11,181)$ increased the power of the meta-analyses.

Analysis of the data by varying the test positive response ('malignant'; and 'malignant and borderline') facilitates interpretation of the test data to guide surgical management. Specifically, the pooled analysis of borderline cases compared to test positive malignant cases provides valuable information to aid not only intraoperative decision-making but also perioperative counselling of patients about likely outcomes.

\section{Weaknesses}

There are three weaknesses regarding pathology reporting within this review. Firstly, although this review addresses the effect of pathologist expertise on frozen section interpretation, all included studies were conducted in university hospitals or tertiary centres, which may introduce a reporting bias within this review. Secondly, given that no studies reported pathologist blinding, we have to assume that all included studies in this review were unblinded. The extent of bias is somewhat limited given the flow and timing of the tests, in that the index test always precedes the reference standard. The implications of unblinded testing might potentially mean that a pathologist reporting the paraffin section would be more likely to agree with the frozen section, especially if it is the same pathologist reporting both. However,in clinical practice the Pathology department usually receives the result of the frozen section as part of required clinical information in submitting tissue for histological processing. Thirdly, the criteria used for diagnosis of borderline ovarian tumours varies internationally. The included studies did not report the criteria used.

Very few studies reported the use of preoperative imaging or tumour markers. It was therefore difficult to make inferences about these variables.

\section{Applicability of findings to the review question}

Frozen section is a useful tool in aiding intraoperative management of suspicious ovarian masses. This review finds that if the frozen section is benign or cancerous, the paraffin section will be concordant in $94 \%$ and $99 \%$ of cases, respectively. In these groups there is a high likelihood patients will receive the appropriate surgery based on frozen section results, as indicated by Naik 2006, thereby avoiding unnecessary staging in those with benign histology according to paraffin section and without compromising those with true stage I ovarian cancer. Lawrie 2015 demonstrated in a subgroup analysis of three trials that, at a median follow-up of 5 years, there was no apparent additional benefit to overall survival from adjuvant chemotherapy in the group that was optimally staged (Bolis 1995; ICON 1; Trimbos 2003). However, they had concerns about selective reporting of the 10-year survival data and performed an exploratory analysis of 'deaths from ovarian cancer' at 10 years. This analysis suggested that "the difference between subgroups (optimally versus suboptimally staged) in deaths from ovarian cancer was not statistically significant (test for subgroup differences: Chi $^{2}$ test $=2.75$, degrees of freedom $(\mathrm{df})=1, \mathrm{P}=0.10$; $\mathrm{I}^{2}$ statistic $=63.6 \%)^{\prime \prime}$.

The prevalence of cancer in a referred population is particularly relevant for borderline ovarian tumours given the degree of discordance with paraffin section diagnosis. In this review, with an average prevalence of cancer of $29 \%$, the chance of a patient with a borderline tumour being appropriately treated with surgical staging is $21 \%$. This would in turn mean that, should all women with borderline frozen section undergo a surgical staging procedure including hysterectomy, pelvic +/- paraaortic lymphadenectomy and omentectomy, $79 \%$ of them would be over treated. This confers unnecessary risk of morbidity, which includes lymphoedema, lymphocyst formation, visceral and neurovascular injury. The benefit, however, is a reduction in morbidity associated with a second surgical procedure should low-risk ovarian cancer be diagnosed on paraffin section.

In their interpretation of this review, readers should evaluate the presented results by comparing the prevalence of test positive (cancer) in their population to examples provided in the Summary of findings 1 . The clinicopathological considerations to be taken into account when using frozen section include the following: women with high-risk disease will require adjuvant platinum-based chemotherapy; optimal staging in true stage I disease confers prognostic benefit; staging will detect stage III disease in a quarter of women who will require dual agent chemotherapy; and women need to be well counselled regarding the risks of over treatment and under treatment if physicians rely on frozen section results.

In addition, although outside the scope of this review, the clinical benefits of frozen section analysis include the ability to diagnose metastatic disease and, in some cases, site of origin. This may lead to better exploration of other organs at laparotomy for site of primary tumour and avoid unnecessary surgical staging in nonovarian malignancy.

\section{AUTHORS' CONCLUSIONS}

\section{Implications for practice}

Frozen section testing of ovarian masses can be used intraoperatively in gynaecological cancer centres for investigation of women with ovarian masses suspected to be early-stage malignancy. In practice, use of frozen section depends on a number of factors. 
- The clinical suspicion of cancer. This is usually reflected by the prevalence of cancer within a referred population, that is, a tertiary centre will report higher rates of cancer than a secondary centre. Women undergoing the index test can be counselled about the advantages and disadvantages of undergoing surgical staging if the frozen section result is borderline.

- The expertise of the gynaecologist to perform a surgical staging procedure should the frozen section result prove to be cancer. The value of the index test depends on the ability of the surgeon to appropriately manage the case.

- The ability of the pathologist to interpret frozen sections and for histopathology departments to provide the frozen section service.

\section{Implications for research}

The largest discordance is within the reporting of frozen section borderline tumours. The authors would encourage future publications to include all reported frozen section results and their histological subtypes so that further subgroup analyses on the borderline population can be performed to minimise reporting bias and heterogeneity analyses can be performed on histological subtypes. Investigation into factors leading to discordance within centres and standardisation of criteria for reporting borderline tumours may help further improve accuracy.
Further research is also warranted, perhaps in the form of a randomised clinical trial, to evaluate the oncological and surgical outcomes from surgical staging in cases of apparent stage I ovarian cancer. This would help establish whether there is a place for frozen section analysis in gynaecological cancer centres and further inform clinical practice by addressing not only survival but also morbidity associated with under- and over-staging in the borderline population.

\section{ACKN OWLEDGEMENTS}

We thank Jo Morrison for her clinical advice. We thank Jane Hayes for designing the search strategy and Gail Quinn and Clare Jess for their contribution to the editorial process. We are thankful to Andrew Bryant and Theresa Lawrie for their help with creating the data extraction tool. We are also very grateful to the Cochrane Diagnostic Test Accuracy team for their invaluable comments as well as the peer referees.

This project was supported by the National Institute for Health Research (NIHR), via Cochrane Incentive funding to the Cochrane Gynaecological, Neuro-oncology and Orphan Cancer Group. The views and opinions expressed herein are those of the authors and do not necessarily reflect those of the Systematic Reviews Programme, NIHR, National Health Service or the Department of Health. 


\section{RE F E R E N C E S}

\section{References to studies included in this review}

Açikalin 2014 \{published data only\}

Açikalin A, Torun G, Bagir E, Bayram F, Zeren H, Gulec U, et al. Intraoperative frozen section in ovarian neoplasms; a tertiary center experience. Turk Patoloji Dergisi [Turkish Journal of Pathology] 2014;30(3):184-8.

Bazot 2006 \{published data only\}

Bazot M, Nassar-Slaba J, Thomassin-Naggara I, Cortez A, Uzan S, Darai E. MR imaging compared with intraoperative frozen-section examination for the diagnosis of adnexal tumors; correlation with final histology. European Radiology 2006;16(12):2687-99.

\section{Bige 2011 \{published data only\}}

Bige O, Demir A, Saygili U, Gode F, Uslu T, Koyuncuoglu M. Frozen section diagnoses of 578 ovarian tumors made by pathologists with and without expertise on gynecologic pathology. Gynecologic Oncology 2011;123(1):43-6.

\section{Boriboonhirunsarn 2004 \{published data only\}}

Boriboonhirunsarn D, Sermboon A. Accuracy of frozen section in the diagnosis of malignant ovarian tumor. The Journal of Obstetrics and Gynaecology Research 2004;30(5):394-9.

\section{Canis 2004 \{published data only\}}

Canis M, Mashiach R, Wattiez A, Botchorishvili R, Rabischong B, Jardon $\mathrm{K}$, et al. Frozen section in laparoscopic management of macroscopically suspicious ovarian masses. Journal of the American Association of Gynecologic Laparoscopists 2004;11(3):365-9.

\section{Cross 2012 \{published data only\}}

Cross PA, Naik R, Patel A, Nayar AG, Hemming JD, Williamson SL, et al. Intra-operative frozen section analysis for suspected earlystage ovarian cancer: 11 years of Gateshead Cancer Centre experience. BJOG: An International Journal of Obstetrics and Gynaecology 2012;119(2):194-201.

\section{Cuello 1999 \{published data only\}}

Cuello M, Galleguillos G, Zarate C, Cordova M, Branes J, Chuaqui $\mathrm{R}$, et al. Frozen-section biopsy in ovarian neoplasm diagnosis: diagnostic correlation according to diameter and weight in tumors of epithelial origin [Biopsia rápida por congelación en el diagnóstico de tumores de ovario: correlación diagnóstica según diámetro y peso en tumores de origen epitelial]. Revista Médica de Chile 1999;127(10):1199-205.

Fanfani 2007 \{published data only\}

Fanfani F, Zannoni GF, Fagotti A, Gagliardi ML, Masciullo V, Testa AC, et al. Importance of a specialized pathologist for the examination of frozen sections of adnexal masses. International Journal of Gynecologic Cancer 2007;17(5):1034-9.

García 1997 \{published data only\}

García A, Calabuig C, Jonguitud A, Covisa A, Atero M, Montesinos $M$, et al. Safety of the intraoperative histology study using cuts through congelation in the diagnosis of ovary tumors
[Seguridad del estudio histológico intraoperatorio mediante cortes por congelación en el diagnóstico de tumores ováricos]. Progresos de Obstetricia y Ginecología 1997;40(3):182-6.

Gorisek 2009 \{published data only\}

Gorisek B, Stare MR, Krajnc I. Accuracy of intra-operative frozen section analysis of ovarian tumours. The Journal of International Medical Research 2009;37(4):1173-8.

\section{Hamed 1993 \{published data only\}}

Hamed F, Badía J, Chuaqui R, Wild R, Barrena N, Oyarzún E, et al. Role of frozen section biopsy in the diagnosis of adnexal neoplasms [Rol de la biopsia rápida por congelación en el diagnóstico de las lesiones tumorales anexiales]. Revista Chilena de Obstetricia y Ginecología 1993;58(5):361-4.

Ilker 2011 \{published data only\}

Ilker A, Aykut B, Muge H, Ibrahim HM, Ulku OB, Sener G, et al. Accuracy of intra-operative frozen section in the diagnosis of ovarian tumours. JPMA: The Journal of the Pakistan Medical Association 2011;61(9):856-8.

Ilvan 2005 \{published data only\}

Ilvan S, Ramazanoglu R, Ulker Akyildiz E, Calay Z, Bese T, Oruc $N$. The accuracy of frozen section (intraoperative consultation) in the diagnosis of ovarian masses. Gynecologic Oncology 2005;97(2):395-9.

Kokka 2009 \{published data only\}

Kokka F, Singh N, Reynolds K, Oram D, Jeyarajah A, Hassan L, et al. The accuracy of frozen section diagnosis in apparent early ovarian cancer - Results from a UK centre. Histopathology 2009;55(6):756-8.

\section{Lim 1997 \{published data only\}}

Lim FK, Yeoh CL, Chong SM, Arulkumaran S. Pre and intraoperative diagnosis of ovarian tumours: how accurate are we?. The Australian \& New Zealand Journal of Obstetrics \& Gynaecology 1997;37(2):223-7.

\section{Maheshwari 2006 \{published data only\}}

Maheshwari A, Gupta S, Kane S, Kulkarni Y, Goyal BK, Tongaonkar HB. Accuracy of intraoperative frozen section in the diagnosis of ovarian neoplasms: experience at a tertiary oncology center. World Journal of Surgical Oncology 2006;4:12.

\section{Malipatil 2013 \{published data only\}}

Malipatil R, Crasta JA. How accurate is intraoperative frozen section in the diagnosis of ovarian tumors?. Journal of Obstetrics and Gynaecology Research 2013;39(3):710-3.

Naik 2006 \{published data only\}

Naik R, Cross P, Lopes A, Godfrey K, Hatem MH. "True" versus "apparent" stage I epithelial ovarian cancer: value of frozen section analysis. International Journal of Gynecological Cancer 2006;16(Suppl 1):41-6. 


\section{Pavlakis 2009 \{published data only\}}

Pavlakis K, Messini I, Vrekoussis T, Yiannou P, Panoskaltsis T, Voulgaris Z. Intraoperative assessment of epithelial and nonepithelial ovarian tumors: a 7-year review. European Journal of Gynaecologic Oncology 2009;30(6):657-60.

Pinto 2001 \{published data only\}

Pinto PB, Andrade LA, Derchain SF. Accuracy of intraoperative frozen section diagnosis of ovarian tumors. Gynecologic Oncology 2001;81(2):230-2.

\section{Puls 1997 \{published data only\}}

Puls L, Heidtman E, Hunter J, Crane M, Stafford J. The accuracy of frozen section by tumor weight for ovarian epithelial neoplasms. Gynecologic Oncology 1997;67(1):16-9.

\section{Rakhshan 2009 \{published data only\}}

Rakhshan A, Zham H, Kazempour M. Accuracy of frozen section diagnosis in ovarian masses: experience at a tertiary oncology center. Archives of Gynecology and Obstetrics 2009;280(2):223-8.

\section{Rose 1994 \{published data only\}}

Rose PG, Rubin RB, Nelson BE, Hunter RE, Reale FR. Accuracy of frozen-section (intraoperative consultation) diagnosis of ovarian tumors. American Journal of Obstetric Gynecology 1994;171(3):823-6.

\section{Stewart 2006 \{published data only\}}

Stewart CJ, Brennan BA, Hammond IG, Leung YC, McCartney AJ. Intraoperative assessment of ovarian tumors: a 5-year review with assessment of discrepant diagnostic cases. International Journal of Gynecological Pathology: Official Journal of the International Society of Gynecological Pathologists 2006;25(3):216-22.

\section{Subbian 2013 \{published data only\}}

Subbian A, Devi U, Bafna U. Accuracy rate of frozen section in ovarian cancers: a regional cancer institute experience. Indian Journal of Cancer 2013;50(4):302-5.

\section{Sukumaran 2014 \{published data only\}}

Sukumaran R, Somanathan T, Mathews A, Kattor J, Sambasivan S, Nair RP. Role of frozen section in intraoperative assessment of ovarian masses: a tertiary oncology center experience. Indian Journal of Surgical Oncology 2014;5(2):99-103.

\section{Suprasert 2008 \{published data only\}}

Suprasert P, Khunamornpong S, Phusong A, Settakorn J, Siriaungkul S. Accuracy of intra-operative frozen sections in the diagnosis of ovarian masses. Asian Pacific Journal of Cancer Prevention: APJCP 2008;9(4):737-40.

\section{Tangjitgamol 2004 \{published data only\}}

Tangjitgamol S, Jesadapatrakul S, Manusirivithaya S, Sheanakul C. Accuracy of frozen section in diagnosis of ovarian mass. International Journal of Gynecologic Cancer 2004;14(2):212-9.

\section{Taskiran 2008 \{published data only\}}

Taskiran C, Erdem O, Onan A, Bozkurt N, Yaman-Tunc S, Ataoglu $\mathrm{O}$, et al. The role of frozen section evaluation in the diagnosis of adnexal mass. International Journal of Gynecologic Cancer 2008;18(2):235-40.

\section{Toneva 2012 \{published data only\}}

Toneva F, Wright $\mathrm{H}$, Razvi K. Accuracy of frozen section in the diagnosis of ovarian tumours. Journal of Obstetrics and Gynaecology 2012;32(5):479-82.

Torres 1998 \{published data only\}

Torres JP, Suso JP, Perea E, Tafur LA, Agudelo M. [Tumores ováricos: correlación entre los informes de estudios solicitados por congelación y la histopatología definitiva. Hospital Universitario del Valle 1994-1997]. Revista Colombiana de Obstetricia y Ginecología 1998;49(3):149-51.

Twaalfhoven 1991 \{published data only\}

Twaalfhoven FC, Peters AA, Trimbos JB, Hermans J, Fleuren GJ. The accuracy of frozen section diagnosis of ovarian tumors. Gynecologic Oncology 1991;41(3):189-92.

Wakahara 2001 \{published data only\} Wakahara F, Kikkawa F, Nawa A, Tamakoshi K, Ino K, Maeda O, et al. Diagnostic efficacy of tumor markers, sonography, and intraoperative frozen section for ovarian tumors. Gynecologic \& Obstetric Investigation 2001;52(3):147-52.

Wang 1998 \{published data only\}

Wang KG, Chen TC, Wang TY, Yang YC, Su TH. Accuracy of frozen section diagnosis in gynecology. Gynecologic Oncology 1998;70(1):105-10.

Wasinghon 2008 \{published data only\}

Wasinghon P, Suthippintawong C, Tuipae S. The accuracy of intraoperative frozen sections in the diagnosis of ovarian tumors. Chotmaihet Thangphaet [Journal of the Medical Association of Thailand] 2008;91(12):1791-5.

Wootipoom 2006 \{published data only\}

Wootipoom V, Dechsukhum C, Hanprasertpong J, Lim A. Accuracy of intraoperative frozen section in diagnosis of ovarian tumors. Chotmaihet Thangphaet [Journal of the Medical Association of Thailand] 2006;89(5):577-82.

\section{Yarandi 2008 \{published data only\}}

Yarandi F, Eftekhar Z, Izadi-Mood N, Shojaei H. Accuracy of intraoperative frozen section in the diagnosis of ovarian tumors. The Australian \& New Zealand Journal of Obstetrics \& Gynaecology 2008;48(4):438-41.

Yeo 1998 \{published data only\}

Yeo E, Yu K, Poddar N, Hui P, Tang L. The accuracy of intraoperative frozen section in the diagnosis of ovarian tumors. Journal of Obstetrics and Gynaecology Research 1998;24(3):189-95. 


\section{References to studies excluded from this review}

\section{Abbasi 2010 \{published data only\}}

Abbasi F, Yekta Z, Aryan A. Evaluation of the compatibility between results of frozen and permanent sections in Urmia University of Medical Sciences during 2001-2002. Histopathology 2010;57(Suppl 1):240.

\section{Abdel-Hady 2012 \{published data only\}}

Abdel-Hady ES, Abdel-Hady Hemida R, Gamal A, El-Shamey M. Fertility sparing surgery for ovarian tumors in children and young adults. Archives of Gynecology and Obstetrics 2012;285(2):469-71.

\section{Abe 2013 \{published data only\}}

Abe A, Sugiyama Y, Furuta R, Furuta N, Matoda M, Takeshima N. Usefulness of intraoperative imprint cytology in ovarian germ cell tumors. Acta Cytologica 2013;57(2):171-6.

\section{Ahmad 2008 \{published data only\}}

Ahmad Z, Barakzai MA, Idrees R, Bhurgri Y. Correlation of intraoperative frozen section consultation with the final diagnosis at a referral center in Karachi, Pakistan. Indian Journal of Pathology \& Microbiology 2008;51(4):469-73.

\section{Alvarez Santin 2011 \{published data only\}}

Alvarez Santín C, Sica A, Melesi S, Feijó A, Garrido G, Rodríguez Alvarez $\mathrm{C}$. Contribution of intraoperative cytology to the diagnosis of ovarian lesions. Acta Cytologica 2011;55(1):85-91.

\section{Anastasiadis 2002 \{published data only\}}

Anastasiadis PG, Romanidis KN, Polichronidis A, Koutlaki NG, Tamiolakis D, Simopoulos K. The contribution of rapid intraoperative cytology to the improvement of ovarian cancer staging. Gynecologic Oncology 2002;86(3):244-9.

\section{Aslam 2010 \{published data only\}}

Aslam MF, Ghayoori R, Khulpateea N. Adnexal masses: relative accuracy of sonography and frozen section in predicting final pathology. Journal of Obstetrics and Gynaecology 2010;30(2):187-189

\section{Atallah 2004 \{published data only\}}

Atallah D, Morice P, Camatte S, Thoury A, Mansour F, Benhassouna J, et al. Place and results of frozen section analysis in the management of malignant and borderline ovarian tumors [Place et résultats de l'examen extemporané dans la stratégie chirurgicale des tumeurs épithéliales malignes et à la limite de la malignité de l'ovaire]. Gynecologie Obstetrique Fertilite 2004;32(7-8):651-6.

\section{Basaran 2014 \{published data only\}}

Basaran D, Salman M, Calis P, Ozek A, Ozgul N, Usubutun A, Yuce K. Diagnostic accuracy of introperative consultation (frozen section) in borderline ovarian tumours and factors associated with misdiagnosis. Journal of Obstetrics \& Gynaecology 2014;34(5):429-34.

\section{Bensaid 2006 \{published data only\}}

Bensaid C, Le Frère Belda MA, Metzger U, Larousserie F, Clément D, Chatellier G, et al. Performance of laparoscopy in identifying malignant ovarian cysts. Surgical Endoscopy 2006;20(9):1410-4.

Brun 2008 \{published data only\}

Brun JL, Cortez A, Rouzier R, Callard P, Bazot M, Uzan S, Daraï E. Factors influencing the use and accuracy of frozen section diagnosis of epithelial ovarian tumors. American Journal of Obstetrics \& Gynecology 2008;199(3):244.e1-7.

Canis 1997 \{published data only\}

Canis M, Pouly JL, Wattiez A, Mage G, Manhes H, Bruhat MA. Laparoscopic management of adnexal masses suspicious at ultrasound. Obstetrics \& Gynecology 1997;89:679-83.

\section{Chapron 1998 \{published data only\}}

Chapron C, Dubuisson JB, Kadoch O, Capella-Allouc S, VacherLavenu MC. Laparoscopic management of organic ovarian cysts: is there a place for frozen section diagnosis?. Human Reproduction 1998;13(2):324-9.

Cheung 1992 \{published data only\}

Cheung A, Collins RJ. Frozen section diagnosis of ovarian neoplasms. An audit. Journal of Obstetrics and Gynaecology 1992;12(3):198-201.

\section{Cingillioglu 2011 \{published data only\}}

Cingillioglu B, Gokcu M, Goklu R, Dicle N, Gultekin E, Yildirim Y. Outcomes of intra-operative frozen section proven borderline ovarian tumors. International Journal of Gynecological Cancer 2011;21(Suppl 3):553.

\section{Coffey 2005 \{published data only\}}

Coffey D, Kaplan AL, Ramzy I. Intraoperative consultation in gynecologic pathology. Archives of Pathology and Laboratory Medicine 2005;129(12):1544-57.

\section{Da Cunha Bastos 1983 \{published data only\}}

Da Cunha Bastos A, Salvatore C, Faria R. Frozen section biopsy of ovarian neoplasms. International Journal of Gynecology and Obstetrics 1983;21(2):103-10.

Dede 2005 \{published data only\}

Dede F, Dilbaz B, Dede H, Ilhan A, Oral S, Haberal A. Laparoscopic management of selected cystic adnexal masses in postmenopausal women. Journal of the Turkish German Gynecological Association 2005;6(3):220-2.

Dottino 1999 \{published data only\}

Dottino PR, Levine DA, Ripley DL, Cohen CJ. Laparoscopic management of adnexal masses in premenopausal and postmenopausal women. Obstetrics \& Gynecology 1999;93(2):223-8.

Fain-Kahn 2009 \{published data only\}

Fain-Kahn V, Poirot C, Uzan C, Prades M, Gouy S, Genestie C, et al. Feasibility of ovarian cryopreservation in borderline ovarian tumours. Human Reproduction 2008;24(4):850-5.

Freitag 2004 \{published data only\}

Freitag P, Jancarrkova N, Fischerova D, Cibula D, Zivny J. Borderline ovarian tumors - 10-year clinical series and literature 
review [Borderline nádory vajecníku--10letý klinický soubor a literární prehled.]. Ceska Gynekolgie 2004;69(4):278-82.

\section{Ganesan 2013 \{published data only\}}

Ganesan R, Brown LJR, Kehoe S, McCluggage WG, ElBahrawy MA. The role of frozen sections in gynaecological oncology: survey of practice in the United Kingdom. European Journal of Obstetrics, Gynecology and Reproductive Biology 2013;166(2):204-8.

\section{Garg 2011 \{published data only\}}

* Garg K, Shih K, Barakat R, Abu-Rustum N, Soslow RA. The accuracy of an intraoperative diagnosis of ovarian borderline tumor varies by histologic subtype. Modern Pathology. Proceedings of USCAP 100th Annual Meeting; 2011 Feb 26 March 4; San Antonio (TX). 2011; Vol. 24:247A.

\section{Geomini 2005 \{published data only\}}

Geomini P, Bremer G, Kruitwagen R, Mol BW. Diagnostic accuracy of frozen section diagnosis of the adnexal mass: a metaanalysis. Gynecologic Oncology 2005;96(1):1-9.

\section{Geomini 2009 \{published data only\}}

Geomini PM, Bremer GL, Kruitwagen RF, Opmeer BC, Mol BW. Patients' preferences in mode of surgery of an adnexal mass. Journal of Psychosomatic Obstetrics \& Gynaecology 2009;30(3):162-7.

\section{Ghaemmaghami 2008 \{published data only\}}

Ghaemmaghami F, Fakour F, Karimi Zarchi M, Behtash N, Modares Gilani M, Mousavi A, et al. Clinical assessment, gross examination, frozen section of ovarian masses: do patients benefit?. Archives of Gynecology \& Obstetrics 2008;278(3):209-13.

\section{Gocku 2013 \{published data only\}}

Gokcu M, Cingillioglu B, Goklu R, Dicle N, Adiyeke M, Sanci M. Outcomes of intra-operative frozen section proven borderline ovarian tumors. International Journal of Gynecological Cancer. Abstracts of 18th International Meeting of the European Society of Gynaecological Oncology (ESGO); 2013 Oct 19-22; Liverpool UK. 2013; Vol. 23:893.

\section{Gol 2003 \{published data only\}}

Gol M, Baloglu A, Yigit S, Dogan M, Aydin C, Yensel U. Accuracy of frozen section diagnosis in ovarian tumors: Is there a change in the course of time?. International Journal of Gynecological Cancer 2003;13(5):593-7.

\section{Gultekin 2011 \{published data only\}}

Gultekin E, Gultekin OE, Cingillioglu B, Sayhan S, Sanci M, Yildirim $Y$. The value of frozen section evaluation in the management of borderline ovarian tumors. Journal of Cancer Research and Therapeutics 2011;7(4):416-20.

\section{Gupta 2013 \{published data only\}}

Gupta N, Rajpal T, Sharma S. Evaluating the accuracy of frozen section in borderline ovarian tumors. Journal of Clinical Oncology. 2013;31(15 Suppl):abstr 5564.

\section{Guzel 2011 \{published data only\}}

Guzel Al, Kuyumcuoglu U, Erdemoglu M. Adnexal masses in postmenopausal and reproductive age women. Journal of Experimental Therapeutics and Oncology 2011;9(2):167-9.

Guzin 2013 \{published data only\}

Guzin K, et al. The accuracy of frozen section diagnosis of ovarian masses and the clinical properties of borderline ovarian tumors (BOTS). ESGO Conference. 2008.

Harmon 2011 \{published data only\}

Harmon B, Hwang S, Parker T, Pearl M, Tornos C. Factors influencing accuracy of frozen section diagnosis of ovarian mucinous tumors: a review of 100 cases. Modern Pathology. Proceedings of USCAP 100th Annual Meeting; 2011 Feb 26 March 4; San Antonio (TX). 2011; Vol. 24:249A.

Hua 2005 \{published data only\} Hua KQ, Jin FM, Xu H, Zhu ZL, Lin JF, Feng YJ. Evaluation of laparoscopic surgery in the early stage malignant tumor of ovary with lower risk. Zhonghua Yi Xue Za Zhi [Chinese Medical Journal] 2005;85(3):169-72. Chinese.

Ismiil 2009 \{published data only\} Ismiil N, Ghorab Z, Nofech-Mozes S, Plotkin A, Covens A, Osborne R, et al. Intraoperative consultation in gynecologic pathology: a 6-year audit at a tertiary care medical center. International Journal of Gynecological Cancer 2009;19(1):152-7.

Ivanov 2005 \{published data only\}

Ivanov S, Ivanov S, Khadzhiolov N. Ovarian tumours--accuracy of frozen section diagnosis. Akush Ginekol 2005;44(1):11-3.

Jaafar 2005 \{published data only\}

Jaffar H. Intra-operative frozen section consultations: concepts, applications and limitations. Malaysian Journal of Medical Sciences 2006;13(1):4-12.

\section{Kato 2011 \{published data only\}}

Kato N, Higuchi J, Ogata S, Ootake H, Iwaba A, Motoyama T. Spherule-like acellular stroma in clear cell carcinoma of the ovary: its utility in frozen section diagnosis. Histopathology 2011;59(4):790-4.

\section{Kayıkçıoğlu 2000 \{published data only\}}

Kayıkçıoğlu F, Pata Ö, Cengiz S, Tulunay G, Boran N, Yalvaç S, et al. Accuracy of frozen section diagnosis in borderline ovarian malignancy. Gynecologic and Obstetric Investigation 2000;49(3):187-9.

\section{Khunamornpong 2003 \{published data only\}}

Khunamornpong S, Siriaunkgul S. Scrape cytology of the ovaries: potential role in intraoperative consultation of ovarian lesions. Diagnostic Cytopathology 2003;28(5):250-7.

\section{Kim 2009a \{published data only\}}

Kim JH, Kim TJ, Park YG, Lee SH, Lee CW, Song MJ, Lee KH, Hur SY, Bae SN, Park JS. Clinical analysis of intra-operative frozen section proven borderline tumors of the ovary. $J$ Gynecol Oncol 2009;20(3):176-80. 
Kim 2009b \{published data only\}

Kim K, Chung HH, Kim JW, Park NH, Song YS, Kang SB. Clinical impact of under-diagnosis by frozen section examination is minimal in borderline ovarian tumors. European Journal of Surgical Oncology 2009;35(9):969-73.

Kim 2013 \{published data only\}

Kim S, Kang W, Choi H. Accuracy of frozen section diagnosis of borderline ovarian tumors. International Journal of Gynecological Cancer. Abstracts of 18th International Meeting of the European Society of Gynaecological Oncology (ESGO); 2013 Oct 19-22; Liverpool UK. 2013; Vol. 23:493.

\section{Konopacka 2012 \{published data only\}}

Konopacka A, Nezhat F, Finger T, Sternchos J. Assessing adnexal masses for malignancy: a comparison of four diagnostic modalities. Proceedings of 41st AAGL Global Congress on Minimally Invasive Gynecology. Las Vegas (NV): American Association of Gynecologic Laparoscopists, 2012.

\section{Kumpulainen 2007 \{published data only\}}

Kumpulainen S, Kuoppala T, Leminen A, Komulainen M, Puistola U, Sankila R, et al. Surgical staging, treatment, and follow-up of borderline tumors in different hospital categories: a prospective nationwide survey in Finland. Acta Obstetricia et Gynecologica 2007;86(5):610-4

\section{Kushima 2013 \{published data only\}}

Kushima M, Kohno Y, Takimoto M. Usefulness of cytological specimens (scrape or imprint smears) for the pathological diagnosis at intraoperative rapid diagnosis of ovarian tumors. Acta Cytologica 2013;57(Suppl 1):103.

Leng 2006 \{published data only\}

Leng JH, Lang JH, Zhang JJ, Feng FZ, Liu ZF, Sun DW, et al. Role of laparoscopy in the diagnosis and treatment of adnexal masses. Zhonghua Yi Xue Za Zhi [Chinese Medical Journal] 2006;119(3):202-6. Chinese.

\section{Li 2009 \{published data only\}}

Li M, Liu YH, Zhuang HG, Lin HH, Zeng RH, Wang XB, et al. Analysis of diagnosis accuracy of frozen sections in 73 cases of borderline tumor of ovary. Zhonghua Bing Li Xue Za Zhi [Chinese Journal of Pathology] 2009;38(2):106-9. Chinese.

\section{Lin 1993 \{published data only\}}

Lin JY, Angel C, DuBeshter B, Walsh CJ. Diagnoses after laparotomy for a mass in the pelvic area in women. Surgery, Gynecology \& Obstetrics 1993;176(4):333-8.

\section{Liu 2010 \{published data only\}}

Liu L, Zhao C, Annamalai L, Kothandaraman N, Biswas A, Choolani M. Haptoglobin proved to be a novel biomarker for intraoperative triage of epithelial ovarian cancer at early stage. Clinical Cancer Research 2010;16(7):B5.

\section{Marana 2005 \{published data only\}}

Marana R, Muzii L, Ferrari S, Catalano G, Zannoni G, Marana E. Management of adnexal cystic masses with unexpected intracystic vegetations detected during laparoscopy. Journal of Minimally Invasive Gynecology 2005;12(6):502-7.

\section{Maruoka 2003 \{published data only\}}

Maruoka N, Ota H, Kushima M, Tsuda Y, Naitoh H. Intraoperative rapid diagnosis of ovarian tumors supported by laser scanning cytometry (LSC). Journal of the Showa Medical Association 2003;63(1):97-105. Japanese.

\section{Medeiros 2005 \{published data only\}}

Medeiros LR, Rosa DD, Edelweiss MI, Stein AT, Bozzetti MC, Zelmanowicz A, et al. Accuracy of frozen-section analysis in the diagnosis of ovarian tumors: a systematic quantitative review. International Journal of Gynecological Cancer 2005;15(2):192-202.

\section{Mendilcioglu 2002 \{published data only\}}

Mendilcioglu I, Zorlu CG, Trak B, Ciftci C, Akinci Z. Laparoscopic management of adnexal masses: safety and effectiveness. The Journal of Reproductive Medicine 2002;47(1):36-40.

\section{Menzin 1995 \{published data only\}}

Menzin AW, Rubin SC, Noumoff JS, LiVolsi VA. The accuracy of a frozen section diagnosis of borderline ovarian malignancy. Gynecologic Oncology 1995;59(2):183-5.

\section{Michael 1996 \{published data only\}}

Michael CW, Lawrence WD, Bedrossian CW. Intraoperative consultation in ovarian lesions: a comparison between cytology and frozen section. Diagnostic Cytopathology 1996;15(5):387-94.

Moodley 2005 \{published data only\}

Moodley M, Bramdev A. Frozen section: its role in gynaecological oncology. Journal of Obstetrics and Gynaecology 2005;25(7):629-34.

\section{Morotti 2011 \{published data only\}}

Morotti M, Valenzano Menada M, Abete L, Fulcheri E, Venturini PL, Ferrero S. Accuracy of intraoperative frozen section in the diagnosis of borderline ovarian tumors. International Journal of Gynecological Cancer. Abstracts of the 17th International Meeting of the European Society of Gynaecological Oncology (ESGO); 2011 Sept 11-14; Milan IT. 2011; Vol. 21:351.

\section{Nasfi 2012 \{published data only\}}

Nasfi A, Charfi L, Sellami-Dhouib R, Mrad K, Sassi S, Abbes I, et al. Mucinous tumors of the ovary: diagnostic challenges at frozen section and clinical implications. Virchows Arch. Abstracts of the 24th European Congress of Pathology; 2012 Sept 8-12; Prague CZ. 2012; Vol. 461:S311.

\section{Nevin 2010 \{published data only\}}

Nevin J, Luesley D. Defining the surgical management of suspected early-stage ovarian cancer by estimating patient numbers through alternative management strategies. BJOG: An International Journal of Obstetrics and Gynaecology 2009;117(1):114.

\section{Obiakor 1991 \{published data only\}}

Obiakor I, Maiman M, Mittal K, Awobuluyi M, DiMaio T, Demopoulos R. The accuracy of frozen section in the diagnosis of ovarian neoplasms. Gynecologic Oncology 1991;43(1):61-3. 
Ozdamar 2006 \{published data only\}

Özdamar S, Bahadir B, Ekem T, Kertíş G, Gün B, Numanoğlu G, et al. Frozen section experience with emphasis on reasons for discordance. Turkish Journal of Cancer 2006;36(4):157-61.

\section{Parker 2011 \{published data only\}}

Parker T, Harmon B, Hwang S, Pearl M, Tornos C. Impact of subspecialization on the intraoperative diagnosis of ovarian lesions: a review of 831 cases. American Journal of Clinical Pathology. Abstracts of the 2011 ASCP Annual Meeting; 2011 October 20-22; Las Vegas NV. 2012; Vol. 138, issue Suppl 1:A212.

\section{Pongsuvareeyakul 2012 \{published data only\}}

Pongsuvareeyakul T, Khunamornpong S, Settakorn J, Sukpan K, Suprasert P, Siriaunkgul S. Accuracy of frozen-section diagnosis of ovarian mucinous tumors. International Journal of Gynecological Cancer 2012;22(3):400-6.

\section{Puga 2011 \{published data only\}}

Puga O, Farias M, Barriga MI, Fernandez M, Nuñez F, Saavedra M, et al. Accuracy of intraoperative frozen section analysis in borderline ovarian tumors. International Journal of Gynecological Cancer 2011;21(Suppl 3):665.

Quan 2004 \{published data only\}

Quan M, Fey J, Eitan R, Abu-Rustum N, Barakat R, Borgen P, et al. Role of laparoscopy in the evaluation of the adnexa in patients with stage IV breast cancer. Gynecologic Oncology 2004;92(1):327-30.

\section{Saglam 2006 \{published data only\}}

Saglam EA, Usubütün A, Küçükali T. Mistakes prevent mistakes: experience from intraoperative consultation with frozen section. European Journal of Obstetrics, Gynecology and Reproductive Biology 2006;125(2):266-8.

\section{Sakurai 2004 \{published data only\}}

Sakurai S. Differential diagnostic significance of frozen ovarian malignancy specimens based on histological architecture, mitotic count and nuclear pleomorphism. Dokkyo Journal of Medical Sciences 2004;31(2):127-37.

Salman 2013 \{published data only\}

Salman, et al. Conference. 2013.

\section{Scurry 1989 \{published data only\}}

Scurry JP, Sumithran E. An assessment of the value of frozen sections in gynecological surgery. Pathology 1989;21(3):159-63.

\section{Seckin 2011 \{published data only\}}

Seckin B1, Ozdener T, Tapisiz OL, Batioğlu S. Laparoscopic treatment of ovarian cysts in adolescents and young adults. Journal of Pediatric and Adolescent Gynecology 2011;24:300-3.

\section{Shahid 2012 \{published data only\}}

Shahid M, Zaheer S, Mubeen A, Rahman K, Sherwani RK. The role of intraoperative cytology in the diagnostic evaluation of ovarian neoplasms. Acta Cytologica 2012;56(5):467-73.
Shih 2011 \{published data only\}

Shih KK, Garg K, Soslow RA, Chi DS, Abu-Rustum NR, Barakat RR. Accuracy of frozen section diagnosis of ovarian borderline tumor. Gynecologic Oncology 2011;123(3):517-21.

\section{Slavutin 1979 \{published data only\}}

Slavutin L, Rotterdam HZ. Frozen section diagnosis of serous epithelial tumors of the ovary. The American Journal of Diagnostic Gynecology and Obstetrics 1979;1(1):89-94.

Song 2011 \{published data only\}

Song T, Choi CH, Kim HJ, Kim MK, Kim TJ, Lee JW, et al. Accuracy of frozen section diagnosis of borderline ovarian tumors. Gynecologic Oncology 2011;122(1):127-31.

Souka 1990 \{published data only\} Souka S, Kamel M, Rocca M, El-Assi M, Hebeishy N, Sheir SH. The combined use of cytological imprint and frozen section in the intraoperative diagnosis of ovarian tumors. International Journal of Gynaecology and Obstetrics 1990;31(1):43-6.

\section{Spann 1994 \{published data only\}}

Spann CO, Kennedy JE, Musoke E. Intraoperative consultation of ovarian neoplasms. Journal of the National Medical Association 1994;86(2):141-4.

Springel 2009 \{published data only\}

Springel EH, Frable WJ, Cohen SA. Accuracy of intra-operative frozen section consultation in diagnosis of epithelial ovarian tumors. Journal of Pelvic Medicine \& Surgery 2009;15(2):50.

\section{Stewart 2005 \{published data only\}}

Stewart CJ, Brennan BA, Hammond IG, Leung YC, McCartney AJ. Accuracy of frozen section in distinguishing primary ovarian neoplasia from tumors metastatic to the ovary. International Journal of Gynecological Pathology: Official Journal of the International Society of Gynecological Pathologists 2005;24(4):356-62.

\section{Stewart 2008 \{published data only\}}

Stewart CJ, Brennan BA, Hammond IG, Leung YC, McCartney AJ, Ruba S. Intraoperative assessment of clear cell carcinoma of the ovary. International Journal of Gynecological Pathology 2008;27:475-82.

\section{Stewart 2010 \{published data only\}}

Stewart CJ, Brennan BA, Koay E, Naran A, Ruba S. Value of cytology in the intraoperative assessment of ovarian tumors: a review of 402 cases and comparison with frozen section diagnosis. Cancer Cytopathology 2010;118(3):127-36.

\section{Storms 2012 \{published data only\}}

Storms AA, Sukumvanich P, Monaco SE, Beriwal S, Krivak TC, Olawaiye $A B$, et al. Mucinous tumors of the ovary: diagnostic challenges at frozen section and clinical implications. Gynecologic Oncology 2012;125(1):75-9.

Takemoto 2014 \{published data only\}

Takemoto S, Ushijima K, Kawano R, Fukui A, Terada A, Fujimoto T, et al. Validity of intraoperative diagnosis at 
laparoscopic surgery for ovarian tumours. The Journal of Minimally Invasive Gynecology 2014;21(4):576-9.

\section{Tempfer 2007 \{published data only\}}

Tempfer CB, Polterauer S, Bentz EK, Reinthaller A, Hefler LA. Accuracy of intraoperative frozen section analysis in borderline tumors of the ovary: a retrospective analysis of 96 cases and review of the literature. Gynecologic Oncology 2007;107(2):248-52.

\section{Twigg 2012 \{published data only\}}

Twigg J, Cruickshank D. Intra-operative frozen section analysis for suspected early-stage ovarian cancer. BJOG: An International Journal of Obstetrics and Gynaecology 2012;119(7):896.

\section{Uguz 2005 \{published data only\}}

Uguz A, Ersoz C, Bolat F, Gokdemir A, Vardar MA. Fine needle aspiration cytology of ovarian lesions. Acta Cytologica 2005;49(2):144-8.

\section{Ulrich 2000 \{published data only\}}

Ulrich U, Paulus W, Schneider A, Keckstein J. Laparoscopic surgery for complex ovarian masses. Journal of the American Association of Gynecologic Laparoscopists 2000;7(3):373-80.

\section{Usubutun 1998 \{published data only\}}

Usubütün A, Altinok G, Küçükali T. The value of intraoperative consultation (frozen section) in the diagnosis of ovarian neoplasms. Acta Obstetricia et Gynecologica Scandinavica 1998;77:1013-6.

\section{Vemavarapu 2014 \{published data only\}}

Vemavarapu, et al. Conference. 2014.

\section{Vijayakumar 2013 \{published data only\}}

Vijayakumar A. The diagnostic utility of intraoperative cytology in the management of ovarian tumours. Journal of Clinical and Diagnostic Research 2013;7(6):1047-50.

\section{Warwick 2009 \{published data only\}}

Warwick J, Vardaki E, Fattizzi N, McNeish I, Jeyarajah A, Oram D, et al. Defining the surgical management of suspected earlystage ovarian cancer by estimating patient numbers through alternative management strategies. BJOG: An International Journal of Obstetrics and Gynaecology 2009; 116 :1225-41.

\section{Wingo 2006 \{published data only\}}

Wingo SN, Knowles LM, Carrick KS, Miller DS, Schorge JO. Retrospective cohort study of surgical staging for ovarian low malignant potential tumors. American Journal of Obstetrics and Gynecology 2006;194(5):e20-e22.

\section{Zhang 1993 \{published data only\}}

Zhang GN. Accuracy of frozen section in diagnosis of ovarian tumors. Zhonghua Fu Chan Ke Za Zhi [Chinese Journal of Obstetrics and Gynecology] 1993;28(10):601-3, 35. Chinese.

\section{Additional references}

\section{Bailey 2006}

Bailey J, Tailor A, Naik R, Lopes A, Godfrey K, Hatem HM, et al. Risk of malignancy index for referral of ovarian cancer cases to a tertiary center: does it identify the correct cases?. International Journal of Gynecological Cancer 2006;16(Suppl 1):30-4.

\section{Bolis 1995}

Bolis G, Colombo N, Pecorelli S, Torri V, Marsoni S, Bonazzi C, et al. Adjuvant treatment for early epithelial ovarian cancer: results of two randomised clinical trials comparing cisplatin to no further treatment or chromic phosphate (32P). G.I.C.O.G.: Gruppo Interregionale Collaborativo in Ginecologia Oncologica. Annals of Oncology 1995;6(9):887-93.

\section{Cancer Research UK 2012}

Cancer Research UK. Ovarian cancer survival statistics. 2012. http://www.cancerresearchuk.org/cancer-info/cancerstats/ types/ovary/survival/ (accessed 1 July 2012).

\section{EUROCARE 2003}

Coleman MP, Gatta G, Verdecchia A, Estève J, Sant M, Storm H, et al. EUROCARE-3 summary: cancer survival in Europe at the end of the 20th century. Annals of Oncology 2003;14(Suppl 5):v128-49.

\section{FIGO 2015}

Prat J, FIGO Committee on Gynecologic Oncology. Staging classification for cancer of the ovary, fallopian tube, and peritoneum. International Journal of Gynaecology and Obstetrics 2014;124(1):1-5.

\section{GLOBOCAN 2012}

Ferlay J, Soerjomataram I, Ervik M, Dikshit R, Eser S, Mathers C, et al. GLOBOCAN 2012 v 1.0, Cancer incidence and mortality worldwide. IARC CancerBase 2013. Available from: http:// globocan.iarc.fr (accessed 4 November 2015).

\section{Helewa 1986}

Helewa ME, Krepart GV, Lotocki R. Staging laparotomy in early epithelial ovarian carcinoma. American Journal of Obstetrics \& Gynecology 1986;154(2):282-6.

\section{ICON 1}

Colombo N, Guthrie D, Chiari S, Parmar M, Qian W, Swart AM, et al. International Collaborative Ovarian Neoplasm (ICON) collaborators. International Collaborative Ovarian Neoplasm trial 1: a randomized trial of adjuvant chemotherapy in women with early-stage ovarian cancer. Journal of the National Cancer Institute 2003;95(2):125-32.

\section{Jacobs 1990}

Jacobs I, Oram D, Fairbanks J, Turner J, Frost C, Grudzinskas JG. A risk of malignancy index incorporating CA 125, ultrasound and menopausal status for the accurate preoperative diagnosis of ovarian cancer. British Journal of Obstetrics and Gynaecology 1990;97(10):922-9. 


\section{Jemal 2008}

Jemal A, Siegel R, Ward E, Hao Y, Xu J, Murray T, et al. Cancer Statistics, 2008. CA: a Cancer Journal for Clinicians 2008;58(2):71-96.

\section{Lawrie 2015}

Lawrie TA, Winter-Roach BA, Heus P, Kitchener HC. Adjuvant (post-surgery) chemotherapy for early stage epithelial ovarian cancer. Cochrane Database of Systematic Reviews 2015, Issue 12. [DOI: 10.1002/14651858.CD004706.pub5]

\section{Macaskill 2010}

Macaskill P, Gatsonis C, Deeks JJ, Harbord RM, Takwoingi Y. Cochrane Handbook for Systematic Reviews of Diagnostic Test Accuracy. In: Deeks JJ, Bossuyt PM, Gatsonis C editor(s). Version 1.0.. Vol. Chapter 10: Analysing and Presenting Results, The Cochrane Collaboration, 2010.

\section{Maggioni 2006}

Maggioni A, Benedetti P, Dell'Anna T, Landoni T, Lissoni A, Pellegrino $A$, et al. Randomised study of systematic lymphadenectomy in patients with epithelial ovarian cancer macroscopically confined to the pelvis. British Journal of Cancer 2006;95(6):699-704.

\section{NCIN 2015}

Public Health England. National Cancer Intelligence Network. http://www.ncin.org.uk/publications/survival_by_stage (accessed 4 November 2015).

\section{NICE 2011}

National Institute for Health and Clinical Excellence (NICE). Ovarian cancer: the recognition and initial management of ovarian cancer. NICE clinical guideline 122. http:// www.nice.org.uk/guidance/CG122 (accessed 4 November 2015).

\section{Reitsma 2005}

Reitsma JB, Glas AS, Rutjes AW, Scholten RJ, Bossuyt PM, Zwinderman $\mathrm{AH}$. Bivariate analysis of sensitivity and specificity produces informative summary measures in diagnostic reviews. Journal of Clinical Epidemiology 2005;58(10):982-90.

\section{Review Manager 2014 [Computer program]}

The Nordic Cochrane Centre, The Cochrane Collaboration. Review Manager (RevMan). Version 5.1. Copenhagen: The Nordic Cochrane Centre, The Cochrane Collaboration, 2014.

\section{Stata 2013 [Computer program]}

Stata. Data analysis and statistical software. Version 13.1. College Station, Texas, USA: StataCorp, 2013.

\section{Trimbos 2003}

Trimbos J, Parmar M, Vergote I, Guthrie D, Bolis G, Colombo N, et al. International Collaborative Ovarian Neoplasm trial 1 and Adjuvant ChemoTherapy in Ovarian Neoplasm trial: two parallel randomized phase III trials of adjuvant chemotherapy in patients with early-stage ovarian carcinoma. Journal of the National Cancer Institute 2003;95(2):105-12.

\section{Trimbos 2010}

Trimbos B, Timmers P, Pecorelli S, Coens C, Ven K, Van der Burg M, et al. Surgical staging and treatment of early ovarian cancer: long-term analysis from a randomized trial. Journal of the National Cancer Institute 2010;102(13):982-7.

\section{Whiting 2011}

Whiting PF, Rutjes AW, Westwood ME, Mallett S, Deeks J J, Reitsma JB, et al. QUADAS-2 Group. QUADAS-2: a revised tool for the quality assessment of diagnostic accuracy studies. Annals of Internal Medicine 2011;155(8):529-36.

\section{Winter-Roach 2012}

Winter-Roach BA, Kitchener HC, Lawrie TA. Adjuvant (postsurgery) chemotherapy for early stage epithelial ovarian cancer. Cochrane Database of Systematic Reviews 2012, Issue 3. [DOI: 10.1002/14651858.CD004706.pub4]

* Indicates the major publication for the study

\section{CHARACTERISTICS OF STUDIES}

Characteristics of included studies [ordered by study ID]

\section{Açikalin 2014}

\section{Study characteristics}

$\begin{array}{ll}\text { Patient sampling } & \text { Design: Retrospective } \\ \text { Setting: Turkey } & \\ & \text { Accrual dates: July } 2006 \text { - January } 2013 \\ & \text { No participants: } 282 \\ & \text { No assessed: } 282 \\ & \text { Inclusion criteria: Re-analysis of charts of } 282 \text { women with an ovarian neoplasm } \\ & (42.8 \% \text { of all gynaecologic FSs) with intraoperative FS reports. Paraffin section di- } \\ & \text { agnoses with non-tumoural ovarian lesions (massive ovarian edema, hemorrhagic } \\ & \text { necrosis, benign cysts, infections) were excluded. } \\ \text { Included previous histological diagnosis: unclear }\end{array}$


Açikalin 2014 (Continued)

Index tests
"All fresh gross specimen were examined by a resident and a pathologist or particularly gynecopathologist, in terms of localization, size, colour, content, heterogeneity, infiltration pattern of the tumour and condition of the ovarian capsule. One to four sections depending on the size and heterogeneity of the tumour were sampled in a cryostat and sections were stained by hematoxylin-eosin. Slides were evaluated and reported to the surgeon by the pathologist. Final PS diagnosis reported by an experienced gynecopathologist was accepted as accurate diagnose."

\begin{tabular}{ll}
\hline Target condition and reference standard(s) & Malignancy; paraffin section \\
\hline Flow and timing & FS before PS. \\
\hline Comparative & \\
\hline Notes & $\begin{array}{l}\text { Re-analysis of charts of } 282 \text { women with an ovarian neoplasm (42.8\% of all gynaeco- } \\
\text { logic FSs) with intraoperative FS reports diagnosed between July } 2006 \text { and January } \\
\text { 2013. Paraffin section diagnoses with non-tumoural ovarian lesions (massive ovari- } \\
\text { an edema, hemorrhagic necrosis, benign cysts, infections) were excluded. }\end{array}$
\end{tabular}

\section{Methodological quality}

\begin{tabular}{llll}
\hline Item & Authors' judgement & Risk of bias & Applicability concerns
\end{tabular}

\section{DOMAIN 1: Patient Selection}

Was a consecutive or random sample of pa- Unclear tients enrolled?

\begin{tabular}{|c|c|}
\hline Was a case-control design avoided? & Yes \\
\hline Did the study avoid inappropriate exclusions? & Unclear \\
\hline $\begin{array}{l}\text { Was the sample representative of patients in } \\
\text { practice }(90 \% \text { stage } \mathrm{I} / \mathrm{II} \text { with RMI>200)? }\end{array}$ & Unclear \\
\hline
\end{tabular}

\begin{tabular}{lll}
\hline & Unclear & Unclear \\
\hline
\end{tabular}

\section{DOMAIN 2: Index Test All tests}

Were the index tests interpreted without

knowledge of the reference standard?

Were the index tests Interpreted by consul- Unclear

tant or specialist gyn-onc pathologist?

\begin{tabular}{lll}
\hline & Unclear & Unclear \\
\hline
\end{tabular}

\section{DOMAIN 3: Reference Standard}

\section{Is the reference standards likely to correctly Yes} classify the target condition?

Were the reference standard results interpret- Unclear ed without knowledge of the results of the index tests?

\begin{tabular}{l} 
Unclear \\
\hline
\end{tabular}


Açikalin 2014 (Continued)

DOMAIN 4: Flow and Timing

Did all patients receive a reference standard? Yes

Did all patients receive the same reference Yes

standard?

Were un-interpretable/intermediate test re- Yes

sults reported?

Were withdrawals from the study explained? Yes

Low

Bazot 2006

\section{Study characteristics}

$\begin{array}{ll}\text { Patient sampling } & \text { Design: Retrospective } \\ & \text { Setting: France } \\ & \text { Accrual dates: Jan } 1999-\text { Dec } 2003 \\ & \text { No participants: } 136 \\ & \text { No assessed: } 151^{\star} \\ & \text { Inclusion criteria: Complex / suspicious adnexal masses referred } \\ & \text { for pre-op MRI } \\ & \text { Included previous histological diagnosis: unclear }\end{array}$

Patient characteristics and setting

Complex / suspicious adnexal masses referred for pre-op MRI. France.

Index tests

FS prepared from vegetations in cyst walls or solid areas selected by macroscopic exam

Target condition and reference standard(s)

Flow and timing

\section{Comparative}

Notes
Malignant or borderline on paraffin section.

FS before PS.
Compares accuracy of pre-op MRI and FS. * 136 women, 32 with bilateral masses ( 15 bilateral and 17 unilateral FS) - total 151 FS analyses included.

\section{Methodological quality}

\begin{tabular}{llll}
\hline Item & $\begin{array}{l}\text { Authors' judge- } \\
\text { ment }\end{array}$ & Risk of bias & $\begin{array}{l}\text { Applicability con- } \\
\text { cerns }\end{array}$ \\
\hline
\end{tabular}

\section{DOMAIN 1: Patient Selection}

\begin{tabular}{ll}
\hline Was a consecutive or random sample of patients enrolled? & Yes \\
\hline Was a case-control design avoided? & Yes \\
\hline Did the study avoid inappropriate exclusions? & Unclear \\
\hline \hline
\end{tabular}


Bazot 2006 (Continued)

Was the sample representative of patients in practice $(90 \% \quad$ Unclear stage I/II with RMI>200)?

Unclear

Unclear

\section{DOMAIN 2: Index Test All tests}

Were the index tests interpreted without knowledge of the ref- Yes erence standard?

Were the index tests Interpreted by consultant or specialist gyn- Unclear onc pathologist?

\begin{tabular}{lll}
\hline Unclear & Low \\
\hline
\end{tabular}

\section{DOMAIN 3: Reference Standard}

Is the reference standards likely to correctly classify the target Yes condition?

Were the reference standard results interpreted without knowl- Unclear edge of the results of the index tests?

\begin{tabular}{lll}
\hline \multicolumn{1}{l}{ Low } & Unclear & \\
\hline DOMAIN 4: Flow and Timing & Yes & Yes \\
\hline Did all patients receive a reference standard? & No \\
\hline Did all patients receive the same reference standard? & No & Low \\
\hline Were un-interpretable/intermediate test results reported? & & \\
\hline Were withdrawals from the study explained? &
\end{tabular}

\section{Bige 2011}

\section{Study characteristics}

\begin{tabular}{ll}
\hline Patient sampling & Design: Retrospective \\
Setting: Turkey & Accrual dates: Jan 2002 - Dec 2010 \\
& No participants: 578 \\
& No assessed: 519 \\
Inclusion criteria: Indications for FS - radiologically or macroscopically be- & nign appearing ovarian masses with high CA125, history of malignancy oth- \\
& er than ovary and fertility preserving surgery for young cases. 59 exclusions \\
& -14 definitive diagnosis not obtained by FS, 23 no ovarian tissue identified \\
& in masses, 22 metastases to ovaries \\
Included previous histological diagnosis: unclear
\end{tabular}

Patient characteristics and setting

University hospital in Turkey 
Bige 2011 (Continued)

Index tests

2-5 sections esp from solid areas, examined by at least 2 consultant pathologists (gynae $83.2 \%$, non-gynae $16.8 \%$ )

Target condition and reference standard(s)

Malignant or borderline disease; paraffin section

Flow and timing

PS performed after FS. 59 patients excluded: in 14, definitive diagnosis could not be obtained at FS; in 23, no ovarian tissue identified in masses; in 22 , metastases to ovary

\section{Comparative}

Notes

FS reported by at least 2 consultant pathologists (gynae pathologists $83.2 \%$, non-gynae $16.8 \%$ ). Unclear if same pathologists reported PS or if FS results masked. Possible interpretation bias.

\section{Methodological quality}

\begin{tabular}{llll}
\hline Item Authors' judgement & Risk of bias & \multicolumn{1}{l}{$\begin{array}{l}\text { Applicability con- } \\
\text { cerns }\end{array}$}
\end{tabular}

\section{DOMAIN 1: Patient Selection}

Was a consecutive or random sample of patients en- Unclear rolled?

\begin{tabular}{|c|c|}
\hline Was a case-control design avoided? & Yes \\
\hline Did the study avoid inappropriate exclusions? & Unclear \\
\hline
\end{tabular}

\begin{tabular}{llll}
\hline DOMAIN 2: Index Test All tests & Unclear & High \\
\hline $\begin{array}{l}\text { Were the index tests interpreted without knowledge } \\
\text { of the reference standard? }\end{array}$ & & \\
\hline $\begin{array}{l}\text { Were the index tests Interpreted by consultant or spe- } \\
\text { cialist gyn-onc pathologist? }\end{array}$ & Low & Low \\
\hline
\end{tabular}

\section{DOMAIN 3: Reference Standard}

\section{Is the reference standards likely to correctly classify Yes}

the target condition?

Were the reference standard results interpreted with- Unclear out knowledge of the results of the index tests?

Unclear Low

\section{DOMAIN 4: Flow and Timing}

Did all patients receive a reference standard? 
Bige 2011 (Continued)

Did all patients receive the same reference standard? Yes

Were un-interpretable/intermediate test results re- Yes ported?

Were withdrawals from the study explained?

Yes

Low

\section{Boriboonhirunsarn 2004}

\section{Study characteristics}

\begin{tabular}{ll}
\hline Patient sampling & Design: Prospective diagnostic test accuracy \\
& Setting: Thailand \\
& Accrual dates: July 2001 to March 2002 \\
& No participants: 147 \\
No assessed: 147 & Inclusion criteria: Included women with ovarian tumours for \\
& surgery. Excluded if give prior treatment for cancer (radiotherapy \\
& or chemotherapy). \\
Included previous histological diagnosis: NR
\end{tabular}

Patient characteristics and setting

Included women with ovarian tumours for surgery. Excluded if give prior treatment for cancer (radiotherapy or chemotherapy).Thailand.

Index tests

Number of slides and area to be sectioned were determined by one experienced pathologist, who also examined and interpreted all slides, 'Slides were interpreted without knowledge of the results of those prepared by the other technique'.

Target condition and reference standard(s)

Flow and timing

Malignant or borderline on PS.

Comparative

Notes Surgical extent not reported.

\section{Methodological quality}

\begin{tabular}{llll}
\hline Item & $\begin{array}{l}\text { Authors' judge- } \\
\text { ment }\end{array}$ & Risk of bias & $\begin{array}{l}\text { Applicability con- } \\
\text { cerns }\end{array}$ \\
\hline
\end{tabular}

\section{DOMAIN 1: Patient Selection}

\begin{tabular}{ll}
\hline Was a consecutive or random sample of patients enrolled? & Yes \\
\hline Was a case-control design avoided? & Yes \\
\hline Did the study avoid inappropriate exclusions? & Yes \\
\hline $\begin{array}{l}\text { Was the sample representative of patients in practice (90\% } \\
\text { stage } 1 / \text { II with RMI>200)? }\end{array}$ & Unclear \\
\hline
\end{tabular}


Boriboonhirunsarn 2004 (Continued)

Unclear

Unclear

\section{DOMAIN 2: Index Test All tests}

Were the index tests interpreted without knowledge of the ref- Yes erence standard?

Were the index tests Interpreted by consultant or specialist gyn- Yes onc pathologist?

\begin{tabular}{lll}
\hline & Low & \\
\hline DOMAIN 3: Reference Standard & & \\
\hline $\begin{array}{l}\text { Is the reference standards likely to correctly classify the target } \\
\text { condition? }\end{array}$ & Yes & Unclear \\
\hline $\begin{array}{l}\text { Were the reference standard results interpreted without knowl- } \\
\text { edge of the results of the index tests? }\end{array}$ & Low \\
\hline DomAIN 4: Flow and Timing & Yes \\
\hline Did all patients receive a reference standard? & Yes \\
\hline Did all patients receive the same reference standard? & Yes \\
\hline Were un-interpretable/intermediate test results reported? & Unclear \\
\hline Were withdrawals from the study explained? & Low \\
\hline
\end{tabular}

\section{Canis 2004}

\section{Study characteristics}

$\begin{array}{ll}\text { Patient sampling } & \text { Design: Retrospective } \\ \text { Setting: Canada } & \text { Accrual dates: } 5 \text { years } \\ & \text { No participants: } 141 \\ & \text { No assessed: } 141 \\ \text { Inclusion criteria: All women undergoing laparoscopy in order to } & \text { treat ovarian or paraovarian tumours. Excluded obvious malig- } \\ \text { nancy and benign masses (uterine, peritoneal cysts, hydrosalp- } \\ \text { inges). } \\ \text { Included previous histological diagnosis: unclear }\end{array}$

Patient characteristics and setting

Macroscopically suspicious ovarian tumours. Large tertiary care centre.

\begin{tabular}{ll}
\hline Index tests & Details not reported \\
\hline Target condition and reference standard(s) & Malignant or borderline disease \\
\hline \hline
\end{tabular}


Canis 2004 (Continued)

Flow and timing

FS before PS.

Comparative

Notes

Laparoscopic management with staging procedure to FS (border-

line or malignant) by either laparoscopy or laparotomy

\section{Methodological quality}

\begin{tabular}{llll}
\hline Item & $\begin{array}{l}\text { Authors' judge- } \\
\text { ment }\end{array}$ & Risk of bias & $\begin{array}{l}\text { Applicability con- } \\
\text { cerns }\end{array}$
\end{tabular}

\section{DOMAIN 1: Patient Selection}

\begin{tabular}{lc}
\hline Was a consecutive or random sample of patients enrolled? & Yes \\
\hline Was a case-control design avoided? & Yes \\
\hline Did the study avoid inappropriate exclusions? & Yes \\
\hline $\begin{array}{l}\text { Was the sample representative of patients in practice }(90 \% \\
\text { stage l/II with RMI>200)? }\end{array}$ & Yes
\end{tabular}

stage $\mathrm{I} / \mathrm{II}$ with $\mathrm{RMI}>200)$ ?

Low Low

\section{DOMAIN 2: Index Test All tests}

Were the index tests interpreted without knowledge of the ref- Yes erence standard?

Were the index tests Interpreted by consultant or specialist gyn- Unclear onc pathologist?

\begin{tabular}{|c|c|c|c|}
\hline & & Unclear & Low \\
\hline \multicolumn{4}{|l|}{ DOMAIN 3: Reference Standard } \\
\hline $\begin{array}{l}\text { Is the reference standards likely to correctly classify the target } \\
\text { condition? }\end{array}$ & Yes & & \\
\hline \multirow[t]{2}{*}{$\begin{array}{l}\text { Were the reference standard results interpreted without knowl- } \\
\text { edge of the results of the index tests? }\end{array}$} & Unclear & & \\
\hline & & Unclear & Low \\
\hline \multicolumn{4}{|l|}{ DOMAIN 4: Flow and Timing } \\
\hline Did all patients receive a reference standard? & Yes & & \\
\hline Did all patients receive the same reference standard? & Yes & & \\
\hline Were un-interpretable/intermediate test results reported? & Yes & & \\
\hline \multirow[t]{2}{*}{ Were withdrawals from the study explained? } & No & & \\
\hline & & Low & \\
\hline
\end{tabular}




\section{Study characteristics}

\begin{tabular}{ll}
\hline Patient sampling & Design: Prospective diagnostic test accuracy \\
& Setting: UK \\
Accrual dates: Jan 2000 to Dec 2010 & No participants: 1445 \\
& No assessed: 1439 \\
& Inclusion criteria: Women with possible ovarian malignancy were \\
& included. Women with obvious disseminated malignancy (FIGO \\
& stage III/IV) were excluded. \\
& Included previous histological diagnosis: yes, 6 cases
\end{tabular}

Patient characteristics and setting

Women with possible ovarian malignancy were included. Women with obvious disseminated malignancy (FIGO stage III/IV) were excluded.Tertiary centre, UK.

\section{Index tests}

Two pieces of tissue taken for FS staining and reporting by consultant pathologist. Report was then phoned through to surgeon who used the info to determine the extent of surgery.

\begin{tabular}{ll}
\hline Target condition and reference standard(s) & Malignant or borderline on PS. \\
\hline Flow and timing & FS before PS. \\
\hline Comparative & \\
\hline Notes & $\begin{array}{l}\text { Women with borderline and malignant diagnosis underwent surgi- } \\
\text { cal staging. }\end{array}$
\end{tabular}

\section{Methodological quality}

\begin{tabular}{|c|c|c|c|}
\hline Item & $\begin{array}{l}\text { Authors' judge- } \\
\text { ment }\end{array}$ & Risk of bias & $\begin{array}{l}\text { Applicability con- } \\
\text { cerns }\end{array}$ \\
\hline
\end{tabular}

\section{DOMAIN 1: Patient Selection}

\begin{tabular}{lll}
\hline Was a consecutive or random sample of patients enrolled? & Yes \\
\hline Was a case-control design avoided? & Yes \\
\hline Did the study avoid inappropriate exclusions? & Yes \\
\hline $\begin{array}{l}\text { Was the sample representative of patients in practice (90\% } \\
\text { stage I/II with RMI>200)? }\end{array}$ & Yes \\
\hline
\end{tabular}

\section{DOMAIN 2: Index Test All tests}

Were the index tests interpreted without knowledge of the ref- Yes erence standard?

Were the index tests Interpreted by consultant or specialist gyn- Yes onc pathologist? 
Cross 2012 (Continued)

\section{DOMAIN 3: Reference Standard}

Is the reference standards likely to correctly classify the target Yes condition?

Were the reference standard results interpreted without knowl- Unclear edge of the results of the index tests?

Unclear

Low

\section{DOMAIN 4: Flow and Timing}

\begin{tabular}{ll}
\hline Did all patients receive a reference standard? & Yes \\
\hline Did all patients receive the same reference standard? & Yes \\
\hline Were un-interpretable/intermediate test results reported? & Yes \\
\hline Were withdrawals from the study explained? & Yes \\
\hline
\end{tabular}

Low

\section{Cuello 1999}

\section{Study characteristics}

\section{Patient sampling}

Design: Retrospective

Setting: Chile

Accrual dates: Jan 1988-Oct 1998

No participants: 842

No assessed: 489

Inclusion criteria: Ovarian masses. $2 \times 2$ data available only for epithelial ovarian masses.

Included previous histological diagnosis: unclear

\section{Patient characteristics and setting}

Index tests

Target condition and reference standard(s)

Flow and timing

Comparative

Notes

\section{Methodological quality}

\begin{tabular}{llll}
\hline Item & $\begin{array}{l}\text { Authors'judge- } \\
\text { ment }\end{array}$ & Risk of bias & $\begin{array}{l}\text { Applicability con- } \\
\text { cerns }\end{array}$
\end{tabular}

Intraoperative frozen section analysis for the diagnosis of early stage ovarian cancer in suspicious pelvic masses (Review)

Copyright $\odot 2016$ The Cochrane Collaboration. Published by John Wiley \& Sons, Ltd.
Epithelial ovarian masses. Chile.

Sections were taken every $3-4 \mathrm{~cm}$, measuring 2-3mm. Frozen sections measuring 5 microns were taken.

Malignant or borderline on PS. 2 × 2 data only available for epithelial ovarian masses. 
Cuello 1999 (Continued)

DOMAIN 1: Patient Selection

\begin{tabular}{|c|c|c|c|}
\hline Was a consecutive or random sample of patients enrolled? & Unclear & & \\
\hline Was a case-control design avoided? & Yes & & \\
\hline Did the study avoid inappropriate exclusions? & Unclear & & \\
\hline \multirow{2}{*}{$\begin{array}{l}\text { Was the sample representative of patients in practice }(90 \% \\
\text { stage I/II with RMI>200)? }\end{array}$} & Unclear & & \\
\hline & & Unclear & Low \\
\hline \multicolumn{4}{|l|}{ DOMAIN 2: Index Test All tests } \\
\hline $\begin{array}{l}\text { Were the index tests interpreted without knowledge of the ref- } \\
\text { erence standard? }\end{array}$ & Yes & & \\
\hline \multirow[t]{2}{*}{$\begin{array}{l}\text { Were the index tests Interpreted by consultant or specialist gyn- } \\
\text { onc pathologist? }\end{array}$} & Unclear & & \\
\hline & & Unclear & Low \\
\hline \multicolumn{4}{|l|}{ DOMAIN 3: Reference Standard } \\
\hline $\begin{array}{l}\text { Is the reference standards likely to correctly classify the target } \\
\text { condition? }\end{array}$ & Yes & & \\
\hline \multirow{2}{*}{$\begin{array}{l}\text { Were the reference standard results interpreted without knowl- } \\
\text { edge of the results of the index tests? }\end{array}$} & Unclear & & \\
\hline & & Unclear & Low \\
\hline \multicolumn{4}{|l|}{ DOMAIN 4: Flow and Timing } \\
\hline Did all patients receive a reference standard? & Yes & & \\
\hline Did all patients receive the same reference standard? & Yes & & \\
\hline Were un-interpretable/intermediate test results reported? & Yes & & \\
\hline \multirow[t]{2}{*}{ Were withdrawals from the study explained? } & Yes & & \\
\hline & & Low & \\
\hline
\end{tabular}

Fanfani 2007

\section{Study characteristics}

Patient sampling

Design: Retrospective

Setting: Italy

Accrual dates: Sept 1999 - Nov 2004

No participants: 693

No assessed: 325 inc 14 deferred

Inclusion criteria: Consecutive patients with adnexal mass 
Fanfani 2007 (Continued)

Included previous histological diagnosis: unclear

Patient characteristics and setting

Index tests
Consecutive patients with adnexal mass. Italy.

FS from 1-2 most representative samples (number of slides not spec)

Malignant (primary or secondary) or borderline on PS.

FS before PS.

Flow and timing

Comparative

Notes 14 deferred cases.

\section{Methodological quality}

\begin{tabular}{llll}
\hline Item & $\begin{array}{l}\text { Authors' judge- } \\
\text { ment }\end{array}$ & Risk of bias & $\begin{array}{l}\text { Applicability con- } \\
\text { cerns }\end{array}$ \\
\hline
\end{tabular}

\section{DOMAIN 1: Patient Selection}

\begin{tabular}{lll}
\hline Was a consecutive or random sample of patients enrolled? & Yes \\
\hline Was a case-control design avoided? & Yes & Unclear \\
\hline Did the study avoid inappropriate exclusions? & Unclear & \\
\hline $\begin{array}{l}\text { Was the sample representative of patients in practice }(90 \% \\
\text { stage I/II with RMI>200)? }\end{array}$ & Low Low \\
\hline
\end{tabular}

\section{DOMAIN 2: Index Test All tests}

Were the index tests interpreted without knowledge of the ref- Yes erence standard?

Were the index tests Interpreted by consultant or specialist gyn- Yes onc pathologist?

\begin{tabular}{lll}
\hline & Low & Low \\
\hline DOMAIN 3: Reference Standard & &
\end{tabular}
Is the reference standards likely to correctly classify the target Yes
condition?

Were the reference standard results interpreted without knowl- Unclear edge of the results of the index tests?

\begin{tabular}{ll}
\hline Unclear & Low \\
\hline DOMAIN 4: Flow and Timing & Yes \\
\hline Did all patients receive a reference standard?
\end{tabular}


Fanfani 2007 (Continued)

Did all patients receive the same reference standard?

Were un-interpretable/intermediate test results reported?

Were withdrawals from the study explained?
Yes

Yes

Yes

\section{García 1997}

\section{Study characteristics}

$\begin{array}{ll}\text { Patient sampling } & \text { Design: Retrospective } \\ & \text { Setting: Valencia } \\ & \text { Accrual dates: Jan } 1994 \text { to Oct } 1995 \\ & \text { No participants: } 30 \\ \text { No assessed: } 30 & \text { Inclusion criteria: Women with adnexal mass undergoing FS. } \\ \text { None other given. } & \text { Included previous histological diagnosis: unclear }\end{array}$

Patient characteristics and setting Uncertain setting in Valencia

Index tests $\quad$ FS between 6-7 sections per specimen.

Target condition and reference standard(s) Malignant or borderline on PS.

Flow and timing FS before PS.

\section{Comparative}

Notes

\section{Methodological quality}

\begin{tabular}{llll}
\hline Item & $\begin{array}{l}\text { Authors' judge- } \\
\text { ment }\end{array}$ & Risk of bias & $\begin{array}{l}\text { Applicability con- } \\
\text { cerns }\end{array}$
\end{tabular}

\section{DOMAIN 1: Patient Selection}

\begin{tabular}{lll}
\hline Was a consecutive or random sample of patients enrolled? & Unclear \\
\hline Was a case-control design avoided? & Unclear & Unclear \\
\hline Did the study avoid inappropriate exclusions? & Unclear & \\
\hline $\begin{array}{l}\text { Was the sample representative of patients in practice }(90 \% \\
\text { stage } / / \text { II with RMI>200)? }\end{array}$ & Unclear & Unclear \\
\hline
\end{tabular}

\section{DOMAIN 2: Index Test All tests}


García 1997 (Continued)

Were the index tests interpreted without knowledge of the ref- Yes erence standard?

Were the index tests Interpreted by consultant or specialist gyn- Unclear onc pathologist?

Unclear

Unclear

\section{DOMAIN 3: Reference Standard}

Is the reference standards likely to correctly classify the target Yes condition?

Were the reference standard results interpreted without knowl- Unclear edge of the results of the index tests?

\begin{tabular}{lll}
\hline & & Unclear \\
\hline DOMAIN 4: Flow and Timing & Yes & Low \\
\hline Did all patients receive a reference standard? & Yes & No \\
\hline Did all patients receive the same reference standard? & No & Low \\
\hline Were un-interpretable/intermediate test results reported? & & \\
\hline Were withdrawals from the study explained? &
\end{tabular}

\section{Gorisek 2009}

\section{Study characteristics}

$\begin{array}{ll}\text { Patient sampling } & \text { Design: Retrospective } \\ & \text { Setting: Slovenia } \\ & \text { Accrual dates: } 1 \text { January } 1993 \text { - } 31 \text { December } 2001 \\ & \text { No participants: } 131 \\ & \text { No assessed: } 131 \\ & \text { Inclusion criteria: Women treated for benign, borderline and malig- } \\ & \text { nant ovarian tumours } \\ \text { Included previous histological diagnosis: unclear }\end{array}$

Patient characteristics and setting Women treated for benign, borderline and malignant ovarian tumour. Slovenia.

Index tests

FS "After tumour removal, the fresh surgical specimen was immediately taken to the Department of Pathologic Morphology at the Maribor Teaching Hospital (now the University Clinical Centre Maribor). A pathologist prepared specimens from representative regions, froze them in a cryostat and cut slices with a microtome. The slices were mounted on a glass slide, stained with haematoxylin and eosin, and were then ready for microscopic evaluation." 
Gorisek 2009 (Continued)
Flow and timing
FS before PS.

\section{Comparative}

Notes

\section{Methodological quality}

\begin{tabular}{llll}
\hline Item Authors' judgement & Risk of bias $\begin{array}{l}\text { Applicability con- } \\
\text { cerns }\end{array}$
\end{tabular}

\section{DOMAIN 1: Patient Selection}

\begin{tabular}{ll}
\hline Was a consecutive or random sample of patients enrolled? & Unclear \\
\hline Was a case-control design avoided? & Yes \\
\hline Did the study avoid inappropriate exclusions? & Unclear \\
\hline
\end{tabular}

Was the sample representative of patients in practice $(90 \% \quad$ Unclear stage I/II with RMI>200)?

\section{Unclear}

Unclear

\section{DOMAIN 2: Index Test All tests}

Were the index tests interpreted without knowledge of the Yes reference standard?

Were the index tests Interpreted by consultant or specialist Unclear gyn-onc pathologist?

\begin{tabular}{lll}
\hline DOMAIN 3: Reference Standard & Unclear & Unclear \\
\hline $\begin{array}{l}\text { Is the reference standards likely to correctly classify the tar- } \\
\text { get condition? }\end{array}$ & Yes & Unclear \\
\hline $\begin{array}{l}\text { Were the reference standard results interpreted without } \\
\text { knowledge of the results of the index tests? }\end{array}$ & Unclear \\
\hline DOMAIN 4: Flow and Timing & Yes \\
\hline Did all patients receive a reference standard? & Yes \\
\hline Did all patients receive the same reference standard? & No \\
\hline Were un-interpretable/intermediate test results reported? & Unclear \\
\hline Were withdrawals from the study explained? &
\end{tabular}

\section{Unclear}




\section{Study characteristics}

\begin{tabular}{ll}
\hline Patient sampling & Design: Retrospective \\
& Setting: Chile \\
& Accrual dates: Jan $1987-$ Oct 1992 \\
& No participants: 324 \\
& No assessed: 324 \\
& Inclusion criteria: Women with peristent pelvic masses aged \\
& 9-81years \\
& Included previous histological diagnosis: unclear
\end{tabular}

Patient characteristics and setting

Women with peristent pelvic masses aged 9-81years. Chile.

Index tests

FS. 5 micron sections of tissue $3-4 \mathrm{~cm} \times 2-3 \mathrm{~mm}$ from mass

Target condition and reference standard(s)

Malignant or borderline on PS.

Flow and timing

FS before PS.

Comparative

Notes

Large age group, not certain representtaive of suspicious masses.

\section{Methodological quality}

\begin{tabular}{|c|c|c|c|}
\hline Item & $\begin{array}{l}\text { Authors' judge- } \\
\text { ment }\end{array}$ & Risk of bias & $\begin{array}{l}\text { Applicability con- } \\
\text { cerns }\end{array}$ \\
\hline
\end{tabular}

\section{DOMAIN 1: Patient Selection}

\begin{tabular}{ll}
\hline Was a consecutive or random sample of patients enrolled? & Unclear \\
\hline Was a case-control design avoided? & Yes \\
\hline Did the study avoid inappropriate exclusions? & Unclear \\
\hline
\end{tabular}

Was the sample representative of patients in practice $(90 \% \quad$ No stage $\mathrm{I} / \mathrm{II}$ with $\mathrm{RMI}>200)$ ?

High

High

\section{DOMAIN 2: Index Test All tests}

Were the index tests interpreted without knowledge of the ref- $\quad$ Yes erence standard?

Were the index tests Interpreted by consultant or specialist gyn- Unclear onc pathologist?

\begin{tabular}{l}
\hline Unclear \\
\hline DOMAIN 3: Reference Standard \\
\hline $\begin{array}{l}\text { Is the reference standards likely to correctly classify the target } \quad \text { Yes } \\
\text { condition? }\end{array}$ \\
\hline
\end{tabular}


Hamed 1993 (Continued)

Were the reference standard results interpreted without knowl- Unclear edge of the results of the index tests?

Unclear

Unclear

\section{DOMAIN 4: Flow and Timing}

\begin{tabular}{ll}
\hline Did all patients receive a reference standard? & Yes \\
\hline Did all patients receive the same reference standard? & Yes \\
\hline Were un-interpretable/intermediate test results reported? & Yes \\
\hline Were withdrawals from the study explained? & Yes \\
\hline
\end{tabular}

Low

\section{Ilker 2011}

\section{Study characteristics}

\begin{tabular}{|c|c|}
\hline Patient sampling & $\begin{array}{l}\text { Design: Retrospective } \\
\text { Setting: Turkey } \\
\text { Accrual dates: Jan } 2002 \text { - Dec } 2008 \\
\text { No participants: } 278 \\
\text { No assessed: } 266 \\
\text { Inclusion criteria: Patients undergoing surgery for ovarian mass } \\
\text { where FS performed } \\
\text { Included previous histological diagnosis: unclear }\end{array}$ \\
\hline Patient characteristics and setting & Ovarian mass. Turkey. \\
\hline Index tests & $\begin{array}{l}\text { FS } 2-5(5 \mu \mathrm{m}) \text { slides from suspicious areas, reported by "expert" } \\
\text { pathologist }\end{array}$ \\
\hline Target condition and reference standard(s) & Malignant or borderline on PS. \\
\hline Flow and timing & FS before PS. \\
\hline \multicolumn{2}{|l|}{ Comparative } \\
\hline Notes & 12 deferred cases. \\
\hline \multicolumn{2}{|l|}{ Methodological quality } \\
\hline Item & $\begin{array}{l}\text { Authors' judge- } \quad \text { Risk of bias } \\
\text { ment }\end{array}$ \\
\hline \multicolumn{2}{|l|}{ DOMAIN 1: Patient Selection } \\
\hline Was a consecutive or random sample of patients enrolled? & Unclear \\
\hline Was a case-control design avoided? & Yes \\
\hline
\end{tabular}


Ilker 2011 (Continued)

Did the study avoid inappropriate exclusions?

Unclear

Was the sample representative of patients in practice $(90 \%$ stage $\mathrm{I} / \mathrm{II}$ with $\mathrm{RMI}>200)$ ?

No

High High

\section{DOMAIN 2: Index Test All tests}

Were the index tests interpreted without knowledge of the ref- $\quad$ Yes erence standard?

Were the index tests Interpreted by consultant or specialist gyn- Yes onc pathologist?

\begin{tabular}{lll}
\hline & Low & \\
\hline DOMAIN 3: Reference Standard & & \\
\hline $\begin{array}{l}\text { Is the reference standards likely to correctly classify the target } \\
\text { condition? }\end{array}$ & Yes & Unclear \\
\hline $\begin{array}{l}\text { Were the reference standard results interpreted without knowl- } \\
\text { edge of the results of the index tests? }\end{array}$ & Low \\
\hline \begin{tabular}{ll} 
DOMAIN 4: Flow and Timing \\
\hline Did all patients receive a reference standard?
\end{tabular} & Yes \\
\hline Did all patients receive the same reference standard? & Yes \\
\hline Were un-interpretable/intermediate test results reported? & Yes \\
\hline Were withdrawals from the study explained? & Yes \\
\hline
\end{tabular}

Low

Ilvan 2005

\section{Study characteristics}

\begin{tabular}{ll}
\hline Patient sampling & Design: Retrospective \\
& Setting: Turkey \\
& Accrual dates: Jan 1995 to Dec 2003 \\
& No participants: 617 \\
& No assessed: 617 \\
& Inclusion criteria: Ovarian masses sent for FS. No exclusions given. \\
& Included grossly benign tumours (22 endometriotic, 3 follicles, 12 \\
& mature teratomas, 9 benign serous cytsadneomas). \\
& Included previous histological diagnosis: unclear \\
\hline Patient characteristics and setting & Pelvic masses in women referred to a tertiary centre. Grossly benign \\
& specimens submitted in 46 cases.
\end{tabular}


Ilvan 2005 (Continued)

Index tests

Target condition and reference standard(s)

Flow and timing

\section{Comparative}

\section{Notes}

FS. Gross examination, touch imprints, sections (between 1 and 4) of ovary. 2 pathologisst in gyn oncology.

Malignant and borderline disease. PS. 2 pathologists experienced in gynaecological pathology interpreted FS. Pathologists also employed touch imprint technique.

Some FS diagnosis (7.5\%) made on gross inspection only FS before PS.

46 grossly benign masses including 22 endometriotic cyst, 3 follicles, 12 mature teratomas, 9 benign serous cystadenomas

\section{Methodological quality}

\begin{tabular}{llll}
\hline Item Authors' judgement & Risk of bias & $\begin{array}{l}\text { Applicability con- } \\
\text { cerns }\end{array}$
\end{tabular}

\section{DOMAIN 1: Patient Selection}

\begin{tabular}{lll}
\hline Was a consecutive or random sample of patients enrolled? & Unclear \\
\hline Was a case-control design avoided? & Yes & Unclear \\
\hline Did the study avoid inappropriate exclusions? & Unclear & Unclear \\
\hline $\begin{array}{l}\text { Was the sample representative of patients in practice }(90 \% \\
\text { stage I/II with RMI>200)? }\end{array}$ & & High
\end{tabular}

\section{DOMAIN 2: Index Test All tests}

Were the index tests interpreted without knowledge of the Yes reference standard?

Were the index tests Interpreted by consultant or specialist Yes gyn-onc pathologist?

Low High

\section{DOMAIN 3: Reference Standard}

Is the reference standards likely to correctly classify the tar- Yes get condition?

Were the reference standard results interpreted without Unclear knowledge of the results of the index tests?

\begin{tabular}{lcc}
\hline & Unclear & Low \\
\hline DOMAIN 4: Flow and Timing & & \\
\hline Did all patients receive a reference standard? & Yes & \\
\hline
\end{tabular}


Ilvan 2005 (Continued)

Did all patients receive the same reference standard?

Yes

Were un-interpretable/intermediate test results reported? No

Were withdrawals from the study explained? Unclear

\section{Kokka 2009}

\section{Study characteristics}

\begin{tabular}{ll} 
Patient sampling & $\begin{array}{l}\text { Design: Retrospective } \\
\text { Setting: UK } \\
\text { Accrual dates: Oct 2006 - May 2008 } \\
\text { No participants: } 61 \\
\text { No assessed: } 50 \\
\text { Inclusion criteria: } \\
\text { Included previous histological diagnosis: unclear }\end{array}$ \\
\hline Patient characteristics and setting & Unclear inclusion criteria. \\
\hline Index tests & FS. No details given. \\
\hline Target condition and reference standard(s) & Malignant or borderline on PS. \\
\hline Flow and timing & FS before PS. \\
\hline Comparative & \\
\hline Notes & $\begin{array}{l}\text { FS was considered in } 71 \text { patients; ten cases were excluded be- } \\
\text { cause of valid reasons; in } 11 \text { of } 31 \text { benign tumours FS was not re- } \\
\text { quested by the surgeon }\end{array}$
\end{tabular}

\section{Methodological quality}

\begin{tabular}{llll}
\hline Item & $\begin{array}{l}\text { Authors' judge- } \\
\text { ment }\end{array}$ & Risk of bias & $\begin{array}{l}\text { Applicability con- } \\
\text { cerns }\end{array}$
\end{tabular}

\section{DOMAIN 1: Patient Selection}

\begin{tabular}{lll}
\hline Was a consecutive or random sample of patients enrolled? & Yes \\
\hline Was a case-control design avoided? & Yes & Unclear \\
\hline Did the study avoid inappropriate exclusions? & Unclear & \\
\hline $\begin{array}{l}\text { Was the sample representative of patients in practice }(90 \% \\
\text { stage I/II with RMI>200)? }\end{array}$ & Low Low \\
\hline
\end{tabular}

\section{DOMAIN 2: Index Test All tests}


Kokka 2009 (Continued)

Were the index tests interpreted without knowledge of the ref- Yes erence standard?

Were the index tests Interpreted by consultant or specialist gyn- Unclear onc pathologist?

\section{Unclear}

Low

\section{DOMAIN 3: Reference Standard}

Is the reference standards likely to correctly classify the target Yes condition?

Were the reference standard results interpreted without knowl- Unclear edge of the results of the index tests?

\begin{tabular}{lll}
\hline & & Unclear \\
\hline DOMAIN 4: Flow and Timing & Yes \\
\hline Did all patients receive a reference standard? & Yes \\
\hline Did all patients receive the same reference standard? & Yes \\
\hline Were un-interpretable/intermediate test results reported? & Yes \\
\hline Were withdrawals from the study explained? & & Low \\
\hline
\end{tabular}

\section{Lim 1997}

\section{Study characteristics}

$\begin{array}{ll}\text { Patient sampling } & \text { Design: Retrospective } \\ & \text { Setting: Singapore } \\ \text { Accrual dates: Jan } 1988 \text { to Dec } 1994 & \text { No participants: } 173 \\ \text { No assessed: } 171 & \text { Inclusion criteria: Women with ovarian tumours and laparotomy and } \\ & \text { FS. No other inclusion details. } \\ \text { Included previous histological diagnosis: unclear }\end{array}$

Patient characteristics and setting

University hospital, Singapore. Pelvic masses. Uncertain if previous diagnosis cancer. Majority of cases benign. Authors describe liberal use of frozen section in their hospital, even if mass thought to be benign

Index tests

FS. If discordant, pathologist reassessed if sampling or interpretational error.

\section{Target condition and reference standard(s)}

\section{Malignant or borderline on PS}

FS before PS. Ultrasound features correlated to final outcome 


\section{Lim 1997 (Continued)}

Comparative

$$
\text { Notes }
$$

2 cases FS diagnosis deferred and not included in analysis. Both were interpretational errors. When accuracy of FS was reassessed for cases where FS was clinically indicated, accuracy was 95.5\% (105 out of

110) for benign, borderline or malignant.

\begin{tabular}{llll}
\hline Methodological quality & & \\
\hline Item & Authors' judgement & Risk of bias & $\begin{array}{l}\text { Applicability con- } \\
\text { cerns }\end{array}$ \\
\hline
\end{tabular}

\section{DOMAIN 1: Patient Selection}

\begin{tabular}{ll}
\hline Was a consecutive or random sample of patients enrolled? & Unclear \\
\hline Was a case-control design avoided? & Unclear \\
\hline Did the study avoid inappropriate exclusions? & Unclear \\
\hline
\end{tabular}

Was the sample representative of patients in practice $(90 \% \quad$ No stage I/II with RMI>200)?

Unclear High

\section{DOMAIN 2: Index Test All tests}

Were the index tests interpreted without knowledge of the Yes reference standard?

Were the index tests Interpreted by consultant or specialist Yes gyn-onc pathologist?

\begin{tabular}{ll}
\hline & Low \\
\hline DOMAIN 3: Reference Standard & Unclear \\
\hline $\begin{array}{l}\text { Is the reference standards likely to correctly classify the tar- } \\
\text { get condition? }\end{array}$ & Yes Unclear \\
\hline $\begin{array}{l}\text { Were the reference standard results interpreted without } \\
\text { knowledge of the results of the index tests? }\end{array}$ & Low \\
\hline DomAIN 4: Flow and Timing & Yes \\
\hline Did all patients receive a reference standard? & Yes \\
\hline Did all patients receive the same reference standard? & Yes \\
\hline Were un-interpretable/intermediate test results reported? & Yes \\
\hline Were withdrawals from the study explained? &
\end{tabular}


Maheshwari 2006

\section{Study characteristics}

\begin{tabular}{ll}
\hline Patient sampling & Design: Retrospective \\
Setting: India & Accrual dates: $1997-2001$ \\
No participants: 241 & No assessed: 210 \\
Inclusion criteria: Excluded non-ovarian FS and deferred FS. & Included previous histological diagnosis: unclear, included cases \\
& with previous cancer at another site
\end{tabular}

Patient characteristics and setting

Unclear inclusion criteria. India.

Index tests

Target condition and reference standard(s)

Flow and timing

Comparative
FS. 1-4 sections at 7-8micrometer intervals.

Malignant or borderline on PS.

FS before PS.

Included 'clinically benign tumours with raised CA125'

\section{Methodological quality}

\begin{tabular}{|c|c|c|c|}
\hline Item & $\begin{array}{l}\text { Authors' judge- } \\
\text { ment }\end{array}$ & Risk of bias & $\begin{array}{l}\text { Applicability con- } \\
\text { cerns }\end{array}$ \\
\hline
\end{tabular}

\section{DOMAIN 1: Patient Selection}

\begin{tabular}{lll}
\hline Was a consecutive or random sample of patients enrolled? & Unclear \\
\hline Was a case-control design avoided? & Yes & Unclear \\
\hline Did the study avoid inappropriate exclusions? & Unclear & \\
\hline $\begin{array}{l}\text { Was the sample representative of patients in practice }(90 \% \\
\text { stage l/II with RMI>200)? }\end{array}$ & Unclear \\
\hline
\end{tabular}

\section{DOMAIN 2: Index Test All tests}

Were the index tests interpreted without knowledge of the ref- Yes erence standard?

Were the index tests Interpreted by consultant or specialist gyn- Unclear onc pathologist?

\begin{tabular}{l}
\hline Unclear \\
\hline DOMAIN 3: Reference Standard \\
\hline $\begin{array}{l}\text { Is the reference standards likely to correctly classify the target } \quad \text { Yes } \\
\text { condition? }\end{array}$ \\
\hline
\end{tabular}




\section{Maheshwari 2006 (Continued)}

Were the reference standard results interpreted without knowl- Unclear edge of the results of the index tests?

Unclear

Low

\section{DOMAIN 4: Flow and Timing}

\begin{tabular}{ll}
\hline Did all patients receive a reference standard? & Yes \\
\hline Did all patients receive the same reference standard? & Yes \\
\hline Were un-interpretable/intermediate test results reported? & Yes \\
\hline Were withdrawals from the study explained? & Yes
\end{tabular}

Low

\section{Malipatil 2013}

\section{Study characteristics}

$\begin{array}{ll}\text { Patient sampling } & \text { Design: Retrospective } \\ & \text { Setting: India } \\ & \text { Accrual dates: } 1999-2008 \\ & \text { No participants: } 223 \\ & \text { No assessed: } 218 \\ \text { Inclusion criteria: } 5 \text { exclusions - FS diagnosis deferred due to ex- } & \text { tensive necrosis / haemorrhage } \\ \text { Included previous histological diagnosis: unclear }\end{array}$

\section{Patient characteristics and setting}

Index tests

Target condition and reference standard(s)

Flow and timing

Comparative

Notes

\section{Unclear inclusion criteria. India.}

FS. At least 2 general surgical pathologists reporting FS. Mean number of FS 2 (1-5) and PS 7 (1-33)
Malignant or borderline on PS.

FS before PS.

377 referrals for diagnosis; intraoperative diagnosis sought in 233 (apparently 223?) cases; diagnosis deferred in five cases due to extensive areas of haemorrhage and necrosis and was excluded from further analysis; 218 cases analysed.

\section{Methodological quality}

\begin{tabular}{llll}
\hline Item & $\begin{array}{l}\text { Authors' judge- } \\
\text { ment }\end{array}$ & Risk of bias & $\begin{array}{l}\text { Applicability con- } \\
\text { cerns }\end{array}$ \\
\hline
\end{tabular}

\section{DOMAIN 1: Patient Selection}

Was a consecutive or random sample of patients enrolled?

Unclear 
Malipatil 2013 (Continued)

Was a case-control design avoided?

\begin{tabular}{ll}
\hline Did the study avoid inappropriate exclusions? & Unclear \\
\hline $\begin{array}{l}\text { Was the sample representative of patients in practice }(90 \% \\
\text { stage } 1 / \text { II with RMI>200)? }\end{array}$ & Unclear
\end{tabular}

stage I/II with RMI>200)?

Unclear

Unclear

\section{DOMAIN 2: Index Test All tests}

Were the index tests interpreted without knowledge of the ref- Yes erence standard?

Were the index tests Interpreted by consultant or specialist gyn- Yes onc pathologist?

\begin{tabular}{lll}
\hline Low & Low \\
\hline
\end{tabular}

\section{DOMAIN 3: Reference Standard}

Is the reference standards likely to correctly classify the target Yes condition?

Were the reference standard results interpreted without knowl- Unclear edge of the results of the index tests?

\begin{tabular}{lll}
\hline DOMAIN 4: Flow and Timing & Unclear & Low \\
\hline Did all patients receive a reference standard? & Yes & Yes \\
\hline Did all patients receive the same reference standard? & Yes \\
\hline Were un-interpretable/intermediate test results reported? & Yes \\
\hline Were withdrawals from the study explained? & & Low \\
\hline
\end{tabular}

\section{Naik 2006}

\section{Study characteristics}

$\begin{array}{ll}\text { Patient sampling } & \text { Design: Retrospective } \\ & \text { Setting: UK } \\ & \text { Accrual dates: July } 2002 \text { to June } 2003 \\ & \text { No participants: } 130 \\ & \text { No assessed: } 130 \text { inc. } 1 \text { deferred } \\ \text { Inclusion criteria: Suspicious pelvic masses } \\ \text { Included previous histological diagnosis: yes }\end{array}$


Naik 2006 (Continued)

\begin{tabular}{lll} 
Index tests & FS. No details given. \\
\hline Target condition and reference standard(s) & Malignant or borderline on PS. \\
\hline Flow and timing & FS before PS. \\
\hline Comparative & 1 deferred was benign. \\
\hline Notes & & Risk of bias \\
\hline Methodological quality & $\begin{array}{l}\text { Authors' judge- } \\
\text { ment }\end{array}$ & cerns
\end{tabular}

DOMAIN 1: Patient Selection

\begin{tabular}{lll}
\hline Was a consecutive or random sample of patients enrolled? & Yes \\
\hline Was a case-control design avoided? & Yes \\
\hline Did the study avoid inappropriate exclusions? & Yes \\
\hline $\begin{array}{l}\text { Was the sample representative of patients in practice }(90 \% \\
\text { stage I/II with RMI>200)? }\end{array}$ & Yes & Low \\
\hline
\end{tabular}

\section{DOMAIN 2: Index Test All tests}

Were the index tests interpreted without knowledge of the ref- Yes erence standard?

Were the index tests Interpreted by consultant or specialist gyn- Unclear onc pathologist?

\begin{tabular}{lcc}
\hline & Unclear & Low \\
\hline DOMAIN 3: Reference Standard &
\end{tabular}

\section{DOMAIN 3: Reference Standard}

Is the reference standards likely to correctly classify the target Yes condition?

Were the reference standard results interpreted without knowl- Yes edge of the results of the index tests?

\begin{tabular}{lll}
\hline DOMAIN 4: Flow and Timing & Unclear & Low \\
\hline Did all patients receive a reference standard? & Yes & Yes \\
\hline Did all patients receive the same reference standard? & Yes \\
\hline Were un-interpretable/intermediate test results reported? &
\end{tabular}


Naik 2006 (Continued)

\section{Pavlakis 2009}

\section{Study characteristics}

$\begin{array}{ll}\text { Patient sampling } & \text { Design: Retrospective } \\ & \text { Setting: Greece } \\ & \text { Accrual dates: Jan } 2000 \text { to Oct } 2006 \\ & \text { No participants: } 932 \\ & \text { No assessed: } 932 \\ & \text { Inclusion criteria: Ovarian or related masses submitted for FS. No } \\ & \text { other details given. } \\ \text { Included previous histological diagnosis: unclear }\end{array}$

Patient characteristics and setting

FS received from various centres. Uncertain if suspicious of malignancy when submitted. Ovarian and related masses sent. 594 of 932 specimens benign on PS.

Index tests

FS. 1 to 3 sections per ovarian or related mass. Examined by gynaecological pathologist.

\section{Target condition and reference standard(s)}

Flow and timing
Malignant or borderline on PS.

FS before PS.

\section{Comparative}

Notes

Uncertain if only suspicious ovarian masses included. Risk of selection bias. Also, only epithelial tumours reported in $3 \times 3$ table

\section{Methodological quality}

\begin{tabular}{llll}
\hline Item & $\begin{array}{l}\text { Authors' judge- } \\
\text { ment }\end{array}$ & Risk of bias & $\begin{array}{l}\text { Applicability con- } \\
\text { cerns }\end{array}$
\end{tabular}

\section{DOMAIN 1: Patient Selection}

\begin{tabular}{lll}
\hline Was a consecutive or random sample of patients enrolled? & Unclear \\
\hline Was a case-control design avoided? & Unclear & Unclear \\
\hline Did the study avoid inappropriate exclusions? & Unclear & High \\
\hline $\begin{array}{l}\text { Was the sample representative of patients in practice }(90 \% \\
\text { stage I/II with RMI>200)? }\end{array}$ & Unclear \\
\hline
\end{tabular}

\section{DOMAIN 2: Index Test All tests}

Were the index tests interpreted without knowledge of the ref- Yes erence standard? 
Pavlakis 2009 (Continued)

Were the index tests Interpreted by consultant or specialist gyn- Yes onc pathologist?

Unclear

Unclear

\section{DOMAIN 3: Reference Standard}

Is the reference standards likely to correctly classify the target Yes condition?

Were the reference standard results interpreted without knowl- Unclear edge of the results of the index tests?

Unclear

Unclear

\section{DOMAIN 4: Flow and Timing}

\begin{tabular}{ll}
\hline Did all patients receive a reference standard? & Yes \\
\hline Did all patients receive the same reference standard? & Yes \\
\hline Were un-interpretable/intermediate test results reported? & No \\
\hline Were withdrawals from the study explained? & No \\
\hline
\end{tabular}

\section{Pinto 2001}

\section{Study characteristics}

\begin{tabular}{ll}
\hline Patient sampling & $\begin{array}{l}\text { Design: Retrospective } \\
\text { Setting: Brazil } \\
\text { Accrual dates: jan } 1994 \text { to April } 1999 \\
\text { No participants: } 243 \\
\text { No assessed: } 243 \\
\text { Inclusion criteria: Ovarian tumours. No other details given. } \\
\text { Included previous histological diagnosis: unclear }\end{array}$ \\
\hline Patient characteristics and setting & $\begin{array}{l}\text { Pathology laboratory in Brazil. Uncertain if tertiary referral centre } \\
\text { for gynaecological malignancies }\end{array}$ \\
\hline Index tests & $\begin{array}{l}\text { FS. 1 to 3 sections per specimen reporrted by general pathologist. } \\
\text { All slides reviewed by specialist gynaecological pathologist. }\end{array}$ \\
\hline Target condition and reference standard(s) & Malignant or borderline on PS. Histological type noted. \\
\hline Flow and timing & FS before PS. \\
\hline Comparative & \\
\hline Notes & All slides (FS and PS) checked by a specialist gynaecological \\
& pathologist
\end{tabular}

\section{Methodological quality}

Intraoperative frozen section analysis for the diagnosis of early stage ovarian cancer in suspicious pelvic masses (Review) 
Pinto 2001 (Continued)

$\begin{array}{llll}\text { Item } & \begin{array}{l}\text { Authors' judge- } \\ \text { ment }\end{array} & \text { Risk of bias } & \begin{array}{l}\text { Applicability con- } \\ \text { cerns }\end{array}\end{array}$

DOMAIN 1: Patient Selection

\begin{tabular}{ll}
\hline Was a consecutive or random sample of patients enrolled? & Unclear \\
\hline Was a case-control design avoided? & Unclear \\
\hline Did the study avoid inappropriate exclusions? & Unclear \\
\hline $\begin{array}{l}\text { Was the sample representative of patients in practice }(90 \% \\
\text { stage } \mathrm{I} / \text { II with RMI>200)? }\end{array}$ & Unclear
\end{tabular}

\section{DOMAIN 2: Index Test All tests}

Were the index tests interpreted without knowledge of the ref- Yes erence standard?

Were the index tests Interpreted by consultant or specialist gyn- Yes onc pathologist?

\begin{tabular}{lll}
\hline & Unclear & Unclear \\
\hline DOMAIN 3: Reference Standard & Yes & Low \\
\hline $\begin{array}{l}\text { Is the reference standards likely to correctly classify the target } \\
\text { Condition? }\end{array}$ & Unclear \\
\hline $\begin{array}{l}\text { Were the reference standard results interpreted without knowl- } \\
\text { edge of the results of the index tests? }\end{array}$ & Yes \\
\hline DOMAIN 4: Flow and Timing & Yes \\
\hline Did all patients receive a reference standard? & No \\
\hline Did all patients receive the same reference standard? & No \\
\hline Were un-interpretable/intermediate test results reported? & Low \\
\hline Were withdrawals from the study explained? & \\
\hline
\end{tabular}

\section{Puls 1997}

\section{Study characteristics}

\begin{tabular}{ll}
\hline Patient sampling & Design: Retrospective \\
& Setting: South Carolina \\
& Accrual dates: 12 years
\end{tabular}


Puls 1997 (Continued)

\begin{tabular}{|c|c|}
\hline & $\begin{array}{l}\text { No participants: } 294 \\
\text { No assessed: } 294 \\
\text { Inclusion criteria: Included all women with both FS and PS analy- } \\
\text { sis of ovarian tumour (serous or mucinous). } \\
\text { Included previous histological diagnosis: } \mathrm{nr}\end{array}$ \\
\hline Patient characteristics and setting & Ovarian tumour. Preoperative diagnosis unclear. South Carolina. \\
\hline Index tests & $\begin{array}{l}\text { FS. One section per centimetre of wall. In most cases, same } \\
\text { pathologist repotrted FS and PS. Pool of } 8 \text { pathologists reporting, } \\
\text { expertise not given. }\end{array}$ \\
\hline Target condition and reference standard(s) & $\begin{array}{l}\text { Malignant and borderline serous and mucinous ovarian tumours } \\
\text { on PS }\end{array}$ \\
\hline \multicolumn{2}{|l|}{ Comparative } \\
\hline Notes & $\begin{array}{l}\text { Of } 632 \text { operations, } 294 \text { were selected for having both FS and PS. } \\
\text { Inconclusive FS is likely to have been excluded }\end{array}$ \\
\hline \multicolumn{2}{|l|}{ Methodological quality } \\
\hline Item & $\begin{array}{lll}\text { Authors' judge- } & \text { Risk of bias } & \text { Applicability con- } \\
\text { ment } & & \text { cerns }\end{array}$ \\
\hline \multicolumn{2}{|l|}{ DOMAIN 1: Patient Selection } \\
\hline Was a case-control design avoided? & Yes \\
\hline Did the study avoid inappropriate exclusions? & Unclear \\
\hline \multirow[t]{2}{*}{$\begin{array}{l}\text { Was the sample representative of patients in practice }(90 \% \\
\text { stage I/II with RMI>200)? }\end{array}$} & Unclear \\
\hline & Low \\
\hline
\end{tabular}

DOMAIN 2: Index Test All tests

Were the index tests interpreted without knowledge of the ref- No erence standard?

Were the index tests Interpreted by consultant or specialist gyn- Unclear onc pathologist?

\section{DOMAIN 3: Reference Standard}

Is the reference standards likely to correctly classify the target Yes condition?

Were the reference standard results interpreted without knowl- No edge of the results of the index tests? 
Puls 1997 (Continued)

High

Low

\section{DOMAIN 4: Flow and Timing}

\begin{tabular}{ll}
\hline Did all patients receive a reference standard? & Yes \\
\hline Did all patients receive the same reference standard? & Yes \\
\hline Were un-interpretable/intermediate test results reported? & No \\
\hline Were withdrawals from the study explained? & Yes \\
\hline
\end{tabular}

Low

Rakhshan 2009

\section{Study characteristics}

\begin{tabular}{|c|c|}
\hline Patient sampling & $\begin{array}{l}\text { Design: Retrospective } \\
\text { Setting: Iran } \\
\text { Accrual dates: March } 1994 \text { - May } 2008 \\
\text { No participants: } 282 \\
\text { No assessed: } 282 \\
\text { Inclusion criteria: Ovarian masses submitted for frozen section } \\
\text { Included previous histological diagnosis: unclear }\end{array}$ \\
\hline Patient characteristics and setting & Ovarian masses. Iran. \\
\hline Index tests & $\begin{array}{l}\text { FS. } 1-5(5 \mu \mathrm{m}) \text { sections interpreted by } 1 \text { of } 5 \text { attending gener- } \\
\text { al pathologists. All FS specimens reviewed by specialist gynae } \\
\text { pathologists for study. }\end{array}$ \\
\hline Target condition and reference standard(s) & Malignant or borderline on PS. \\
\hline Flow and timing & FS before PS. \\
\hline \multicolumn{2}{|l|}{ Comparative } \\
\hline Notes & No deferred cases. Large proportion of cases benign. \\
\hline \multicolumn{2}{|l|}{ Methodological quality } \\
\hline Item & $\begin{array}{lll}\begin{array}{l}\text { Authors' judge- } \\
\text { ment }\end{array} & \text { Risk of bias } & \begin{array}{l}\text { Applicability con- } \\
\text { cerns }\end{array}\end{array}$ \\
\hline \multicolumn{2}{|l|}{ DOMAIN 1: Patient Selection } \\
\hline Was a consecutive or random sample of patients enrolled? & Unclear \\
\hline Was a case-control design avoided? & Yes \\
\hline Did the study avoid inappropriate exclusions? & Unclear \\
\hline
\end{tabular}


Rakhshan 2009 (Continued)

Was the sample representative of patients in practice $(90 \% \quad$ Unclear stage I/II with RMI>200)?

Unclear

Unclear

\section{DOMAIN 2: Index Test All tests}

Were the index tests interpreted without knowledge of the ref- Yes erence standard?

Were the index tests Interpreted by consultant or specialist gyn- Yes onc pathologist?

\begin{tabular}{lcl}
\hline & Low & Low \\
\hline DOMAIN 3: Reference Standard &
\end{tabular}

\section{DOMAIN 3: Reference Standard}

Is the reference standards likely to correctly classify the target Yes condition?

Were the reference standard results interpreted without knowl- Unclear edge of the results of the index tests?

\begin{tabular}{lll}
\hline DOMAIN 4: Flow and Timing & Unclear & Low \\
\hline Did all patients receive a reference standard? & Yes & Yes \\
\hline Did all patients receive the same reference standard? & Yes \\
\hline Were un-interpretable/intermediate test results reported? & Yes \\
\hline Were withdrawals from the study explained? & & Low \\
\hline
\end{tabular}

\section{Rose 1994}

\section{Study characteristics}

$\begin{array}{ll}\text { Patient sampling } & \text { Design: Retrospective } \\ & \text { Setting: USA } \\ & \text { Accrual dates: June1983-1993 } \\ & \text { No participants: } 383 \\ & \text { No assessed: } 383 \\ \text { Inclusion criteria: None given } & \text { Included previous histological diagnosis: unclear }\end{array}$

\begin{tabular}{ll}
\hline Patient characteristics and setting & Unclear inclusion criteria. USA. \\
\hline Index tests & FS. 0-4 sections at 2-3mm intervals \\
\hline Target condition and reference standard(s) & Malignant or borderline on PS. \\
\hline
\end{tabular}


Rose 1994 (Continued)

Flow and timing

FS before PS.

\section{Comparative}

Notes

\section{Methodological quality}

\begin{tabular}{llll}
\hline Item & $\begin{array}{l}\text { Authors' judge- } \\
\text { ment }\end{array}$ & Risk of bias & $\begin{array}{l}\text { Applicability con- } \\
\text { cerns }\end{array}$
\end{tabular}

\section{DOMAIN 1: Patient Selection}

\begin{tabular}{ll}
\hline Was a consecutive or random sample of patients enrolled? & Unclear \\
\hline Was a case-control design avoided? & Yes \\
\hline Did the study avoid inappropriate exclusions? & Unclear \\
\hline $\begin{array}{l}\text { Was the sample representative of patients in practice }(90 \% \\
\text { stage } / / \text { II with RMI>200)? }\end{array}$ & Unclear \\
\hline
\end{tabular}

\begin{tabular}{lll}
\hline & Unclear & Unclear \\
\hline DOMAIN 2: Index Test All tests & & \\
\hline
\end{tabular}

Were the index tests interpreted without knowledge of the ref- Yes erence standard?

Were the index tests Interpreted by consultant or specialist gyn- Unclear onc pathologist?

\begin{tabular}{lll}
\hline & Unclear & Unclear \\
\hline DOMAIN 3: Reference Standard & & \\
\hline $\begin{array}{l}\text { Is the reference standards likely to correctly classify the target } \\
\text { Condition? }\end{array}$ & Yes Unclear \\
\hline $\begin{array}{l}\text { Were the reference standard results interpreted without knowl- } \\
\text { edge of the results of the index tests? }\end{array}$ & Low \\
\hline DomAIN 4: Flow and Timing & Yes \\
\hline Did all patients receive a reference standard? & Yes \\
\hline Did all patients receive the same reference standard? & No \\
\hline Were un-interpretable/intermediate test results reported? & No \\
\hline Were withdrawals from the study explained? & Low \\
\hline
\end{tabular}


Stewart 2006

\section{Study characteristics}

\begin{tabular}{|c|c|}
\hline Patient sampling & $\begin{array}{l}\text { Design: retrospective } \\
\text { Setting: tertiary hospital, Australia } \\
\text { Accrual dates: Jan } 1999 \text { to Dec } 2003 \\
\text { No participants: } 914 \\
\text { No assessed: } 914 \\
\text { Inclusion criteria: FS of omentum and lymph node included. } \\
\text { Included previous histological diagnosis: NR }\end{array}$ \\
\hline Patient characteristics and setting & $\begin{array}{l}\text { Tertiary centre pelvic masses. FS of omentum and lymph node in- } \\
\text { cluded. }\end{array}$ \\
\hline Index tests & $\begin{array}{l}\text { FS of omentum and lymph node included. Pathologhists in gener- } \\
\text { al surgery and gyn oncology employed. }\end{array}$ \\
\hline Target condition and reference standard(s) & Malignant or borderline on PS. \\
\hline Flow and timing & FS before PS. \\
\hline \multicolumn{2}{|l|}{ Comparative } \\
\hline Notes & Good study with useful $2 \times 2$ table \\
\hline \multicolumn{2}{|l|}{ Methodological quality } \\
\hline Item & $\begin{array}{l}\text { Applicability con- } \\
\text { cerns }\end{array}$ \\
\hline
\end{tabular}

\section{DOMAIN 1: Patient Selection}

\begin{tabular}{lll}
\hline Was a consecutive or random sample of patients enrolled? & Yes \\
\hline Was a case-control design avoided? & Yes & Yes \\
\hline Did the study avoid inappropriate exclusions? & Unclear & Low \\
\hline $\begin{array}{l}\text { Was the sample representative of patients in practice (90\% } \\
\text { stage I/Il with RMI>200)? }\end{array}$ & \\
\hline $\begin{array}{l}\text { DomAIN 2: Index Test All tests } \\
\text { Were the index tests interpreted without knowledge of the ref- }\end{array}$ & Yes \\
\hline erence standard? & \\
\hline $\begin{array}{l}\text { Were the index tests Interpreted by consultant or specialist gyn- } \\
\text { onc pathologist? }\end{array}$ & Yes \\
\hline
\end{tabular}

DOMAIN 3: Reference Standard 
Stewart 2006 (Continued) Is the reference standards likely to correctly classify the target Yes
condition?

Were the reference standard results interpreted without knowl- Unclear edge of the results of the index tests?

\begin{tabular}{ll}
\hline DOMAIN 4: Flow and Timing & Low \\
\hline Did all patients receive a reference standard? & Yes \\
\hline Did all patients receive the same reference standard? & Yes \\
\hline Were un-interpretable/intermediate test results reported? & No \\
\hline Were withdrawals from the study explained? & Yes \\
\hline
\end{tabular}

Low

\section{Subbian 2013}

\section{Study characteristics}

\begin{tabular}{ll}
\hline Patient sampling & Design: Retrospective \\
Setting: India & Accrual dates: March 2004 - January 2006 \\
& No participants: 135 \\
& No assessed: 117 \\
Inclusion criteria: Retrospective analysis of reports of frozen section and paraf- & fin block diagnoses of patients undergoing surgery as primary line of therapy for \\
suspected ovarian neoplasms \\
Included previous histological diagnosis: unclear
\end{tabular}

Patient characteristics and setting

Index tests
Suspected ovarian neoplasms, India.

FS. "All the frozen section diagnoses were made by a team of expert on$\mathrm{co}$-pathologists at the institute. Before sectioning, gross examination of the tumor was carried out and frozen section samples were taken from solid or suspicious areas. The number of bits sampled varied from one to three (average of two). The frozen section and the permanent section reports of each patient were compared. The frozen section results were divided into the following groups: Deferred, benign, borderline and malignant. Reports mentioned as 'suggestive of ', 'suspicious of ' or 'compatible with' were included in the diagnoses mentioned."
Target condition and reference standard(s)

Flow and timing

Malignant or borderline on PS.

FS before PS.

\section{Comparative}

\section{Notes}

Retrospective selection based on having had FS and PS . Deferred cases: 8/135 (5.9\%). Ten patients diagnosed with non-neoplastic conditions were also excluded. 
Subbian 2013 (Continued)

Methodological quality

\begin{tabular}{llll}
\hline Item & Authors' judgement & Risk of bias & Applicability concerns \\
\hline
\end{tabular}

DOMAIN 1: Patient Selection

Was a consecutive or random sample of patients Unclear
enrolled?
enrolled?

\begin{tabular}{lll}
\hline Was a case-control design avoided? & Yes \\
\hline Did the study avoid inappropriate exclusions? & Unclear & \\
\hline $\begin{array}{l}\text { Was the sample representative of patients in } \\
\text { practice }(90 \% \text { stage } / / \text { II with RMI>200)? }\end{array}$ & Unclear & Low \\
\hline
\end{tabular}

\section{DOMAIN 2: Index Test All tests}

Were the index tests interpreted without knowl- Yes edge of the reference standard?

Were the index tests Interpreted by consultant or Yes specialist gyn-onc pathologist?

\begin{tabular}{lll}
\hline & Low Low & Low \\
\hline DOMAIN 3: Reference Standard &
\end{tabular}

Is the reference standards likely to correctly clas- Yes

sify the target condition?

Were the reference standard results interpret- Unclear

ed without knowledge of the results of the index

tests?

\begin{tabular}{lll}
\hline DOMAIN 4: Flow and Timing & Unclear & Low \\
\hline Did all patients receive a reference standard? & Yes & \\
\hline $\begin{array}{l}\text { Did all patients receive the same reference stan- } \\
\text { dard? }\end{array}$ & Yes \\
\hline $\begin{array}{l}\text { Were un-interpretable/intermediate test results } \\
\text { reported? }\end{array}$ & No & Unclear \\
\hline Were withdrawals from the study explained? & Yes & \\
\hline
\end{tabular}




\section{Sukumaran 2014}

\section{Study characteristics}

$\begin{array}{ll}\text { Patient sampling } & \text { Design: Retrospective } \\ \text { Setting: India } & \text { Accrual dates: 2009-2012 } \\ \text { No participants: } 237 \\ \text { No assessed: } 233 \text { (4 deferred) } \\ \text { Inclusion criteria: Excluded torsion } \\ \text { Included previous histological diagnosis: unclear }\end{array}$

Patient characteristics and setting

Torted pelvoic masses excluded. India.

Index tests

Target condition and reference standard(s)

Flow and timing

Comparative

\begin{tabular}{lll}
\hline Notes & 4 deferred on FS. \\
\hline Methodological quality & $\begin{array}{l}\text { Risk of bias } \\
\text { Item }\end{array}$ & $\begin{array}{l}\text { Applicability con- } \\
\text { cerns }\end{array}$ \\
\hline DOMAIN 1: Patient Selection & Unclear & \\
\hline Was a consecutive or random sample of patients enrolled? & Yes & \\
\hline Was a case-control design avoided? & Unclear & \\
\hline Did the study avoid inappropriate exclusions? & Unclear & Unclear \\
\hline $\begin{array}{l}\text { Was the sample representative of patients in practice }(90 \% \\
\text { stage l/ll with RMI>200)? }\end{array}$ & \\
\hline
\end{tabular}

\section{DOMAIN 2: Index Test All tests}

Were the index tests interpreted without knowledge of the ref- Yes erence standard?

Were the index tests Interpreted by consultant or specialist gyn- Unclear onc pathologist?

\section{FS. 2-5 sections each 4-5microns}

Malignant or borderline on PS.

FS before PS.

Authors' judge- Risk of bias

Applicability con-

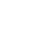


Sukumaran 2014 (Continued)

Unclear

Low

\section{DOMAIN 4: Flow and Timing}

\begin{tabular}{ll}
\hline Did all patients receive a reference standard? & Yes \\
\hline Did all patients receive the same reference standard? & Yes \\
\hline Were un-interpretable/intermediate test results reported? & Yes \\
\hline Were withdrawals from the study explained? & Yes \\
\hline
\end{tabular}

Low

\section{Suprasert 2008}

\section{Study characteristics}

\begin{tabular}{ll}
\hline Patient sampling & Design: Retrospective review \\
Setting: Thailand & Accrual dates: Jan 2001 to Dec 2005 \\
No participants: 127 & No assessed: 112 \\
Inclusion criteria: Women with pelvic masses. Excluded infarcted & masses (4) or deferred (18) frozen section analysis. \\
Included previous histological diagnosis: no
\end{tabular}

Patient characteristics and setting

Index tests

Target condition and reference standard(s)

Flow and timing

\section{Comparative}

\section{Notes}

Retrospective review. 15 excluded due to infarction and deferred FS No stage given.Variable sections were performed by Pathologist.
FS. Number of frozen sections determined by attending Patholosidered not definitely diagnostic.

Malignant or borderline on PS.

Specimens submitted to FS at surgeon's discretion - no clear protocol. FS before PS. gist. Deferred FS when suspicion of borderline or malignant con-

\begin{tabular}{llll}
\hline Methodological quality & & \\
\hline Item & $\begin{array}{l}\text { Authors' judge- } \\
\text { ment }\end{array}$ & Risk of bias & $\begin{array}{l}\text { Applicability con- } \\
\text { cerns }\end{array}$ \\
\hline
\end{tabular}

DOMAIN 1: Patient Selection

Was a consecutive or random sample of patients enrolled? Yes

Was a case-control design avoided?

Yes 
Suprasert 2008 (Continued)

Did the study avoid inappropriate exclusions?

Was the sample representative of patients in practice $(90 \%$ stage I/II with RMI>200)?

\begin{tabular}{lll}
\hline Unclear & Unclear \\
\hline
\end{tabular}

\section{DOMAIN 2: Index Test All tests}

Were the index tests interpreted without knowledge of the ref- $\quad$ Yes erence standard?

Were the index tests Interpreted by consultant or specialist gyn- Unclear onc pathologist?

\begin{tabular}{lll}
\hline & Unclear & Unclear \\
\hline DOMAIN 3: Reference Standard & & \\
\hline $\begin{array}{l}\text { Is the reference standards likely to correctly classify the target } \\
\text { condition? }\end{array}$ & Yes & Unclear \\
\hline $\begin{array}{l}\text { Were the reference standard results interpreted without knowl- } \\
\text { edge of the results of the index tests? }\end{array}$ & Low \\
\hline DOMAIN 4: Flow and Timing & Yes \\
\hline Did all patients receive a reference standard? & Yes \\
\hline Did all patients receive the same reference standard? & Yes \\
\hline Were un-interpretable/intermediate test results reported? & Yes \\
\hline Were withdrawals from the study explained? & \\
\hline
\end{tabular}

Low

\section{Tangjitgamol 2004}

\section{Study characteristics}

\begin{tabular}{ll}
\hline Patient sampling & Design: Retrospective \\
& Setting: Thailand \\
& Accrual dates: Jan 1992 to Jan 2002 \\
& No participants: 212 \\
& No assessed: 212 inc. 13 deferred \\
& Inclusion criteria: Intact ovarian masses submitted. \\
Included previous histological diagnosis: unclear
\end{tabular}

Patient characteristics and setting

Index tests
Intact ovarioan masses. Thailand.

FS. No details given. 
Tangjitgamol 2004 (Continued)
Target condition and reference standard(s)
Malignant or borderline on PS.

Flow and timing

FS before PS.

Comparative

\section{Notes}

Included 13 deferred ( 7 benign, 76 borderline, 121 malignant).

High percentage malignant PS. Risk selection bias.

\section{Methodological quality}

\begin{tabular}{llll}
\hline Item & $\begin{array}{l}\text { Authors' judge- } \\
\text { ment }\end{array}$ & Risk of bias & $\begin{array}{l}\text { Applicability con- } \\
\text { cerns }\end{array}$
\end{tabular}

\section{DOMAIN 1: Patient Selection}

\begin{tabular}{lll}
\hline Was a consecutive or random sample of patients enrolled? & Unclear \\
\hline Was a case-control design avoided? & Yes & Unclear \\
\hline Did the study avoid inappropriate exclusions? & Unclear & Unclear \\
\hline $\begin{array}{l}\text { Was the sample representative of patients in practice }(90 \% \\
\text { stage I/II with RMI>200)? }\end{array}$ & & Unclear \\
\hline
\end{tabular}

\section{DOMAIN 2: Index Test All tests}

Were the index tests interpreted without knowledge of the ref- Yes erence standard?

Were the index tests Interpreted by consultant or specialist gyn- Unclear onc pathologist?

Unclear Unclear

\section{DOMAIN 3: Reference Standard}

Is the reference standards likely to correctly classify the target Yes condition?

Were the reference standard results interpreted without knowl- Unclear edge of the results of the index tests?

\begin{tabular}{lll}
\hline & & Unclear \\
\hline DOMAIN 4: Flow and Timing & Yes \\
\hline Did all patients receive a reference standard? & Yes \\
\hline Did all patients receive the same reference standard? & Yes \\
\hline Were un-interpretable/intermediate test results reported? & Yes \\
\hline Were withdrawals from the study explained? &
\end{tabular}




\section{Taskiran 2008}

\section{Study characteristics}

\begin{tabular}{|c|c|}
\hline Patient sampling & $\begin{array}{l}\text { Design: Retrospective } \\
\text { Setting: Turkey } \\
\text { Accrual dates: } 1997 \text { - } 2006 \\
\text { No participants: } 207 \\
\text { No assessed: } 207 \text { inc } 3 \text { deferred } \\
\text { Inclusion criteria: Consecutive exploratory laparotomies for pelvic } \\
\text { mass } \\
\text { Included previous histological diagnosis: unclear }\end{array}$ \\
\hline Patient characteristics and setting & Pelvic masses. Turkey. \\
\hline Index tests & $\begin{array}{l}\text { FS }(5 \mu \mathrm{m}) \text { from most suspected areas of mass, solid / papillary } \\
\text { areas of tumour wall. No info on number of slides or reporting } \\
\text { pathologists. }\end{array}$ \\
\hline Target condition and reference standard(s) & Malignant or borderline on PS. \\
\hline Flow and timing & FS beforer PS. \\
\hline \multicolumn{2}{|l|}{ Comparative } \\
\hline Notes & 3 deferred cases. \\
\hline
\end{tabular}

\section{Methodological quality}

\begin{tabular}{llll}
\hline Item & $\begin{array}{l}\text { Authors' judge- } \\
\text { ment }\end{array}$ & Risk of bias & $\begin{array}{l}\text { Applicability con- } \\
\text { cerns }\end{array}$
\end{tabular}

\section{DOMAIN 1: Patient Selection}

\begin{tabular}{lll}
\hline Was a consecutive or random sample of patients enrolled? & Yes \\
\hline Was a case-control design avoided? & Yes & Unclear \\
\hline Did the study avoid inappropriate exclusions? & Unclear & \\
\hline $\begin{array}{l}\text { Was the sample representative of patients in practice }(90 \% \\
\text { stage } / / \text { II with RMI>200)? }\end{array}$ & Low \\
\hline
\end{tabular}

\section{DOMAIN 2: Index Test All tests}

Were the index tests interpreted without knowledge of the ref- Yes erence standard?

\section{Were the index tests Interpreted by consultant or specialist gyn- Unclear} onc pathologist? 
Taskiran 2008 (Continued)

Unclear

Unclear

\section{DOMAIN 3: Reference Standard}

Is the reference standards likely to correctly classify the target Yes condition?

Were the reference standard results interpreted without knowl- Unclear edge of the results of the index tests?

Unclear

Low

\section{DOMAIN 4: Flow and Timing}

\begin{tabular}{ll}
\hline Did all patients receive a reference standard? & Yes \\
\hline Did all patients receive the same reference standard? & Yes \\
\hline Were un-interpretable/intermediate test results reported? & Yes \\
\hline Were withdrawals from the study explained? & Yes \\
\hline
\end{tabular}

Low

\section{Toneva 2012}

\section{Study characteristics}

\begin{tabular}{|c|c|}
\hline Patient sampling & $\begin{array}{l}\text { Design: Retrospective } \\
\text { Setting: UK } \\
\text { Accrual dates: Oct } 2005 \text { - Sept } 2008 \\
\text { No participants: } 67 \\
\text { No assessed: } 66 \\
\text { Inclusion criteria: FS in } 67 \text { cases (29.7\%), } 1 \text { excluded due to miss- } \\
\text { ing data } \\
\text { Included previous histological diagnosis: unclear }\end{array}$ \\
\hline Patient characteristics and setting & Unclear inclusion criteria. UK. \\
\hline Index tests & FS. $3-5$ sections. \\
\hline Target condition and reference standard(s) & Malignant or borderline on PS. \\
\hline Flow and timing & FS befiore PS. \\
\hline \multicolumn{2}{|l|}{ Comparative } \\
\hline Notes & - \\
\hline \multicolumn{2}{|l|}{ Methodological quality } \\
\hline Item & $\begin{array}{l}\text { Authors' judge- } \quad \text { Risk of bias } \\
\text { ment }\end{array}$ \\
\hline
\end{tabular}


Toneva 2012 (Continued)

\title{
DOMAIN 1: Patient Selection
}

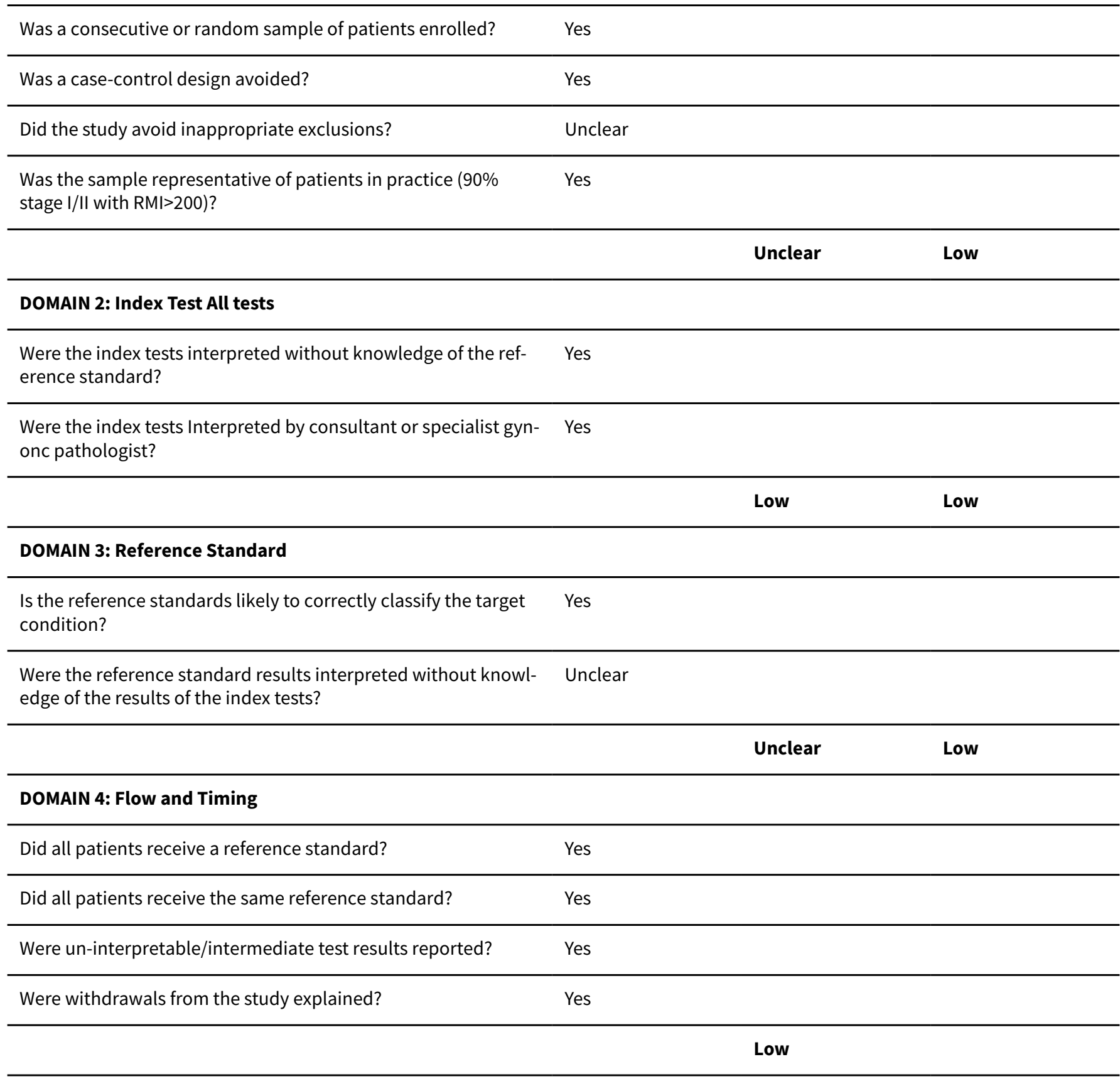

\section{Torres 1998}

\section{Study characteristics}

Patient sampling

\author{
Design: Retrospective \\ Setting: Colombia \\ Accrual dates: Jan1994-Dec 1997 \\ No participants: 199 \\ No assessed: 199- (73 excluded, 3 deferred diagnoses $)=123$ \\ Inclusion criteria: Mass
}


Torres 1998 (Continued)

Included previous histological diagnosis: unclear

Patient characteristics and setting

Index tests

Target condition and reference standard(s)

Flow and timing

Comparative

Notes

\section{Methodological quality}

\begin{tabular}{|c|c|c|c|}
\hline Item & $\begin{array}{l}\text { Authors' judge- } \\
\text { ment }\end{array}$ & Risk of bias & $\begin{array}{l}\text { Applicability con- } \\
\text { cerns }\end{array}$ \\
\hline
\end{tabular}

\section{DOMAIN 1: Patient Selection}

\begin{tabular}{ll}
\hline Was a consecutive or random sample of patients enrolled? & Unclear \\
\hline Was a case-control design avoided? & Unclea \\
\hline Did the study avoid inappropriate exclusions? & Unclear \\
\hline $\begin{array}{l}\text { Was the sample representative of patients in practice }(90 \% \\
\text { stage } \mathrm{I} / \mathrm{Il} \text { with RMI>200)? }\end{array}$ & Unclea
\end{tabular}

\begin{tabular}{lll}
\hline & Unclear & Unclear \\
\hline DOMAIN 2: Index Test All tests & & \\
\hline
\end{tabular}

Were the index tests interpreted without knowledge of the ref- Yes erence standard?

Were the index tests Interpreted by consultant or specialist gyn- Unclear onc pathologist?

Unclear
Unclear

\section{DOMAIN 3: Reference Standard}

Is the reference standards likely to correctly classify the target Yes condition?

Were the reference standard results interpreted without knowl- Unclear edge of the results of the index tests?

\begin{tabular}{lll}
\hline & Unclear & Low \\
\hline DOMAIN 4: Flow and Timing & Yes \\
\hline Did all patients receive a reference standard? & Yes \\
\hline Did all patients receive the same reference standard? &
\end{tabular}


Torres 1998 (Continued)

Were un-interpretable/intermediate test results reported? Yes

Were withdrawals from the study explained? Yes

Low

Twaalfhoven 1991

\section{Study characteristics}

\begin{tabular}{|c|c|}
\hline Patient sampling & $\begin{array}{l}\text { Design: Retrospective } \\
\text { Setting: Netherlands } \\
\text { Accrual dates: Jan 1984-Jan } 1990 \\
\text { No participants: } 176 \\
\text { No assessed: } 176 \text { inc. } 11 \text { deferred } \\
\text { Inclusion criteria: Included } 27 \text { ovarian biopsies and } 149 \text { ovaries. } \\
\text { Included previous histological diagnosis: unclear }\end{array}$ \\
\hline Patient characteristics and setting & Ovarian biopsies and ovaries submitted for FS. Netherlands. \\
\hline Index tests & FS. No details given. \\
\hline Target condition and reference standard(s) & Malignant or borderline on PS. \\
\hline Flow and timing & FS before PS. \\
\hline \multicolumn{2}{|l|}{ Comparative } \\
\hline Notes & 11 Deferred ( 1 benign, 4 borderline, 6 malignant). \\
\hline \multicolumn{2}{|l|}{ Methodological quality } \\
\hline Item & $\begin{array}{l}\text { Applicability con- } \\
\text { cerns }\end{array}$ \\
\hline
\end{tabular}

\section{DOMAIN 1: Patient Selection}

\begin{tabular}{lll}
\hline Was a consecutive or random sample of patients enrolled? & Unclear \\
\hline Was a case-control design avoided? & Yes & Unclear \\
\hline Did the study avoid inappropriate exclusions? & Unclear & \\
\hline $\begin{array}{l}\text { Was the sample representative of patients in practice (90\% } \\
\text { stage I/II with RMI>200)? }\end{array}$ & & Unclear \\
\hline
\end{tabular}

\section{DOMAIN 2: Index Test All tests}

Were the index tests interpreted without knowledge of the ref- Yes erence standard? 
Twaalfhoven 1991 (Continued)

Were the index tests Interpreted by consultant or specialist gyn- Unclear onc pathologist?

\begin{tabular}{lll}
\hline DOMAIN 3: Reference Standard & Unclear & Unclear \\
\hline $\begin{array}{l}\text { Is the reference standards likely to correctly classify the target } \\
\text { condition? }\end{array}$ & Yes & Unclear \\
\hline $\begin{array}{l}\text { Were the reference standard results interpreted without knowl- } \\
\text { edge of the results of the index tests? }\end{array}$ & Low \\
\hline DomAIN 4: Flow and Timing & Yes \\
\hline Did all patients receive a reference standard? & Yes \\
\hline Did all patients receive the same reference standard? & Yes \\
\hline Were un-interpretable/intermediate test results reported? & Unclear \\
\hline Were withdrawals from the study explained? & Unclear \\
\hline
\end{tabular}

Wakahara 2001

\section{Study characteristics}

\begin{tabular}{ll}
\hline Patient sampling & $\begin{array}{l}\text { Design: Prospective } \\
\text { Setting: Japan }\end{array}$ \\
& $\begin{array}{l}\text { Accrual dates: } 1994 \text { - } 1999 \\
\text { No participants: } 292 \\
\text { No assessed: } 187 \\
\text { Inclusion criteria: None given } \\
\text { Included previous histological diagnosis: unclear }\end{array}$ \\
\hline Patient characteristics and setting & Unclear inclusion criteria. Japan. \\
\hline Index tests & FS. Single pathologist reported all FS and PS \\
\hline Target condition and reference standard(s) & Malignant or borderline on PS. \\
\hline Flow and timing & FS before PS. \\
\hline Comparative & \\
\hline Notes & $\begin{array}{l}\text { Principal aim to assess performance of US / tumour markers in dif- } \\
\text { ferentiating malignant from benign adnexal masses. }\end{array}$ \\
\hline Methodological quality & \\
\hline
\end{tabular}


Wakahara 2001 (Continued)

$\begin{array}{llll}\text { Item } & \begin{array}{l}\text { Authors' judge- } \\ \text { ment }\end{array} & \text { Risk of bias } & \begin{array}{l}\text { Applicability con- } \\ \text { cerns }\end{array}\end{array}$

DOMAIN 1: Patient Selection

\begin{tabular}{ll}
\hline Was a consecutive or random sample of patients enrolled? & Unclear \\
\hline Was a case-control design avoided? & Yes \\
\hline Did the study avoid inappropriate exclusions? & Unclear \\
\hline $\begin{array}{l}\text { Was the sample representative of patients in practice }(90 \% \\
\text { stage I/II with RMI>200)? }\end{array}$ & Unclear
\end{tabular}

Unclear

Unclear

\section{DOMAIN 2: Index Test All tests}

Were the index tests interpreted without knowledge of the ref- Yes erence standard?

Were the index tests Interpreted by consultant or specialist gyn- Unclear onc pathologist?

\begin{tabular}{lcc}
\hline & Low & Low \\
\hline DOMAIN 3: Reference Standard &
\end{tabular}

\section{DOMAIN 3: Reference Standard}

Is the reference standards likely to correctly classify the target Yes condition?

Were the reference standard results interpreted without knowl- Unclear edge of the results of the index tests?

\begin{tabular}{lll}
\hline \multicolumn{1}{l}{} & Unclear \\
\hline DOMAIN 4: Flow and Timing & Yes \\
\hline Did all patients receive a reference standard? & Yes \\
\hline Did all patients receive the same reference standard? & No \\
\hline Were un-interpretable/intermediate test results reported? & Unclear & Low \\
\hline Were withdrawals from the study explained? & \\
\hline
\end{tabular}

\section{Wang 1998}

\section{Study characteristics}

Patient sampling

Design: Retrospective

Setting: Taiwan

Accrual dates: Jan 1991 to June 1996 
No participants: 299

No assessed: 299

Inclusion criteria: Unclear if all were pelvic masses. Also reported

FS in lymphatic, uterine and other tissue samples.

Included previous histological diagnosis: $\mathrm{nr}$

Patient characteristics and setting

Index tests

Target condition and reference standard(s)

Flow and timing
Unclear if hospital setting. Pelvic masses. Taiwan.

FS. Berween 1 and several FS were performed each case. Different grades of pathologist were employed. Most were general surgical pathologists (not gynaecological oncology pathologists.)

Benign, borderline and malignant ovarian diagnosis on PS.

FS before PS. Interpretation of ovaries varied in number of sections submitted for FS. Same pathologist reported both the FS and PS in most cases. Interpretation bias.

Comparative

Notes

Also reported FS in lymphatic, uterine and other tissue samples.

\section{Methodological quality}

\begin{tabular}{|c|c|c|c|}
\hline Item & $\begin{array}{l}\text { Authors' judge- } \\
\text { ment }\end{array}$ & Risk of bias & $\begin{array}{l}\text { Applicability con- } \\
\text { cerns }\end{array}$ \\
\hline
\end{tabular}

\section{DOMAIN 1: Patient Selection}

\begin{tabular}{lll}
\hline Was a consecutive or random sample of patients enrolled? & Yes \\
\hline Was a case-control design avoided? & Yes & Unclear \\
\hline Did the study avoid inappropriate exclusions? & Unclear & \\
\hline $\begin{array}{l}\text { Was the sample representative of patients in practice (90\% } \\
\text { stage I/II with RMI>200)? }\end{array}$ & Unclear High
\end{tabular}

\section{DOMAIN 2: Index Test All tests}

Were the index tests interpreted without knowledge of the ref- No erence standard?

Were the index tests Interpreted by consultant or specialist gyn- No onc pathologist?

High

High

\section{DOMAIN 3: Reference Standard}

Is the reference standards likely to correctly classify the target Yes condition?

Were the reference standard results interpreted without knowl- No edge of the results of the index tests? 
Wang 1998 (Continued)

High

Low

\section{DOMAIN 4: Flow and Timing}

\begin{tabular}{ll}
\hline Did all patients receive a reference standard? & Yes \\
\hline Did all patients receive the same reference standard? & Yes \\
\hline Were un-interpretable/intermediate test results reported? & Yes \\
\hline Were withdrawals from the study explained? & Yes \\
\hline
\end{tabular}

Low

Wasinghon 2008

\section{Study characteristics}

\begin{tabular}{ll}
\hline Patient sampling & Design: Retrospective \\
& Setting: Thailand \\
& Accrual dates: Jan 2002 - Dec 2006 \\
& No participants: 376 \\
& No assessed: 376 \\
Inclusion criteria: Consecutive ovarian tumours undergoing \\
surgery where FS and PS performed \\
Included previous histological diagnosis: unclear
\end{tabular}

Patient characteristics and setting Consecutive ovarian masses. Thailand.

Index tests

FS 1-2 slides, reported by 5 pathologists (expertise unclear)

Target condition and reference standard(s) Malignant or borderline on PS.

Flow and timing

FS before PS.

Comparative

Notes No deferred cases.

\section{Methodological quality}

\begin{tabular}{llll}
\hline Item & $\begin{array}{l}\text { Authors' judge- } \\
\text { ment }\end{array}$ & Risk of bias & $\begin{array}{l}\text { Applicability con- } \\
\text { cerns }\end{array}$ \\
\hline
\end{tabular}

\section{DOMAIN 1: Patient Selection}

\begin{tabular}{ll}
\hline Was a consecutive or random sample of patients enrolled? & Yes \\
\hline Was a case-control design avoided? & Yes \\
\hline Did the study avoid inappropriate exclusions? & Unclear \\
\hline $\begin{array}{l}\text { Was the sample representative of patients in practice }(90 \% \\
\text { stage I/II with RMI>200)? }\end{array}$ & Unclear \\
\hline
\end{tabular}


Wasinghon 2008 (Continued)

\section{DOMAIN 2: Index Test All tests}

Were the index tests interpreted without knowledge of the ref- Yes erence standard?

Were the index tests Interpreted by consultant or specialist gyn- Unclear onc pathologist?

\section{Unclear}

Low

\section{DOMAIN 3: Reference Standard}

Is the reference standards likely to correctly classify the target Yes condition?

Were the reference standard results interpreted without knowl- Unclear edge of the results of the index tests?

\begin{tabular}{lll}
\hline DOMAIN 4: Flow and Timing & Unclear & Low \\
\hline Did all patients receive a reference standard? & Yes & Yes \\
\hline Did all patients receive the same reference standard? & Yes \\
\hline Were un-interpretable/intermediate test results reported? & Yes \\
\hline Were withdrawals from the study explained? & & Low \\
\hline
\end{tabular}

Wootipoom 2006

\section{Study characteristics}

\begin{tabular}{ll}
\hline Patient sampling & $\begin{array}{l}\text { Design: Retrospective } \\
\text { Setting: Thailand } \\
\text { Accrual dates: May } 1999 \text { to Oct 2004 } \\
\text { No participants: } 229 \\
\text { No assessed: } 213\end{array}$ \\
& $\begin{array}{l}\text { Inclusion criteria: Excluded 16 deferred diagnoses. } \\
\text { Included previous histological diagnosis: unclear }\end{array}$ \\
\hline Patient characteristics and setting & Unclear inclusion criteria. Thailand. \\
\hline Index tests & FS. No details given. \\
\hline Target condition and reference standard(s) & Malignant or borderline on PS. \\
\hline Flow and timing & FS before PS. \\
\hline
\end{tabular}




\section{Wootipoom 2006 (Continued)}

Comparative

Notes 16 deferred diagnoses on FS excluded.

\section{Methodological quality}

\begin{tabular}{|c|c|c|c|}
\hline Item & $\begin{array}{l}\text { Authors' judge- } \\
\text { ment }\end{array}$ & Risk of bias & $\begin{array}{l}\text { Applicability con- } \\
\text { cerns }\end{array}$ \\
\hline
\end{tabular}

\section{DOMAIN 1: Patient Selection}

\begin{tabular}{ll}
\hline Was a consecutive or random sample of patients enrolled? & Unclear \\
\hline Was a case-control design avoided? & Yes \\
\hline Did the study avoid inappropriate exclusions? & Unclear \\
\hline $\begin{array}{l}\text { Was the sample representative of patients in practice }(90 \% \\
\text { stage I/II with RMI>200)? }\end{array}$ & Unclear
\end{tabular}

\begin{tabular}{lll}
\hline & Unclear & Unclear \\
\hline DOMAIN 2: Index Test All tests & &
\end{tabular}

Were the index tests interpreted without knowledge of the ref- Yes erence standard?

Were the index tests Interpreted by consultant or specialist gyn- Unclear onc pathologist?

\begin{tabular}{lll}
\hline & Unclear & Unclear \\
\hline DOMAIN 3: Reference Standard & & \\
\hline $\begin{array}{l}\text { Is the reference standards likely to correctly classify the target } \\
\text { condition? }\end{array}$ & Yes & Unclear \\
\hline $\begin{array}{l}\text { Were the reference standard results interpreted without knowl- } \\
\text { edge of the results of the index tests? }\end{array}$ & Low \\
\hline DOMAIN 4: Flow and Timing & Yes \\
\hline Did all patients receive a reference standard? & Yes \\
\hline Did all patients receive the same reference standard? & No \\
\hline Were un-interpretable/intermediate test results reported? & Yes \\
\hline Were withdrawals from the study explained? &
\end{tabular}

\section{Low}


Yarandi 2008

\section{Study characteristics}

Patient sampling

Design: Retrospective

Setting: Iran

Accrual dates: Jan 2004 - Aug 2006

No participants: 106

No assessed: 106

Inclusion criteria: All women with ovarian tumours who had a FS

diagnosis. Excluded patients with neo-adjuvant chemo/radiother-

apy.

Included previous histological diagnosis: unclear

Patient characteristics and setting

Index tests

Target condition and reference standard(s)

Flow and timing

Comparative

Notes

\section{Methodological quality}

\begin{tabular}{llll}
\hline Item & $\begin{array}{l}\text { Authors' judge- } \\
\text { ment }\end{array}$ & Risk of bias & $\begin{array}{l}\text { Applicability con- } \\
\text { cerns }\end{array}$
\end{tabular}

\section{DOMAIN 1: Patient Selection}

\begin{tabular}{lll}
\hline Was a consecutive or random sample of patients enrolled? & Unclear & \\
\hline Was a case-control design avoided? & Unclear & Unclear \\
\hline Did the study avoid inappropriate exclusions? & Unclear & Low \\
\hline $\begin{array}{l}\text { Was the sample representative of patients in practice (90\% } \\
\text { stage I/II with RMI>200)? }\end{array}$ & \\
\hline $\begin{array}{l}\text { DomAIN 2: Index Test All tests } \\
\text { erence standard? }\end{array}$ & Yes \\
\hline $\begin{array}{l}\text { Were the index tests Interpreted by consultant or specialist gyn- } \\
\text { onc pathologist? }\end{array}$ & Yes \\
\hline
\end{tabular}

DOMAIN 3: Reference Standard 
Yarandi 2008 (Continued)

Is the reference standards likely to correctly classify the target Yes condition?

Were the reference standard results interpreted without knowl- Unclear edge of the results of the index tests?

Unclear

Low

\section{DOMAIN 4: Flow and Timing}

\begin{tabular}{ll}
\hline Did all patients receive a reference standard? & Yes \\
\hline Did all patients receive the same reference standard? & Yes \\
\hline Were un-interpretable/intermediate test results reported? & No \\
\hline Were withdrawals from the study explained? & Yes \\
\hline
\end{tabular}

Low

Yeo 1998

\section{Study characteristics}

\begin{tabular}{ll}
\hline Patient sampling & Design: Retrospective \\
& Setting: China \\
& Accrual dates: Jan 1990 to Dec 1995 \\
& No participants: 316 \\
No assessed: 316 & Inclusion criteria: Pelvic masses. \\
Included previous histological diagnosis: unclear
\end{tabular}

Patient characteristics and setting Pelvic masses. Hospital, unknown if tertiary. China.

Index tests $\quad$ FS. 2 sections taken at FS in 85\% cases. Experienced pathologist.
Same pathologist reported PS and FS.

Target condition and reference standard(s)

Malignant or borderline on PS. PS performed by pathologist who interpreted FS. Third party quality assurance performed by a third author.

Flow and timing

FS before PS.

Comparative

Notes

\section{Methodological quality}

\begin{tabular}{llll}
\hline Item & $\begin{array}{l}\text { Authors'judge- } \\
\text { ment }\end{array}$ & Risk of bias & $\begin{array}{l}\text { Applicability con- } \\
\text { cerns }\end{array}$ \\
\hline
\end{tabular}

\section{DOMAIN 1: Patient Selection}

Was a consecutive or random sample of patients enrolled? 
Yeo 1998 (Continued)

Was a case-control design avoided?

\begin{tabular}{ll}
\hline Did the study avoid inappropriate exclusions? & Unclear \\
\hline $\begin{array}{l}\text { Was the sample representative of patients in practice }(90 \% \\
\text { stage } 1 / \text { II with RMI>200)? }\end{array}$ & Unclear
\end{tabular}

stage I/II with RMI>200)?

\begin{tabular}{llc}
\hline DOMAIN 2: Index Test All tests & Unclear & Unclear \\
\hline $\begin{array}{l}\text { Were the index tests interpreted without knowledge of the ref- } \\
\text { erence standard? }\end{array}$ & Yes \\
\hline $\begin{array}{l}\text { Were the index tests Interpreted by consultant or specialist gyn- } \\
\text { onc pathologist? }\end{array}$ & Low & Low \\
\hline
\end{tabular}

\section{DOMAIN 3: Reference Standard}

Is the reference standards likely to correctly classify the target Yes condition?

Were the reference standard results interpreted without knowl- No edge of the results of the index tests?

\begin{tabular}{lll}
\hline DOMAIN 4: Flow and Timing & High & Low \\
\hline Did all patients receive a reference standard? & Yes & Yes \\
\hline Did all patients receive the same reference standard? & No \\
\hline Were un-interpretable/intermediate test results reported? & No \\
\hline Were withdrawals from the study explained? & & Low \\
\hline
\end{tabular}

FS: frozen section; PS: paraffin section.

Characteristics of excluded studies [ordered by study ID]

\begin{tabular}{ll}
\hline Study & Reason for exclusion \\
\hline Abbasi 2010 & $\begin{array}{l}\text { Conference abstract. Retrospective study of } 105 \text { patients comparing value of intraoperative cytol- } \\
\text { ogy and FS. Unable to construct } 3 \times 3 \text { table from data. }\end{array}$ \\
\hline Abdel-Hady 2012 & $\begin{array}{l}\text { Not a DTA study. A study of fertility-conserving surgery for ovarian tumours in children and young } \\
\text { adults 6-20 years of age. Although frozen section was performed, evaluation of its accuracy was not } \\
\text { part of the study. }\end{array}$ \\
\hline Abe 2013 & Retrospective review of accuracy of FS and imprint cytology in 23 ovarian germ cell tumours \\
\hline \hline
\end{tabular}




\begin{tabular}{ll}
\hline Study & Reason for exclusion \\
\hline Ahmad 2008 & $\begin{array}{l}\text { Retrospective study of all FS analyses performed at an institution in Pakistan during 2006 ( } \mathrm{N}=356) . \\
\text { Cohort was not limited to women with ovarian tumours, who comprised only } 9 \% \text { of the sample }\end{array}$ \\
\hline Alvarez Santin 2011 & $\begin{array}{l}\text { Retrospective study of intraoperative consultations of ovarian neoplastic and non-neoplastic le- } \\
\text { sions ( } \mathrm{N}=337) \text {. Intraoperative diagnoses based on macroscopic exam, FS, imprint cytology or } \\
\text { smears, and cyto-histological correlation. Intraoperative diagnoses compared with final histologic } \\
\text { diagnoses. }\end{array}$
\end{tabular}

\begin{tabular}{|c|c|}
\hline Anastasiadis 2002 & $\begin{array}{l}\text { Retrospective study of PW and imprint cytology for } 52 \text { patients undergoing primary surgery for } \\
\text { ovarian cancer. }\end{array}$ \\
\hline Aslam 2010 & $\begin{array}{l}\text { Retrospective study of FS analyses compared to preoperative ultrasound and final paraffin section } \\
\text { diagnosis. Investigators selected the first } 400 \text { women with malignant ovarian tumours and } 400 \text { with } \\
\text { benign tumours between August } 2000 \text { and March } 2007 \text {. Cohort was not limited to early ovarian can- } \\
\text { cer and comprised a significant proportion of metastatic tumours (56\%). Sensitivity, specificity, } \\
\text { PPV and NPV calculated but unable to construct } 3 \times 3 \text { table. }\end{array}$ \\
\hline
\end{tabular}

Atallah 2004 Commentary on management of ovarian masses at laparoscopy, including role of FS. No compari-
son of FS to PS.

\begin{tabular}{ll}
\hline Basaran 2014 & Only borderline cases \\
\hline Bensaid 2006 & $\begin{array}{l}\text { Retrospective study of } 313 \text { patients to assess performance of laparoscopy +/- FS to identify malig- } \\
\text { nancy. FS performed in } 111(35 \%) \text { patients. Results compared to final histology }\end{array}$ \\
\hline Brun 2008 & Retrospective study of patients with epithelial ovarian cancer only \\
\hline Canis 1997 & Laparoscopic versus laparotomy for management of pelvic masses
\end{tabular}

\begin{tabular}{ll}
\hline Chapron 1998 & $\begin{array}{l}\text { Review of laparoscopic management of pelvic masses. FS reserved for } 26 \text { pelvic masses with CA125 } \\
\text { within range of 4-76. Not representative of population being studied }\end{array}$ \\
\hline
\end{tabular}

Cheung $1992 \quad$ Retrospective review of all ovarian masses sent for FS, including those to determine extent of metastases and bilaterality of tumour; unable to construct $3 \times 3$ table from data for FS sent for suspicious pelvic masses.

\begin{tabular}{ll}
\hline Cingillioglu 2011 & $\begin{array}{l}\text { Conference abstract. Retrospective study of borderline tumours diagnosed at FS, PS or both in a } \\
\text { single unit in Turkey 2000-2011 }\end{array}$ \\
\hline Coffey 2005 & Review of role of intraoperative consultation, no data provided \\
\hline Da Cunha Bastos 1983 & $\begin{array}{l}\text { Included obviously malignant masses. Expertise of pathologists unclear. Unable to extract data for } \\
3 \times 3 \text { table }\end{array}$
\end{tabular}

\begin{tabular}{ll}
\hline Dede 2005 & Use of frozen section laparoscopically for predicted benign masses \\
\hline Dottino 1999 & $\begin{array}{l}\text { Prospective study of } 160 \text { women undergoing laparoscopic evaluation with FS for adnexal masses. } \\
\text { Large masses above umbilicus excluded. No comparison with PS, only discordant cases reported. }\end{array}$ \\
\hline
\end{tabular}

\begin{tabular}{ll}
\hline Fain-Kahn 2009 & $\begin{array}{l}\text { Ovarian cryoperservation amongst young women undergoing surgery for borderline ovarian tu- } \\
\text { mours. }\end{array}$ \\
\hline Freitag 2004 & $\begin{array}{l}\text { Retrospective review of management of } 38 \text { patients with borderline ovarian tumours. Not compar- } \\
\text { ing FS to PS }\end{array}$ \\
\hline Ganesan 2013 & Survey of UK practice of FS in gynaecological oncology \\
\hline
\end{tabular}




\begin{tabular}{|c|c|}
\hline Study & Reason for exclusion \\
\hline Garg 2011 & $\begin{array}{l}\text { Conference abstract. Retrospective study of } 166 \text { patients with borderline ovarian tumours only. FS } \\
\text { and PS results compared. Unable to construct } 3 \times 3 \text { table from data }\end{array}$ \\
\hline Geomini 2005 & Meta-analysis \\
\hline Geomini 2009 & Survey on women's attitudes towards frozen section diagnosis \\
\hline Ghaemmaghami 2008 & $\begin{array}{l}\text { Retrospective study of } 150 \text { women undergoing laparotomy for adnexal masses in Iran. } 143 \text { had FS. } \\
\text { Unable to construct } 3 \times 3 \text { table from data }\end{array}$ \\
\hline Gocku 2013 & Conference abstract only. Retrospective review of 113 tumours diagnosed on either PS or FS \\
\hline Gol 2003 & $\begin{array}{l}\text { All of the data adds up to } 221 \text { women, but authors report } 222 \text { women. Table } 2 \text { data does not add up } \\
\text { and does not match data in text }\end{array}$ \\
\hline Gultekin 2011 & Retrospective study of 82 patients with borderline tumours only. FS and PS results compared \\
\hline Gupta 2013 & $\begin{array}{l}\text { Conference abstract. Retrospective study of } 52 \text { patients with borderline tumours only. FS and PS } \\
\text { results compared, unable to construct } 3 \times 3 \text { table }\end{array}$ \\
\hline Guzel 2011 & $\begin{array}{l}\text { Prospective study of postmenopausal and women of reproductive age }(\mathrm{N}=80) \text { with predicted be- } \\
\text { nign adnexal masses. FS in } 75 \% \text { of cases but no data on accuracy. }\end{array}$ \\
\hline Guzin 2013 & Conference abstract. Retrospective review of 40 borderline tumours diagnosed on either FS or PS \\
\hline Harmon 2011 & $\begin{array}{l}\text { Conference abstract. Retrospective study of } 100 \text { consecutive ovarian mucinous tumours that un- } \\
\text { derwent FS. FS and PS results compared }\end{array}$ \\
\hline Hua 2005 & Full article in Chinese \\
\hline Ismiil 2009 & $\begin{array}{l}\text { Retropsective review } 731 \mathrm{FS} \text { from all gynaecological operations performed, } 29 \text { performed for ovar- } \\
\text { ian cyst and } 591 \text { from ovary/tube. } 257 \text { of these were performed by general gynaecologist or sur- } \\
\text { geon. This is not representative of the population being studied. }\end{array}$ \\
\hline Ivanov 2005 & Full article in Bulgarian \\
\hline Jaafar 2005 & Review of frozen section concepts. Not original research \\
\hline Kato 2011 & $\begin{array}{l}\text { Review of histopathological features of FS for } 40 \text { clear cell carcinomas and } 30 \text { serous ovarian tu- } \\
\text { mours }\end{array}$ \\
\hline
\end{tabular}

\begin{tabular}{ll}
\hline Kayıkçığlu 2000 & Retrospective study of 33 patients with borderline tumours only. FS and PS results compared \\
\hline Khunamornpong 2003 & $\begin{array}{l}\text { Prospective study of } 131 \text { ovarian masses submitted for scrape cytology and not intraoperative } \\
\text { frozen section analysis }\end{array}$ \\
\hline Kim 2009a & Retrospective study of 101 patients with borderline tumours only. FS and PS results compared \\
\hline Kim 2009b & $\begin{array}{l}\text { Retrospective study of } 209 \text { patients with borderline tumours only. FS (182 cases) and PS results } \\
\text { compared }\end{array}$ \\
\hline Kim 2013 & Conference abstract only. Retrospective review of 179 borderline tumours diagnosed on FS \\
\hline Konopacka 2012 & $\begin{array}{l}\text { Prospective observational study of } 131 \text { patients undergoing laparoscopic surgery for adnexal mass- } \\
\text { es. FS performed in } 87 \text { cases. Unable to construct } 3 \times 3 \text { table from data }\end{array}$ \\
\hline
\end{tabular}




\begin{tabular}{ll}
\hline Study & Reason for exclusion \\
\hline Kumpulainen 2007 & $\begin{array}{l}\text { Prospective study of } 65 \text { patients with borderline tumours only to assess staging/treatment and out- } \\
\text { comes in different hospital settings. FS in half of cases, results compared to PS }\end{array}$ \\
\hline Kushima 2013 & 3 case reports on usefulness of intraoperative cytology \\
\hline Leng 2006 & Retrospective review of benign pelvic masses managed with laparoscopy \\
\hline Li 2009 & Full article in Chinese \\
\hline Lin 1993 & $\begin{array}{l}\text { Retrospective review of } 80 \text { women undergoing laparotomy for pelvic mass. FS in } 48 \text { cases with dis- } \\
\text { cussion of discordant cases but no data provided }\end{array}$
\end{tabular}

Prospective review of diagnostic accuracy of haptoglobin level in ovarian cyst fluid for intraopera-
tive triage of epithelial ovarian cancers

\begin{tabular}{ll}
\hline Marana 2005 & $\begin{array}{l}\text { Prospective study of FS of adnexal masses at laparoscopy for ultrasonographically non-suspicious } \\
\text { adnexal mass }\end{array}$
\end{tabular}

\begin{tabular}{ll}
\hline Maruoka 2003 & Full article in Japanese \\
\hline Medeiros 2005 & Quantitative systematic review of diagnostic accuracy of FS, including 14 studies \\
\hline Mendilcioglu 2002 & $\begin{array}{l}\text { Retrospective study of } 61 \text { patients undergoing laparoscopy for adnexal masses, aiming to assess } \\
\text { the safety of laparoscopic approach. FS performed in only } 8(13 \%) \text { of cases }\end{array}$ \\
\hline
\end{tabular}

\begin{tabular}{ll}
\hline Menzin 1995 & Retrospective review of 48 patients with FS diagnosis borderline tumour. 2 patients were stage II, \\
10 patients were stage III. This is not representative of the population being studied
\end{tabular}

\begin{tabular}{ll}
\hline Michael 1996 & Comparison of cytology and frozen section. No comparison to paraffin section \\
\hline Moodley 2005 & Commentary on frozen section. Not original research \\
\hline
\end{tabular}

\begin{tabular}{ll}
\hline Morotti 2011 & Conference abstract. Retrospective review of 98 borderline tumours diagnosed by FS, PS or both. \\
& Unable to construct $3 \times 3$ table from data
\end{tabular}

\begin{tabular}{ll}
\hline Nasfi 2012 & $\begin{array}{l}\text { Retrospective study of } 79 \text { ovarian mucinous tumours that underwent FS. FS and PS results com- } \\
\text { pared }\end{array}$ \\
\hline Nevin 2010 & Letter in response to Warwick 2009. \\
\hline Obiakor 1991 & $\begin{array}{l}\text { Retrospective review of } 311 \text { FS classified as benign or malignant. Unable to construct } 3 \times 3 \text { table } \\
\text { from data }\end{array}$ \\
\hline Ozdamar 2006 & $\begin{array}{l}\text { Retrospective review of all FS analysed in a pathology laboratory 2001-2005. No details provided } \\
\text { for ovarian masses alone }\end{array}$ \\
\hline Parker 2011 & $\begin{array}{l}\text { Conference abstract only. Review of 831 frozen sections interpreted by general or specialist gynae- } \\
\text { cological pathologists }\end{array}$ \\
\hline Pongsuvareeyakul 2012 & \begin{tabular}{l} 
Retrospective study of mucinous tumours only \\
\hline Puga 2011
\end{tabular} \\
\hline Conference abstract. Retrospective study of 67 patients with borderline tumours only. Unable to \\
construct $3 \times 3$ table from data
\end{tabular}




\begin{tabular}{|c|c|}
\hline Study & Reason for exclusion \\
\hline Saglam 2006 & $\begin{array}{l}\text { Letter to editor discussing } 4 \text { discordant cases of a total } 174 \text { FS performed during } 2002 \text { in a single } \\
\text { unit }\end{array}$ \\
\hline Sakurai 2004 & Full article in Japanese \\
\hline Salman 2013 & Conference abstract only. 745 pelvic masses undergoing FS \\
\hline Scurry 1989 & $\begin{array}{l}\text { Retrospective review of } 203 \text { FS from all gynaecological operations, including } 73 \text { ovarian. No report } \\
\text { that these were suspicious masses. Authors agree that many FS were performed on grossly benign } \\
\text { appearing cysts. Not representative of population being studied in this review }\end{array}$ \\
\hline Seckin 2011 & $\begin{array}{l}\text { Retrospective study of females } 25 \text { years or younger undergoing laparoscopic surgery for presumed } \\
\text { benign ovarian cysts }\end{array}$ \\
\hline Shahid 2012 & Reports role of intraoperative cytology not frozen section. \\
\hline Shih 2011 & Retrospective study of 120 patients with borderline tumours diagnosed at FS \\
\hline Slavutin 1979 & $\begin{array}{l}\text { Retrospective study of } 55 \text { patients with serous ovarian tumours. FS and PS reviewed by } 2 \text { patholo- } \\
\text { gists for study and compared with original results }\end{array}$ \\
\hline
\end{tabular}

\begin{tabular}{ll}
\hline Song 2011 & Retrospective study of 354 patients with borderline tumours only. FS and PS results compared \\
\hline Souka 1990 & $\begin{array}{l}\text { Retrospective review of combined use of imprint cytology and FS to evaluate } 50 \text { pelvic masses at } \\
\text { laparotomy. Borderline tumours at PS were grouped together with malignant. Unable to construct } \\
3 \times 3 \text { table }\end{array}$ \\
\hline Spann 1994 & $\begin{array}{l}\text { Report on role of FS and gross inspection combined. Unable to extract data for FS alone. May not } \\
\text { be representative of study population as } 88 \% \text { of intraoperative consultations were benign diag- } \\
\text { noses }\end{array}$
\end{tabular}

\begin{tabular}{ll}
\hline Springel 2009 & Retrospective study of FS intraoperative consultations reported as epithelial ovarian tumours. \\
\hline Stewart 2005 & $\begin{array}{l}\text { Retrospective study of } 914 \text { patients in Australia looking at accuracy of FS to determine primary } \\
\text { from metastatic disease, 1999-2003. } 32 \text { patients known to have extra-ovarian disease at time of FS. } \\
\text { Patient selection bias therefore high. FS omentum and lymph node included }\end{array}$
\end{tabular}

\begin{tabular}{ll}
\hline Stewart 2008 & $\begin{array}{l}\text { Results for clear cell carcinoma were assessed separately and compared with a similar number } \\
\text { with serous and endometrial cancer }\end{array}$ \\
\hline Stewart 2010 & 402 cases where cytology was compared to frozen section. No comparison to paraffin section made \\
\hline Storms 2012 & Retrospective review of 73 ovarian mucinous tumours \\
\hline Takemoto 2014 & $\begin{array}{l}\text { Retrospective review of benign masses diagnosed at FS at laparoscopy. Not representative of study } \\
\text { population }\end{array}$ \\
\hline Tempfer 2007 & Borderline tumours only \\
\hline Twigg 2012 & Letter in response to Cross 2012 \\
\hline Uguz 2005 & $\begin{array}{l}\text { Prospective study of } 62 \text { women having FNAC of ovarian masses and not intraoperative frozen sec- } \\
\text { tion analysis }\end{array}$ \\
\hline Ulrich 2000 & $\begin{array}{l}\text { Retrospective analysis of FS results for } 226 \text { adnexal masses. Excluded simple masses on USS and } \\
\text { suspicious masses that required conversion to laparotomy. Heavy selection bias in that masses not }\end{array}$
\end{tabular}




\begin{tabular}{ll}
\hline Study & Reason for exclusion \\
\hline & $\begin{array}{l}\text { considered to need laparotomy were excluded. As a result, } 202 \text { of } 211 \text { studied women had benign } \\
\text { disease on PS. }\end{array}$ \\
\hline Usubutun 1998 & $\begin{array}{l}\text { Retrospective review of } 360 \text { ovarian masses with FS. } 12 \text { deferred cases. Unable to construct } 3 \times 3 \text { ta- } \\
\text { ble from data }\end{array}$ \\
\hline Vemavarapu 2014 & Conference abstract only. Retrospective review of 73 pelvic masses submitted for FS \\
\hline Wijayakumar 2013 & $\begin{array}{l}\text { Prospective study of intraoperative imprint cytology in } 50 \text { patients with suspected ovarian malig- } \\
\text { nancy }\end{array}$ \\
\hline Wingo 2006 & $\begin{array}{l}\text { Retrospective study to determine optimal management strategy for women with suspected stage I } \\
\text { ovarian cancer. No data on FS accuracy }\end{array}$ \\
\hline Zhang 1993 & Retrospective study of 32 patients with borderline (low malignant potential) tumours only \\
\hline
\end{tabular}

FNAC: fine needle aspiration cytology; FS: frozen section; NPV: negative predictive value; PPV: positive predictive value; PS: paraffin section; PW: peritoneal washing; USS: ultrasound scan.

\section{A T A}

Presented below are all the data for all of the tests entered into the review.

\section{Table Tests. Data tables by test}

\begin{tabular}{lll}
\hline Test & No. of studies & No. of participants \\
\hline 1 Frozen section: Threshold Malignancy vs Borderline or Benign & 38 & 11181 \\
\hline 2 Frozen section: Threshold Malignancy or Borderline vs Benign & 38 & 11181 \\
\hline $\begin{array}{l}\text { 3 Frozen section: Threshold Malignancy vs Borderline or Benign when FS indi- } \\
\text { cated Mal or BOT }\end{array}$ & 38 & 3953 \\
\hline
\end{tabular}


Test 1. Frozen section: Threshold Malignancy vs Borderline or Benign.

Review: Intraoperative frozen section analysis for the diagnosis of early stage ovarian cancer in suspicious pelvic masses

Test: 1 Frozen section: Threshold Malignancy vs Borderline or Benign

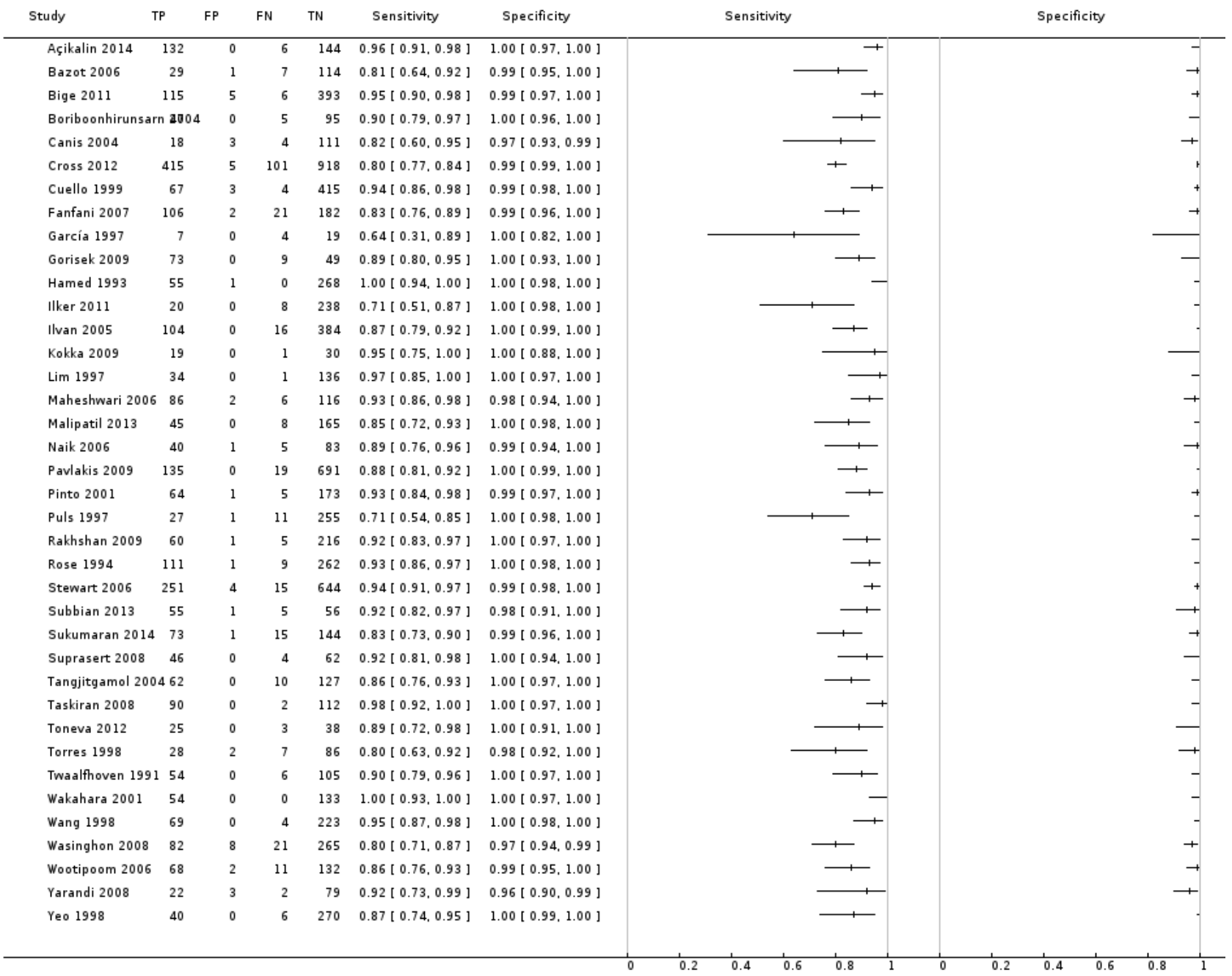


Test 2. Frozen section: Threshold Malignancy or Borderline vs Benign.

Review: Intraoperative frozen section analysis for the diagnosis of early stage ovarian cancer in suspicious pelvic masses Test: 2 Frozen section: Threshold Malignancy or Borderline vs Benign

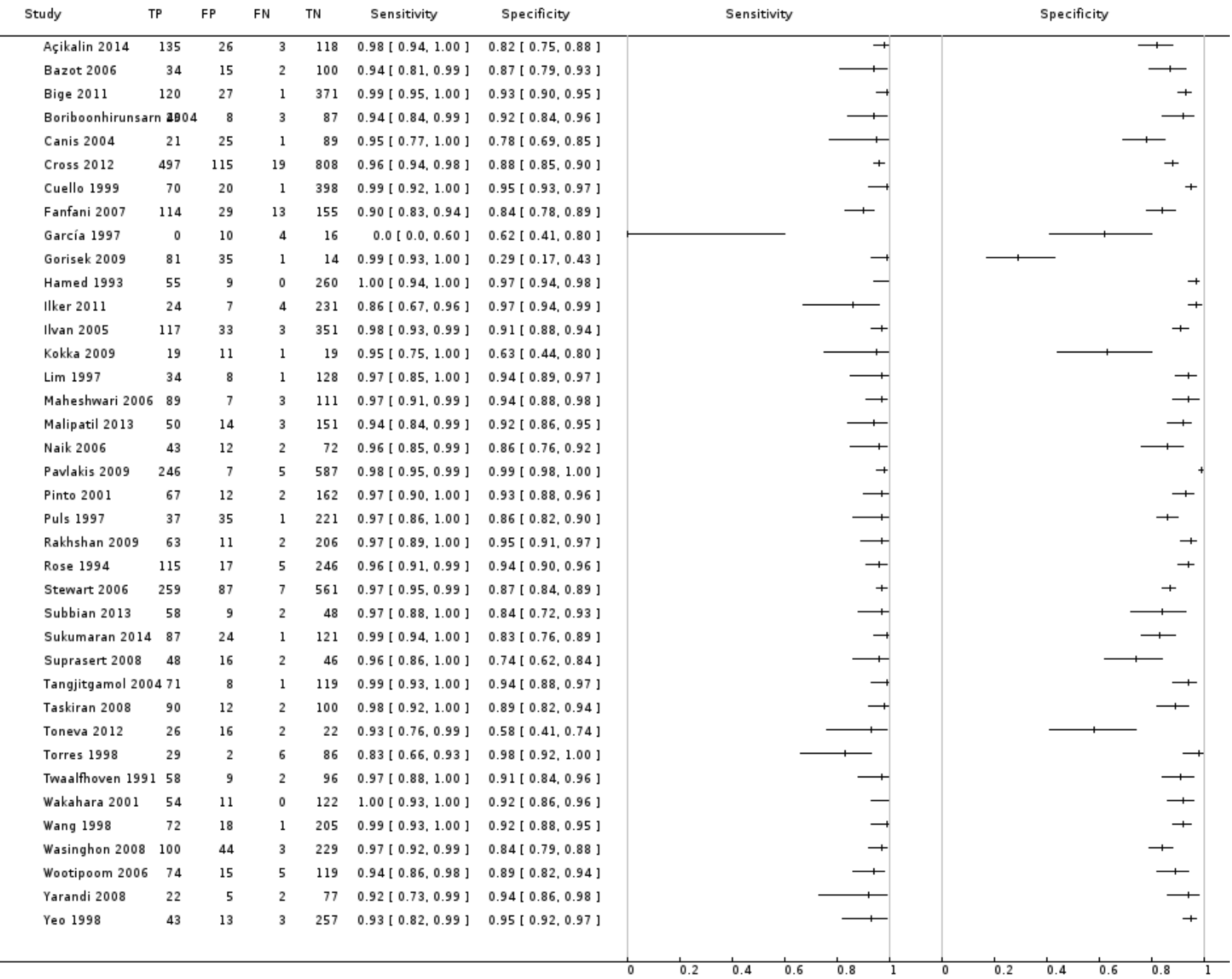


Test 3. Frozen section: Threshold Malignancy vs Borderline or Benign when FS indicated Mal or BOT.

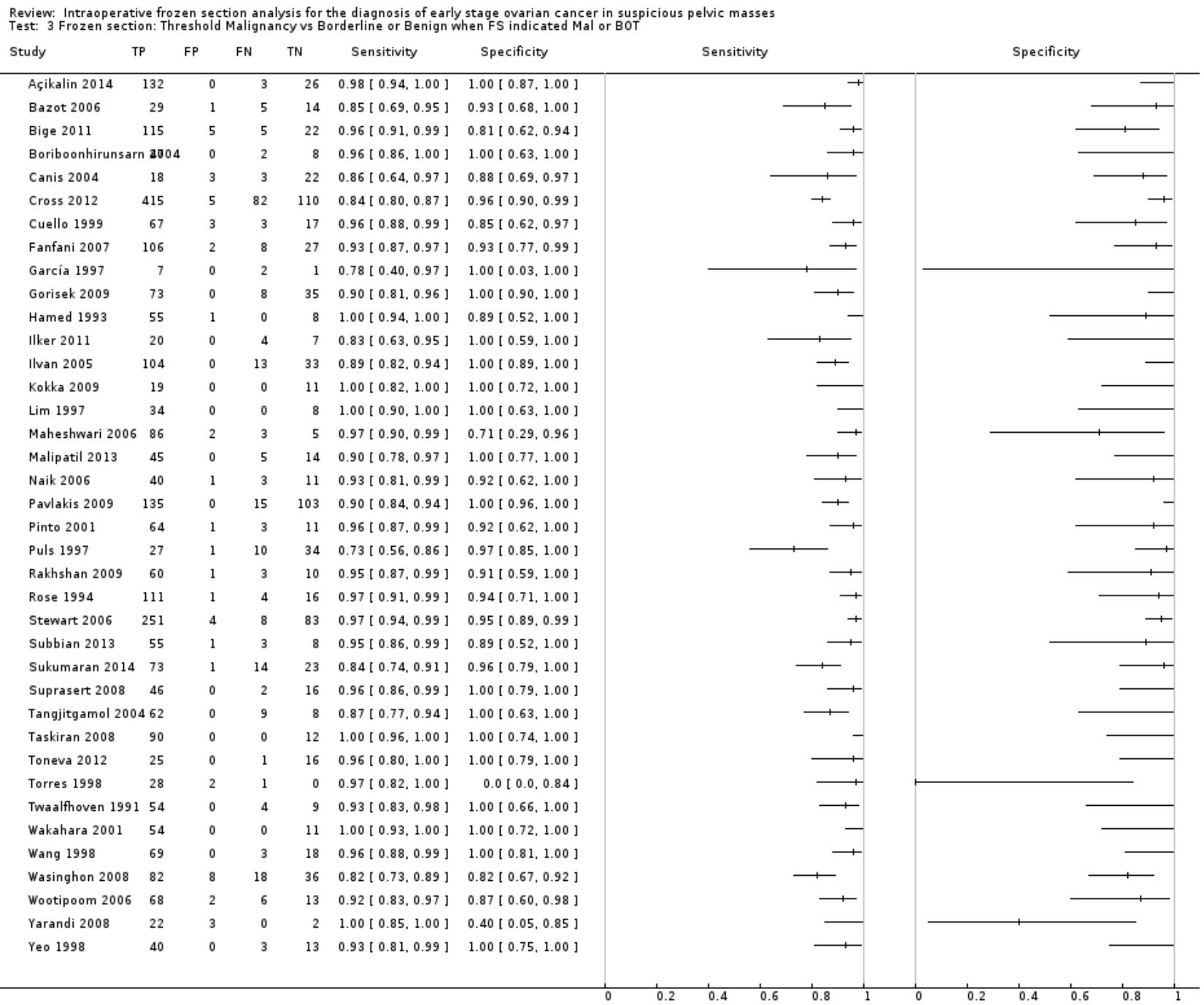

ADDITIONAL TABLES

Table 1. Accuracy of frozen section malignant results to identify women with malignancy

\begin{tabular}{llll}
\hline Frozen section & $\begin{array}{l}\text { Paraffin section } \\
\text { positive test }\end{array}$ & $\begin{array}{l}\text { Paraffin section } \\
\text { negative test }\end{array}$ & Benign \\
\cline { 2 - 4 } & Malignant & Borderline & False positive \\
\hline Malignant & True positive & False positive & True negative \\
\hline Borderline & False negative & True negative & True negative \\
\hline Benign & False negative & True negative &
\end{tabular}


Table 2. Accuracy of frozen section malignant or borderline results to identify women with malignancy

\begin{tabular}{llll}
\hline Frozen section & $\begin{array}{l}\text { Paraffin section } \\
\text { positive test }\end{array}$ & $\begin{array}{l}\text { Paraffin section } \\
\text { negative test }\end{array}$ & Benign \\
\cline { 2 - 4 } & Malignant & Borderline & FPFalse positive \\
\hline Malignant & True positive & False positive & False positive \\
\hline Borderline & True positive & False positive & True negative \\
\hline Benign & False negative & True negative &
\end{tabular}

\section{AP PE N DICES}

\section{Appendix 1. International Federation of Gynecology and Obstetrics (FIGO) staging of ovarian cancer}

Stage $I$. Stage I consists of tumour limited to the ovaries or fallopian tubes.

- Stage IA includes the following: tumour limited to one ovary (capsule intact) or fallopian tube. No tumour on the external surface of the ovary or fallopian tube. No malignant cells in ascites or peritoneal washings

- Stage IB includes the following: tumour limited to both ovaries (capsules intact) or fallopian tubes. No tumour on the external surface of the ovaries or fallopian tubes. No malignant cells in ascites or peritoneal washings

- Stage IC includes tumour limited to one or both ovaries or fallopian tubes, with any of the following: Stage IC1: Surgical spill. Stage IC2: Capsule ruptured before surgery, or tumour on ovarian or fallopian tube surface. Stage IC3: Malignant cells in the ascites or peritoneal washings

Stage II . In stage II tumour involves one or both ovaries or fallopian tubes, with pelvic extension (below pelvic brim) or primary peritoneal cancer.

- Stage IIA: Extension, implants or both on at least one of the following: uterus, ovaries and fallopian tubes.

- Stage IIB: Extension to other pelvic intraperitoneal tissues

Stage III . In stage III, tumour involves one or both ovaries or fallopian tubes, or primary peritoneal cancer, with cytologically or histologically confirmed spread to the peritoneum outside the pelvis and/or metastasis to the retroperitoneal lymph nodes.

- Stage IIIA includes the following: Stage IIIA1: Positive (cytologically or histologically proven) retroperitoneal lymph nodes only. Stage IIIA1(i) Metastasis up to $10 \mathrm{~mm}$ in greatest dimension. Stage IIIA1(ii) Metastasis more than $10 \mathrm{~mm}$ in greatest dimension. Stage IIIA2: Microscopic extrapelvic (above the pelvic brim) peritoneal involvement with or without positive retroperitoneal lymph nodes

- Stage IIIB involves macroscopic peritoneal metastasis beyond the pelvis up to $2 \mathrm{~cm}$ in greatest dimension, with or without metastasis to the retroperitoneal lymph nodes.

- Stage IIIC involves macroscopic peritoneal metastasis beyond the pelvis more than $2 \mathrm{~cm}$ in greatest dimension, with or without metastasis to the retroperitoneal lymph nodes. Stage IIIC includes extension of tumour to the capsule of liver and spleen without parenchymal involvement of either organ.

Stage IV . Stage IV consists of distant metastasis, excluding peritoneal metastases, and includes the following:

- Stage IVA: pleural effusion with positive cytology.

- Stage IVB: parenchymal metastases and metastases to extra-abdominal organs (including inguinal lymph nodes and lymph nodes outside of the abdominal cavity)

\section{Appendix 2. MEDLINE (Ovid) search strategy}

1. exp Ovarian Neoplasms/

2. (ovar* adj5 (cancer ${ }^{\star}$ or tumor* or tumour ${ }^{\star}$ or adenocarcinoma* or carcinosarcoma*or cystadenocarcinoma* or carcinoma* or malignan $^{\star}$ or neoplas ${ }^{\star}$ or carcinogen* or teratoma* or metasta* or mass or masses)).tw,ot.

3. (thecoma* or luteoma*).tw,ot.

4. 1 or 2 or 3 
5. Frozen Sections/

6. (FS or FSA or IFS or IFSA).tw,ot.

7. (frozen or quick) adj5 section ${ }^{\star} . t w, o t$.

8. ((intraoperative or intra-operative) adj5 (consultation* or histolog* or diagnos ${ }^{\star}$ or patholog*)).tw,ot.

9. (cryosection* or cryogenic*).tw,ot.

10.(fresh or frozen) adj5 tissue $\left.{ }^{\star}\right)$.tw,ot.

11.5 or 6 or 7 or 8 or 9 or 10

12.4 and 11

13.exp animals/ not humans.sh.

14.12 not 13

key: tw=textword, ot=original title

WHAT'S NEW

\begin{tabular}{lll}
\hline Date & Event & Description \\
\hline 21 September 2016 & Amended & Contact details updated. \\
\hline
\end{tabular}

\section{CONTRIBUTIONS OF AUTHORS}

- Guarantor of the review: RN

- Conceiving the idea: RN, AP, PC

- Designing and coordinating the review: NR, RN

- Data collection for the review; designing search strategies; undertaking searches; screening search results: TL, NR, JH

- Organising retrieval of papers: NR, AB

- Screening retrieved papers against inclusion criteria: NR, AP

- Appraising quality of papers: $N R, A B, R S$

- Extracting data from papers: NR, AB, CF, RS, SM

- Providing additional data about papers: NR

- Obtaining and screening data on unpublished studies: NR, AP

- Data management of the review: NR

- Entering data into RevMan: NR, SM, RS

- Analysis and interpretation of data: SM, NR, RS

- Providing a methodological perspective; providing a clinical perspective; providing a policy perspective; providing a consumer perspective: RN, NR, AP, PC

- Writing the review: NR, SM

- Providing general advice on the review: RN, NR, AP, PC, KG

- Securing funding for the review: NR, RN

\section{DECLARATIONS OF INTEREST}

$\mathrm{PC}, \mathrm{AP}$ and $\mathrm{RN}$ were authors in a study that met the inclusion criteria in the review.

NR: none known.

$A B$ : none known.

SM: Received payment for methodology work on review.

RS: none known.

CF: none known.

KG: none known.

\section{SOURCES OF SUPPORT}

\section{Internal sources}

- No sources of support supplied 


\section{External sources}

- Department of Health, UK.

NHS Cochrane Collaboration programme Grant Scheme CPG-10/4001/12

\section{DIFFERENCES BETWEEN PROTOCOLANDREVIEW}

We clarified that we used sensitivity and specificity in our primary analysis to assess accuracy.

We clarified that our objectives included assessment for the following two thresholds for frozen section.

1. Test positive is cancer.

2. Test positive is cancer and borderline.

The reference standard test threshold for all analyses is test positive cancer and test negative borderline or benign.

The secondary objective of the protocol (renamed secondary objective \#1 in the review) could not be addressed due to lack of data in included studies. We included an additional analysis, Secondary objective \#2, which was the closest substitute to secondary objective \#1, which could be addressed.

There was insufficient data to examine heterogeneity except for pathologist reader experience. We did not assess reporting bias, based on recommendations in the Cochrane Handbook for Diagnostic Test Accuracy Reviews.

\section{INDEX TERMS}

\section{Medical Subject Headings (MeSH)}

Diagnostic Errors [statistics \& numerical data]; False Negative Reactions; False Positive Reactions; Frozen Sections [ ${ }^{\star}$ methods]; Intraoperative Period; Neoplasm Staging [*methods]; Ovarian Neoplasms [* pathology] [surgery]; Paraffin Embedding; Pelvic Neoplasms [pathology]; Retrospective Studies; Sensitivity and Specificity

\section{MeSH check words}

Female; Humans 